Prepared for the U.S. Department of Energy under Contract DE-AC05-76RL01830

\title{
PJM Controller Testing with Prototypic PJM Nozzle Configuration
}

\section{JR Bontha \\ F Nigl \\ DR Weier \\ RJ Leigh \\ ED Johnson ${ }^{1}$}

${ }^{1}$ Bechtel National Incorporated, Richland, Washington
WA Wilcox
DM Pfund
AW Baumann
Y Wang ${ }^{1}$

August 2009 


\title{
DISCLAIMER
}

This report was prepared as an account of work sponsored by an agency of the United States Government. Neither the United States Government nor any agency thereof, nor Battelle Memorial Institute, nor any of their employees, makes any warranty, express or implied, or assumes any legal liability or responsibility for the accuracy, completeness, or usefulness of any information, apparatus, product, or process disclosed, or represents that its use would not infringe privately owned rights. Reference herein to any specific commercial product, process, or service by trade name, trademark, manufacturer, or otherwise does not necessarily constitute or imply its endorsement, recommendation, or favoring by the United States Government or any agency thereof, or Battelle Memorial Institute. The views and opinions of authors expressed herein do not necessarily state or reflect those of the United States Government or any agency thereof.

\author{
PACIFIC NORTHWEST NATIONAL LABORATORY \\ operated by \\ BATTELLE \\ for the \\ UNITED STATES DEPARTMENT OF ENERGY \\ under Contract DE-ACO5-76RL01830 \\ Printed in the United States of America \\ Available to DOE and DOE contractors from the \\ Office of Scientific and Technical Information, \\ P.O. Box 62, Oak Ridge, TN 37831-0062; \\ ph: (865) 576-8401 \\ fax: (865) 5765728 \\ email: reports@osti.gov
}

Available to the public from the National Technical Information Service,

U.S. Department of Commerce, 5285 Port Royal Rd., Springfield, VA 22161

ph: (800) 553-6847

fax: (703) 605-6900

email: orders@ntis.gov

online ordering: http://www.ntis.gov/help/ordermethods.aspx\#online 


\title{
PJM Controller Testing with Prototypic PJM Nozzle Configuration
}

\author{
JR Bontha \\ WA Wilcox \\ F Nigl \\ DM Pfund \\ DR Weier \\ RJ Leigh \\ AW Baumann \\ ED Johnson ${ }^{1}$ \\ Y Wang ${ }^{1}$ \\ ${ }^{1}$ Bechtel National Incorporated, Richland, Washington
}

August 2009

Test Specification: 24590-WTP-TSP-RT-08-001, Rev. 0

Test Plan: TP RPP-WTP-604, Rev. 0

R\&T Focus Area: Pretreatment \& HLW Vitrification

Pacific Northwest National Laboratory

Richland, Washington 99352 
PNNL-18267

WTP-RPT-179, Rev 0

COMPLETENESS OF TESTING

This report describes the results of work and testing specified by Test Specification 24590-WTP-TSP-RT-08-001, Rev. O Pulse Jet Mixer Controller Testing and Test Plan TP-RPP-WTP-604, Rev. 0 Test Plan for PJM Controller Testing with 4PJM System. The work and any associated testing followed the quality assurance requirements outlined in the Test Specification/Plan. The descriptions provided in this test report are an accurate account of both the conduct of the work and the data collected. Test plan results are reported. Also reported are any unusual or anomalous occurrences that are different from expected results. The test results and this report have been reviewed and verified.

Approved:

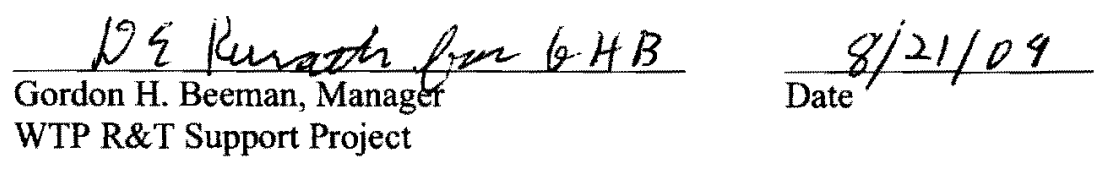




\section{Contents}

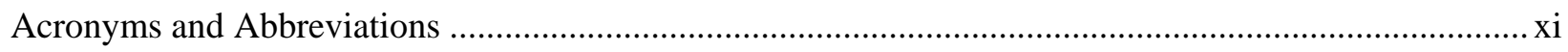

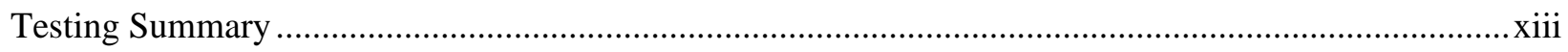

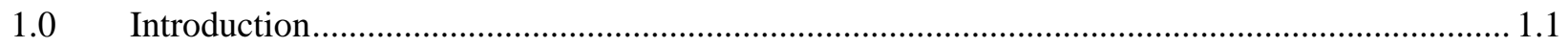

1.1 Pulse Jet Mixers and Waste Treatment Plant Mixing ..................................................... 1.1

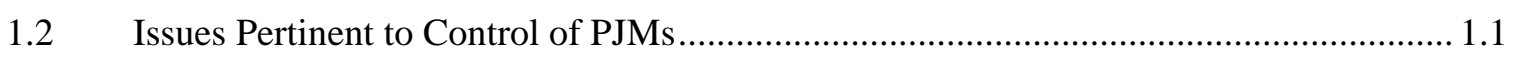

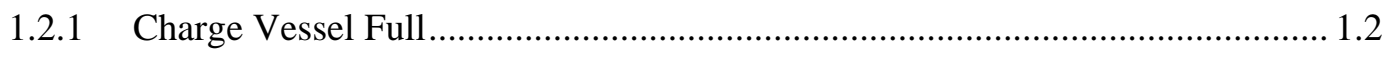

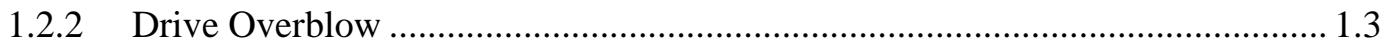

1.3 Summary of Earlier Controller Testing Results.............................................................. 1.3

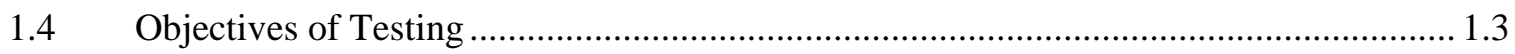

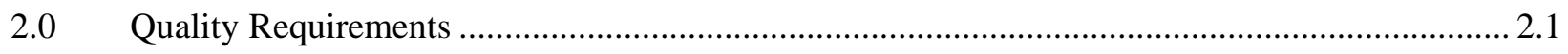

$2.1 \quad$ Application of RPP-WTP Quality Assurance Requirements........................................ 2.1

2.2 Conduct of Experimental and Analytical Work......................................................... 2.1

2.3 Internal Data Verification and Validation.................................................................. 2.2

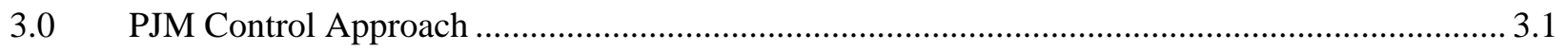

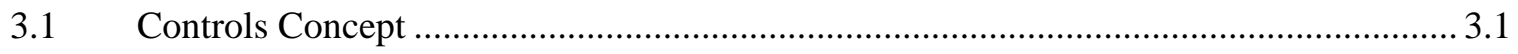

3.1.1 Suction Phase and Charge Vessel Full............................................................. 3.2

3.1.2 Drive Phase and Drive Overblow Detection.................................................... 3.3

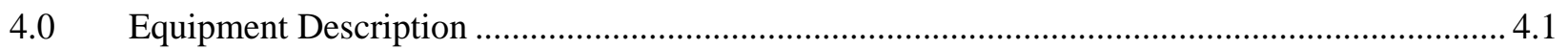

4.1 Supernate Tank and 4PJM Assembly …...................................................................... 4.1

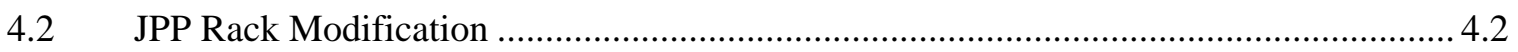

4.3 Pressure Transmitter in the Flush Line ......................................................................... 4.3

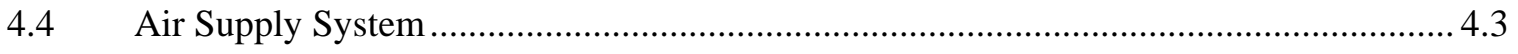

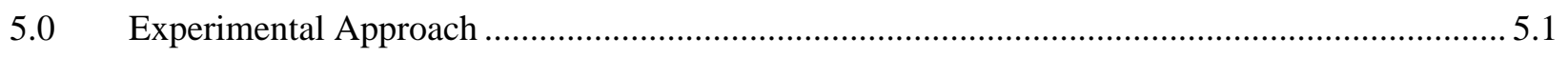

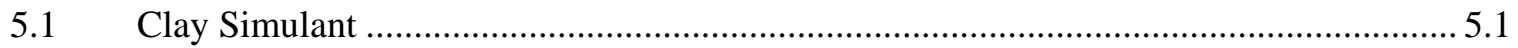

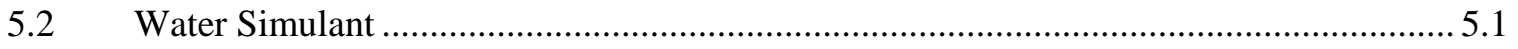

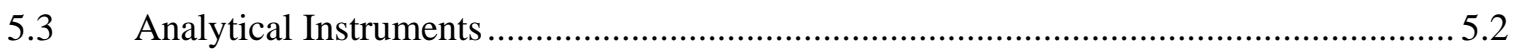

5.4 Instrument Description and Manufacturer Specified Accuracies ..................................... 5.2

5.4.1 JPP Suction, Drive, and Flush Line Pressure.................................................... 5.2

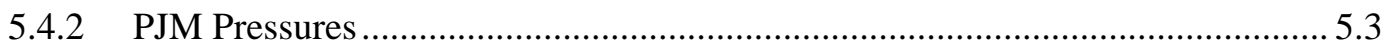

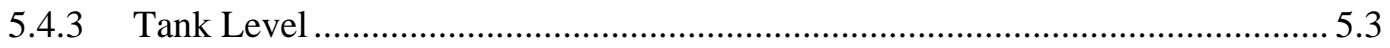

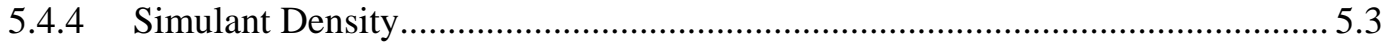

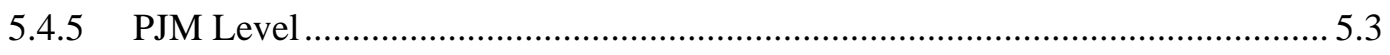

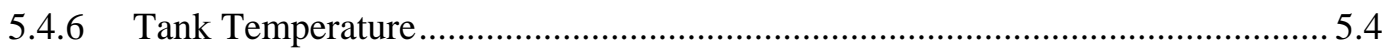

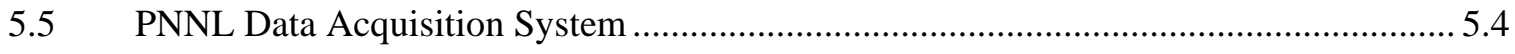

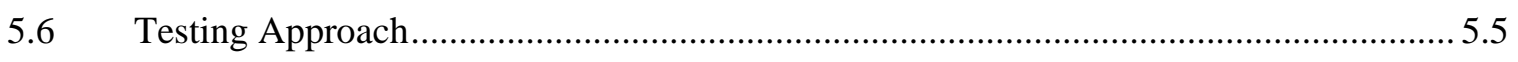

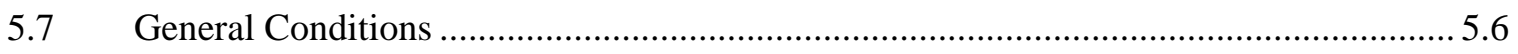

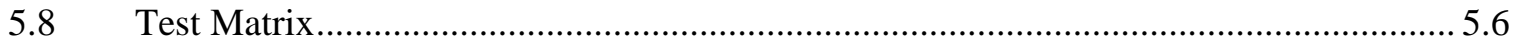




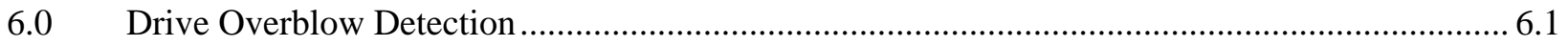

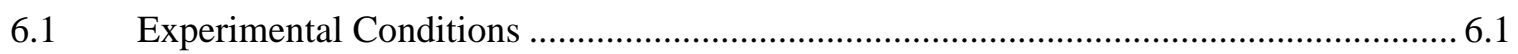

6.2 Drive Overblow Detection with the ABB Controller ................................................... 6.2

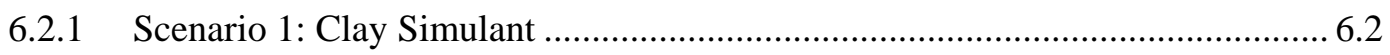

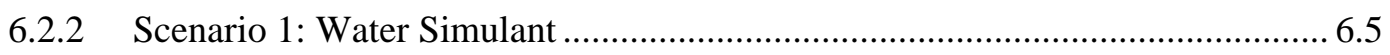

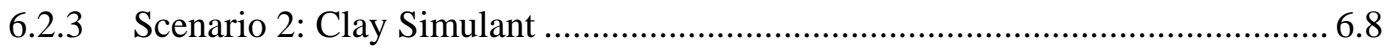

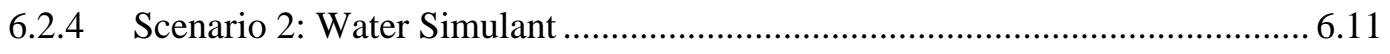

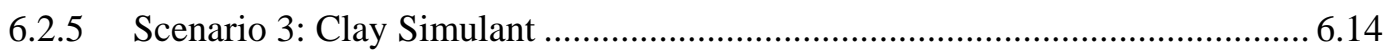

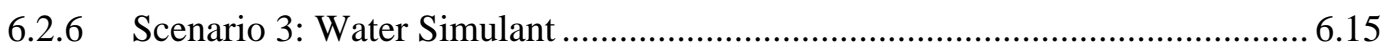

6.2.7 Overall Results for DOB Detection with the ABB Controller.......................... 6.19

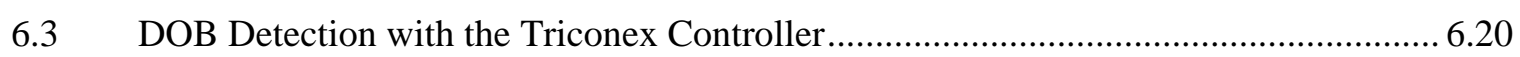

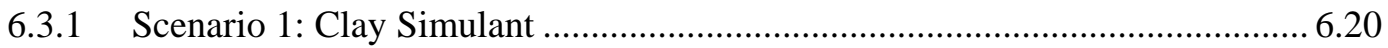

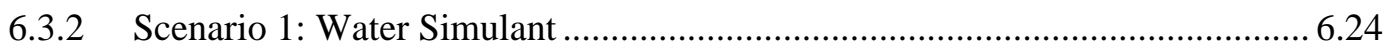

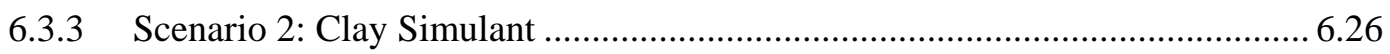

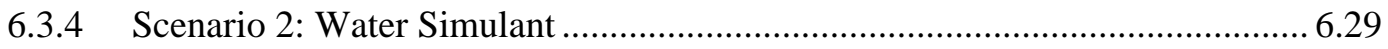

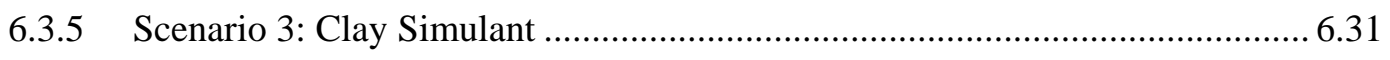

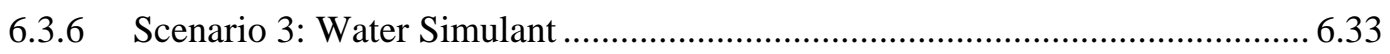

6.3.7 Overall Results for DOB Detection with the Triconex Controller ................... 6.35

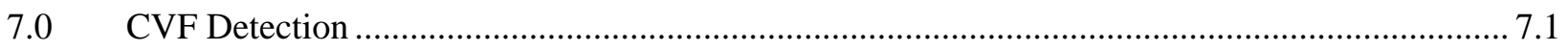

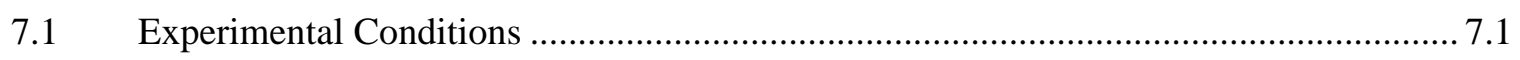

7.2 CVF Detection with the ABB Controller...................................................................... 7.1

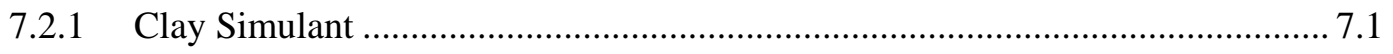

7.2.2 Water Simulant .......................................................................................... 7.4

7.2.3 Overall Results for CVF Detection with the ABB Controller ............................ 7.6

7.3 CVF Detection with the Triconex Controller .............................................................. 7.7

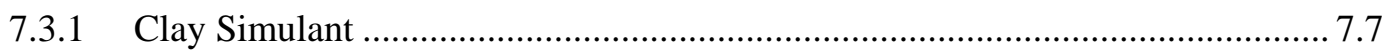

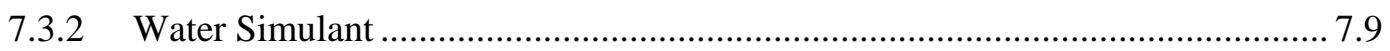

7.3.3 Overall Results for CVF Detection with the Triconex Controller .................... 7.13

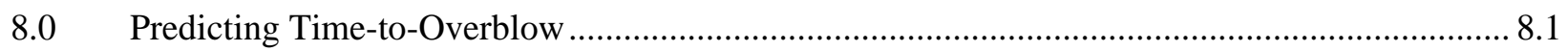

$8.1 \quad$ Determination of Time-To-Overblow............................................................................ 8.1

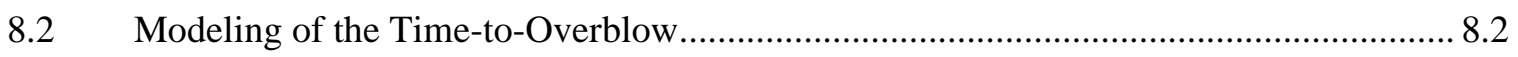

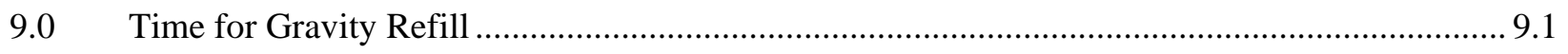

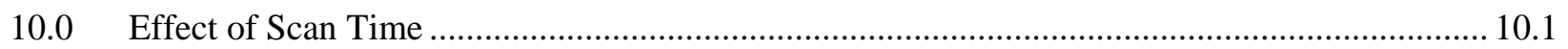

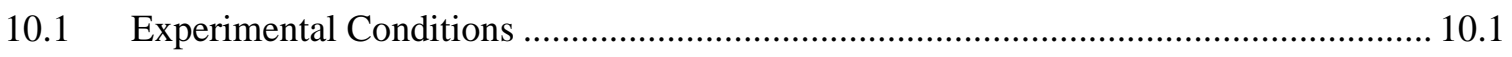

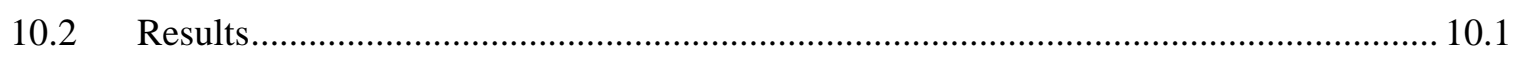

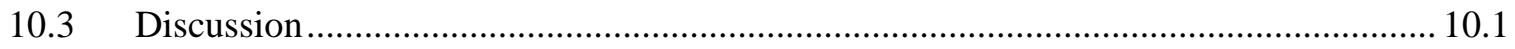

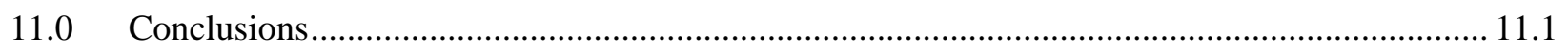

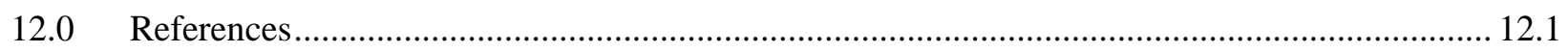

Appendix A Testing Log Run ................................................................................................... A.1 


\section{Figures}

Figure 1.1. Schematic of the Different Phases in a PJM Cycle Control of PJM Operation..................... 1.2

Figure 3.1. Schematic of the PJM Controller Implementation Arrangement ......................................... 3.1

Figure 3.2. An Example of Typical Drive and Suction Pressure Profiles During the Suction Phase.

Figure 3.3. An Example of the Typical Confidence Profiles During the Suction Phase ........................ 3.3

Figure 3.4. Example of Typical Drive and Suction Pressure Profiles During the Drive Phase with Drive Overblow

Figure 3.5. Example of Typical Flush Line Confidence Profile During Drive Phase with Drive Overblow

Figure 4.1. Plan View of the Four PJM Configuration (Bontha et al. 2003b) ...................................... 4.1

Figure 4.2. Plan View of Test Vessel with Fill Heights...................................................................... 4.2

Figure 4.3. Schematic of the Modification to the JPP/Airline of PJM\#A to Include the Extension Piping and the Flush Line....

Figure 5.1. Method of Inserting Level Probe into PJM

Figure 6.1. Histograms of the True and False Overblow Peaks for DOB Detection Scenario 1 (4PJM-Full Case) with ABB Controller in Clay Simulant at (a) High, (b) Mid, and (c) Low Fill Levels

Figure 6.2. Histograms Over All Fill Levels of the True and False Overblow Peaks for DOB Detection Scenario 1 (4PJM-Full Case) with ABB Controller in Clay Simulant.

Figure 6.3. Flush Line Confidence Values for DOB Detection Scenario 1 (4PJM-Full Case) with ABB Controller in Clay Simulant at the High Fill Level

Figure 6.4. Histograms of the True and False Overblow Peaks for DOB Detection Scenario 1 (4PJM-Full Case) with ABB Controller in Water Simulant at (a) High, (b) Mid, and (c) Low Fill Levels

Figure 6.5. Histograms Over All Fill Levels of the True and False Overblow Peaks for DOB Detection Scenario 1 (4PJM-Full Case) with ABB Controller in Water Simulant.

Figure 6.6. Flush Line Confidence Values for DOB Detection Scenario 1 (4PJM-Full Case) with ABB Controller in Water Simulant at the High Fill Level

Figure 6.7. Histograms of the True and False Overblow Peaks for DOB Detection Scenario 2 (1PJM-Full Case) with ABB Controller in Clay Simulant at (a) High, (b) Mid, and (c) Low Fill Levels

Figure 6.8. Histograms Over All Fill Levels of the True and False Overblow Peaks for DOB Detection Scenario 2 (1PJM-Full Case) with ABB Controller in Clay Simulant.

Figure 6.9. Flush Line Confidence Values for DOB Detection Scenario 2 (1PJM-Full Case) with ABB Controller in Clay Simulant at the Low Fill Level

Figure 6.10. Histograms of the True and False Overblow Peaks for DOB Detection Scenario 2 (1PJM-Full Case) with ABB Controller in Water Simulant at (a) High, (b) Mid, and (c) Low Fill Levels

Figure 6.11. Histograms Over All Fill Levels of the True and False Overblow Peaks for DOB Detection Scenario 2 (1PJM-Full Case) with ABB Controller in Water Simulant. 
Figure 6.12. Flush Line Confidence Values for DOB Detection Scenario 2 (1PJM-Full Case) with ABB Controller in Water Simulant at the Low Fill Level

Figure 6.13. Histograms of the True and False Overblow Peaks for DOB Detection Scenario 3 (4PJM-Partial Case) with ABB Controller in Clay Simulant at (a) High and (b) Mid Fill Levels

Figure 6.14. Histograms Over High and Mid Level Data Combined for the True and False Overblow Peaks for DOB Detection Scenario 3 (4PJM-Partial Case) with ABB Controller in Clay Simulant

Figure 6.15. Flush Line Confidence Values for DOB Detection Scenario 3 (4PJM-Partial Case) with ABB Controller in Clay Simulant at the High Fill (top) and Mid (bottom) Levels

Figure 6.16. Histograms of the True and False Overblow Peaks for DOB Detection Scenario 3 (4PJM-Partial Case) with ABB Controller in Water Simulant at (a) High and (b) Mid Fill Levels.

Figure 6.17. Histograms Over High and Mid Level Data Combined for the True and False Overblow Peaks for DOB Detection Scenario 3 (4PJM-Partial Case) with ABB Controller in Water Simulant.....

Figure 6.18. Flush Line Confidence Values for DOB Detection Scenario 3 (4PJM-Partial Case) with ABB Controller in Water Simulant at the High Fill (top) and Mid (bottom) Levels.

Figure 6.19. Combined Histograms for the True and False Overblow Peaks Over All Scenario 1 (4-PJM Full) and Scenario 2 (1PJM-Full) Cases (both simulants, all levels) for DOB Detection with ABB Controller (Light shaded - true peaks. Dark shaded - false peaks.).

Figure 6.20. Limiting Case Histograms for True and False Overblow Peaks for DOB Detection with ABB Controller and Approximating Normal Distributions.

Figure 6.21. Histograms of the True and False Overblow Peaks for DOB Detection Scenario 1 (4-PJM Full) with Triconex Controller in Clay Simulant at (a) High, (b) Mid, and (c) Low Fill Levels .

Figure 6.22. Histograms Over All Fill Levels of the True and False Overblow Peaks for DOB Detection Scenario 1 (4-PJM Full) with Triconex Controller in Clay Simulant

Figure 6.23. Flush Line Confidence Values for DOB Detection Scenario 1 (4-PJM Full) with Triconex Controller with Clay Simulant at the High (top), Mid (middle), and Low (bottom) Levels

Figure 6.24. Histograms of the True and False Overblow Peaks for DOB Detection Scenario 1 (4-PJM Full) with Triconex Controller in Water Simulant at (a) High, (b) Mid, and (c) Low Fill Levels .

Figure 6.25. Histograms Over All Fill Levels of the True and False Overblow Peaks for DOB Detection Scenario 1 (4-PJM Full) with Triconex Controller in Water Simulant

Figure 6.26. Flush Line Confidence Values for DOB Detection Scenario 1 (4-PJM Full) with Triconex Controller with Water Simulant at the Mid (top) and Low (bottom) Levels.

Figure 6.27. Histograms of the True and False Overblow Peaks for DOB Detection Scenario 2 (1-PJM Full) with Triconex Controller in Clay Simulant at (a) High, (b) Mid, and (c) Low Fill Levels

Figure 6.28. Histograms Over All Fill Levels of the True and False Overblow Peaks for DOB Detection Scenario 2 with Triconex Controller in Clay Simulant.

Figure 6.29. Flush Line Confidence Values for DOB Detection Scenario 2 (1-PJM Full) with Triconex Controller in Clay Simulant at the Mid Fill Level. 
Figure 6.30. Histograms of the True and False Overblow Peaks for DOB Detection Scenario 2 (1-PJM Full) with Triconex Controller in Water Simulant at (a) High, (b) Mid, and (c) Low Fill Levels

Figure 6.31. Histograms Over All Fill Levels of the True and False Overblow Peaks for DOB Detection Scenario 2 (1-PJM Full) with Triconex Controller in Water Simulant

Figure 6.32. Flush Line Confidence Values for DOB Detection Scenario 2 (1-PJM Full) with Triconex Controller in Water Simulant at the Mid Fill Level

Figure 6.33. Histograms of the True and False Overblow Peaks for DOB Detection Scenario 3 (4-PJM Partial) with Triconex Controller in Clay Simulant at (a) High and (b) Mid Fill Levels.

Figure 6.34. Histograms Over High and Mid Level Data Combined for the True and False Overblow Peaks for DOB Detection Scenario 3 (4-PJM Partial) with Triconex Controller in Clay Simulant

Figure 6.35. Flush Line Confidence Values for DOB Detection Scenario 3 (4-PJM Partial) with Triconex Controller in Clay Simulant at the Mid Level

Figure 6.36. Histograms of the True and False Overblow Peaks for DOB Detection Scenario 3 with Triconex Controller in Water Simulant at (a) High and (b) Mid Fill Levels

Figure 6.37. Histograms over High and Mid Level Data Combined for the True and False Overblow Peaks for DOB Detection Scenario 3 with Triconex Controller in Water Simulant

Figure 6.38. Flush Line Confidence Values for DOB Detection Scenario 3 with Triconex Controller in Water Simulant at the Mid Fill Level.

Figure 6.39. Combined Histograms for the True and False Overblow Peaks Over All Scenario 1 (4-PJM Full) and Scenario 2 (1PJM-Full) Cases (Both Simulants, All Levels) for DOB Detection with Triconex Controller

Figure 6.40. Limiting Histograms for True and False Overblow Peaks for DOB Detection with Triconex Controller and Approximating Normal Distributions

Figure 7.1. Histograms of the True and False Peaks for CVF Detection with ABB Controller in Clay Simulant at (a) High, (b) Mid, and (c) Low Fill Levels

Figure 7.2. Histograms Over All Fill Levels of the True and False Peaks for CVF with ABB Controller in Clay Simulant.

Figure 7.3. PJM\#A Confidence Values for CVF Detection with ABB Controller in Clay Simulant at the Mid (top) and Low (Bottom) Fill Levels

Figure 7.4. Histograms of the True and False Peaks for CVF Detection with ABB Controller in Water Simulant at (a) High, (b) Mid, and (c) Low Fill Levels ....................................................... 7.5

Figure 7.5. Histograms Over All Fill Levels of the True and False Peaks for CVF with ABB Controller in Water Simulant.

Figure 7.6. Combined Histograms for the True and False Peaks Over All Cases (both simulants, all levels) for CVF Detection with ABB Controller

Figure 7.7. Limiting Histograms for True and False Peaks for CVF Detection with ABB Controller and Approximating Normal Distributions .

Figure 7.8. Histograms of the True and False Peaks for CVF Detection with Triconex Controller in Clay Simulant at (a) High, (b) Mid (10 second mask), (c) Mid (15 second mask) and (d) Low Fill Levels. 
Figure 7.9. Histograms Over All Fill Levels of the True and False Peaks for CVF with Triconex Controller in Clay Simulant (obtained with the 15 second mask on the PJM\#A confidence data near the start of the fill)

Figure 7.10. PJM\#A Confidence Values for CVF Detection with Triconex Controller in Clay Simulant at the High (top), Mid (middle) and Low (bottom) Fill Levels .

Figure 7.11. Histograms of the True and False Peaks for CVF Detection with Triconex Controller in Water Simulant at (a) High, (b) Mid (10 second mask), (c) Mid (15 second mask) and (d) Low Fill Levels.

Figure 7.12. Histograms Over All Fill Levels of the True and False Peaks for CVF with Triconex Controller in Water Simulant (obtained with the 15 second mask on the PJM\#A confidence data near the start of the fill)

Figure 7.13. Combined Histograms for the True and False Peaks Over All Cases (both simulants, all levels) for CVF Detection with Triconex Controller with the 10 Second- (top) and 15 Second-wide (bottom) Masks

Figure 7.14. Limiting Histograms for "True and False Peaks for CVF Detection with Triconex Controller and Approximating Normal Distributions

Figure 8.1. Illustration of the Drive Phase During a PJM Cycle 8.1

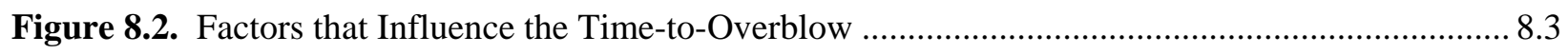

Figure 8.3. Time-to-Overblow Data in the 4PJM Configuration.

Figure 9.1. Typical PJM\#A Levels During Gravity Fill and Suction Fill Using Clay Simulant at the High Fill Level

Figure 9.2. Typical PJM\#A Drive Pressure at the JPP Showing the End of the Drive Phase................. 9.2

Figure 9.3. Typical PJM\#A Level Probe Data at the End of the Refill Phase

Figure 9.4. Comparison of a Single Cycle of PJM Level Data in the Gravity Refill Tests with Clay and Water Simulants

Figure 9.5. Comparison of a Single Cycle of PJM Level Data in the Gravity Refill Tests with Clay and Water Simulants

Figure 10.1. Effect of Scan Time on ABB Controller's Ability to Detect a Drive Overblow. The area under each distribution equals the total number of PJM cycles sampled, $\mathrm{N}$

Figure 10.2. Effect of Scan Time on Triconex Controller's Ability to Detect a Drive Overblow. The area under each distribution equals the total number of PJM cycles sampled, N. 


\section{Tables}

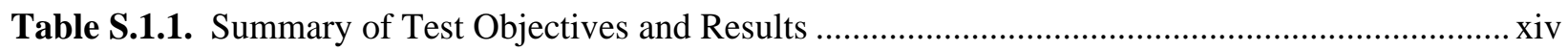

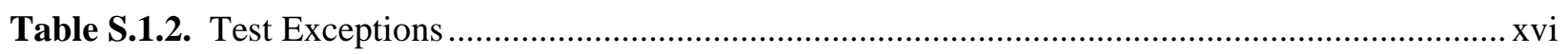

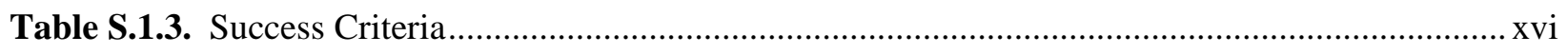

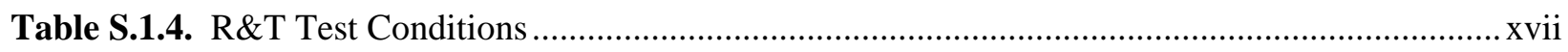

Table 5.1. List of the Various Analytical Instruments Used in the Controller Testing........................... 5.2

Table 5.2. Acceptable Tolerances for the Various NQA-1 Reportable Data Logged on the PNNL

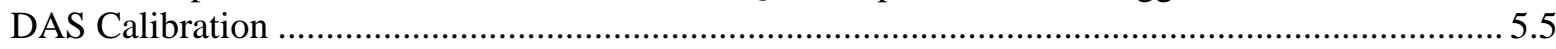

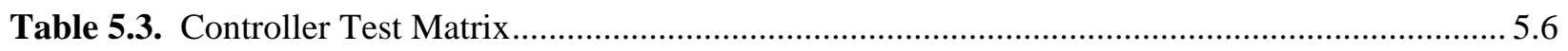

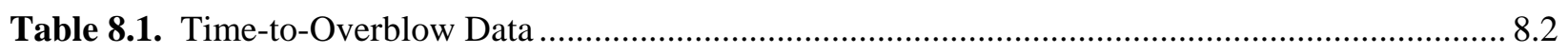

Table 9.1. Gravity Refill Times for Clay and Water Simulants at an H/D = 0.8 …........................... 9.3 



\section{Acronyms and Abbreviations}

$\begin{array}{ll}\text { BNI } & \text { Bechtel National Inc. } \\ \text { C\&I } & \text { Controls \& Instrumentation (a department within BNI) } \\ \text { CVF } & \text { Charge vessel full } \\ \text { DAS } & \text { Data acquisition systems } \\ \text { DOB } & \text { Drive overblow } \\ \text { DOE } & \text { U.S. Department of Energy } \\ \text { FIO } & \text { For information only (data that are not NQA-1 reportable) } \\ \text { HLW } & \text { High-level waste } \\ \text { ITR } & \text { Independent Technical Review } \\ \text { JPP } & \text { Jet pump pair } \\ \text { LAW } & \text { Low-activity waste } \\ \text { PJM } & \text { Pulse jet mixer } \\ \text { PNNL } & \text { Pacific Northwest National Laboratory } \\ \text { PNWD } & \text { Battelle Pacific Northwest Division } \\ \text { RPP-WTP } & \text { River Protection Project - Waste Treatment Plant } \\ \text { WTP } & \text { Waste Treatment Plant }\end{array}$





\section{Testing Summary}

The U.S. Department of Energy (DOE) Office of River Protection's Waste Treatment Plant (WTP) is being designed and built to pre-treat and then vitrify a large portion of the wastes in Hanford's 177 underground waste storage tanks. The WTP consists of three primary facilities-pretreatment, lowactivity waste (LAW) vitrification, and high-level waste (HLW) vitrification. The pretreatment facility will receive waste piped from the Hanford tank farms and separate it into a high-volume, low-activity liquid stream stripped of most solids and radionuclides and a much smaller volume of HLW slurry containing most of the solids and most of the radioactivity.

Many of the vessels in the pretreatment facility will contain pulse jet mixers (PJM) that will provide some or all of the mixing in the vessels. Pulse jet mixer technology was selected for use in black cell regions of the WTP, where maintenance cannot be performed once hot testing and operations commence. The PJMs have no moving mechanical parts that require maintenance. The vessels with the most concentrated slurries will also be mixed with air spargers and/or steady jets in addition to the mixing provided by the PJMs.

Pulse jet mixers are susceptible to overblows that can generate large hydrodynamic forces, forces that can damage mixing vessels or their internal parts. The probability of an overblow increases if a PJM does not fill completely. The purpose of the testing performed for this report was to determine how reliable and repeatable the primary and safety (or backup) PJM control systems are at detecting drive overblows (DOB) and charge vessel full (CVF) conditions.

Testing was performed on the ABB 800xA ${ }^{1}$ and Triconex ${ }^{2}$ control systems. The controllers operated an array of four PJMs installed in an approximately $13 \mathrm{ft}$ diameter $\times 15 \mathrm{ft}$ tall tank located in the high bay of the Pacific Northwest National Laboratory (PNNL) 336 Building test facility. The PJMs were fitted with 4 inch diameter discharge nozzles representative of the nozzles to be used in the WTP. This work supplemented earlier controller tests done on PJMs with 2 inch nozzles (Bontha et al. 2007). Those earlier tests enabled the selection of appropriate pressure transmitters with associated piping and resulted in an alternate overblow detection algorithm that uses data from pressure transmitters mounted in a water flush line on the PJM airlines. Much of that earlier work was only qualitative, however, due to a data logger equipment failure that occurred during the 2007 testing. The objectives of the current work focused on providing quantitative determinations of the ability of the BNI controllers to detect DOB and CVF conditions.

On both control systems, a DOB or CVF is indicated when the values of particular internal functions, called confidence values, cross predetermined thresholds. There are two types of confidence values; one based on a transformation of jet pump pair (JPP) drive and suction pressures, the other based on the pressure in the flush line. In the present testing, we collected confidence levels output from the ABB and Triconex controllers. These data were analyzed in terms of the true and noise confidence peaks generated during multiple cycles of DOB and CVF events. The distributions of peak and noise amplitudes were compared to see if thresholds could be set that would enable the detection of DOB and CVF events at

\footnotetext{
${ }^{1}$ ABB Ltd, Zurich, Switzerland.

${ }^{2}$ IPS, Plano, Texas.
} 
high probabilities, while keeping false detections to low probabilities. Supporting data were also collected on PJM operation, including data on PJM pressures and levels, to provide direct experimental evidence of when PJMs were filling, full, driving, or overblowing.

\section{Objectives}

Table S.1.1 summarizes objectives and results of the PJM controller testing.

Table S.1.1. Summary of Test Objectives and Results

\begin{tabular}{|c|c|c|}
\hline Test Objective & $\begin{array}{c}\text { Objective } \\
\text { Met? }\end{array}$ & Discussion \\
\hline \multirow[t]{5}{*}{$\begin{array}{l}\text { Establish reliability of the } \\
\text { ABB and Triconex control } \\
\text { systems to detect overblows. }\end{array}$} & \multirow[t]{5}{*}{ Yes } & $\begin{array}{l}\text { The ability of the ABB and Triconex controllers to detect drive overblows } \\
\text { was evaluated at three levels (low, mid, high) using two simulant types to } \\
\text { bound the upper and lower range of the WTP waste rheology and vessel } \\
\text { operating conditions. Tests were run for single PJM and multiple PJM } \\
\text { operations using both the flush line algorithm and the normal algorithm. }\end{array}$ \\
\hline & & $\begin{array}{l}\text { The reliability and repeatability of each controller in detecting drive } \\
\text { overblows with one, and with all four PJMs operating at a time was } \\
\text { determined by causing PJM\#A to repeatedly overblow over approximately } \\
300 \text { cycles at each test condition (as specified in TP-RPP-WTP-604 Rev.0). }\end{array}$ \\
\hline & & $\begin{array}{l}\text { Overblows were observed under three different operating scenarios, 1) All } \\
\text { four PJMs running and all filling (overblow of PJM\#A occurred because of } \\
\text { excessive drive time), 2) Only one PJM operating and it filled completely } \\
\text { (overblow of PJM\#A occurred because of excessive drive time), and 3) All } \\
\text { four PJMs operating but one does not fill completely (overblow of the } \\
\text { incompletely filled PJM occurred because it emptied sooner than expected). }\end{array}$ \\
\hline & & $\begin{array}{l}\text { Confidence level data were collected and analyzed to determine if DOB can } \\
\text { be detected at a } 99 \% \text { probability, assuming a maximum allowed false alarm } \\
\text { probability of } 1 \% \text { of operating cycles. }\end{array}$ \\
\hline & & $\begin{array}{l}\text { The results of the testing presented in Section } 6 \text { indicate that the BNI } \\
\text { controllers are not capable of detecting drive overblows under all } \\
\text { circumstances. Both the ABB and Triconex controllers failed to reliably } \\
\text { detect overblows under the scenario where a PJM overblow occurred because } \\
\text { the pulse tube was not completely full before the start of the drive phase. } \\
\text { Under such conditions the peak amplitudes of the flush line confidence levels } \\
\text { were small and their distribution significantly overlapped the distribution of } \\
\text { noise peaks. Thus the overblow signal was often indistinguishable from } \\
\text { normal operating noise. However, PJM overblow was successfully detected } \\
\text { with both controllers when the charge vessel was completely full prior to the } \\
\text { start of the drive phase. }\end{array}$ \\
\hline $\begin{array}{l}\text { Establish ability of the } \\
\text { Triconex system to control } \\
\text { the PJMs in normal } \\
\text { operation. }\end{array}$ & Yes & $\begin{array}{l}\text { The Triconex system successfully operated the PJMs under all normal test } \\
\text { conditions. These results are presented in Sections } 6 \text { and 7, in terms of the } \\
\text { Triconex controller's ability to detect DOB and CVF events. }\end{array}$ \\
\hline $\begin{array}{l}\text { Verify ability to detect } \\
\text { charge vessel full using } \\
\text { 4-inch nozzles. }\end{array}$ & Yes & $\begin{array}{l}\text { With each controller and at each test condition, the ability of the controllers } \\
\text { to successfully detect PJM\#A CVF was verified by collecting confidence } \\
\text { data on PNNL Data acquisition Systems for approximately } 100 \text { cycles (as }\end{array}$ \\
\hline
\end{tabular}




\begin{tabular}{|c|c|c|}
\hline \multirow[t]{4}{*}{ Test Objective } & $\begin{array}{l}\text { Objective } \\
\text { Met? }\end{array}$ & Discussion \\
\hline & & $\begin{array}{l}\text { specified in TP-RPP-WTP-604 Rev.0). For each test, the controller settings } \\
\text { for PJM\#A were set such that PJM\#A charge vessel was full before the start } \\
\text { of the drive cycle. }\end{array}$ \\
\hline & & $\begin{array}{l}\text { The recorded PJM\#A confidence data were analyzed to determine the } \\
\text { effectiveness of the controller to detect CVF. Again, the analysis was to } \\
\text { determine if a 99\% probability of detection could be achieved at a } 1 \% \text { false } \\
\text { alarm probability. }\end{array}$ \\
\hline & & $\begin{array}{l}\text { The results of CVF detection are presented in Section 7. Both controllers } \\
\text { could detect CVF above baseline noise during normal operation when the } \\
\text { PJMs were allowed to fill completely. However, the testing reported here did } \\
\text { not challenge the CVF detection algorithm with abnormal PJM operation and } \\
\text { did not assess false positive rates. In other words, conditions that might } \\
\text { cause false CVF detection were not the primary focus of the present study. }\end{array}$ \\
\hline \multirow[t]{3}{*}{$\begin{array}{l}\text { Determine optimal } \\
\text { controller scan rate for } \\
\text { overblow detection using the } \\
\text { WTP Flush line algorithm. }\end{array}$} & Yes & $\begin{array}{l}\text { Drive overblows were detected using the WTP flush line algorithm at } 50 \mathrm{~ms} \text {, } \\
100 \mathrm{~ms}, 150 \mathrm{~ms} \text { and } 250 \mathrm{~ms} \text { controller scan periods. The influence of the scan } \\
\text { rate on DOB detection was determined at an H/D }=0.8 \text { with water simulant } \\
\text { only and approximately } 20 \text { cycles at each test condition. }\end{array}$ \\
\hline & & Both ABB and Triconex controllers were so tested, as per TI-RPP-WTP-639. \\
\hline & & $\begin{array}{l}\text { The results of the effect of scan rate on controller performance are presented } \\
\text { in Section } 10 \text {. Faster scan rates seemed to improve DOB detection. We } \\
\text { recommend however that more research be done on this topic due to the } \\
\text { small number of PJM cycles sampled in this study. }\end{array}$ \\
\hline \multirow[t]{3}{*}{$\begin{array}{l}\text { Collect data for time to } \\
\text { overblow given the waste } \\
\text { density-gravity-height (rho- } \\
\text { g-h) characteristics for each } \\
\text { waste type. }\end{array}$} & Yes & $\begin{array}{l}\text { Collected time-to-overblow at all three levels (low, mid, high) using both } \\
\text { simulant types with all four PJMs operating. Times-to-overblow were } \\
\text { estimated from PJM\#A levels, headspace pressures, and JPP pressures. } \\
\text { Estimates were made for approximately } 30 \text { cycles at each test condition (as } \\
\text { specified in TP-RPP-WTP-604 Rev.0). }\end{array}$ \\
\hline & & $\begin{array}{l}\text { The times-to-overblow were related to the headspace pressure minus the } \\
\text { liquid head above the nozzle. }\end{array}$ \\
\hline & & The time-to-overblow results are presented in Section 8. \\
\hline \multirow[t]{2}{*}{$\begin{array}{l}\text { Determine how long it takes } \\
\text { for the PJM to refill at high } \\
\text { water and clay levels after } \\
\text { an } 80 \% \text { - } 85 \% \text { stroke with } \\
\text { no suction (gravity re-fill). }\end{array}$} & Yes & $\begin{array}{l}\text { These determinations were made with both clay and water simulants at the } \\
\text { high fill level }(\mathrm{H} / \mathrm{D}=0.8) \text {. The time to gravity refill the PJM was estimated } \\
\text { from PJM level and pressure data acquired for approximately } 30 \text { cycles for } \\
\text { each simulant. The PJM was considered full when the level reached } 99 \% \text { of } \\
\text { the final steady state value. }\end{array}$ \\
\hline & & The gravity refill test results are presented in Section 9. \\
\hline
\end{tabular}

\section{Test Exceptions}

No test exceptions applied to these PJM controller tests. 
Table S.1.2. Test Exceptions

Test Exceptions

None

Description of Test Exceptions

N/A

\section{Results and Performance Against Success Criteria}

The research and technology success criteria are discussed in Table S.1.3.

Table S.1.3. Success Criteria

\begin{tabular}{|c|c|}
\hline Success Criterion & How Testing Did or Did Not Meet Success Criterion \\
\hline \multirow{3}{*}{$\begin{array}{l}\text { The success criteria of the PJM } \\
\text { overblow testing was to provide the } \\
\text { suction, drive, and flush line } \\
\text { pressures, vessel level and density, } \\
\text { and calculated confidence values, } \\
\text { with supporting data and testing } \\
\text { documentation for each set of } \\
\text { conditions tested. }\end{array}$} & $\begin{array}{l}\text { All data called for in the Bechtel National, Inc. (BNI) approved Test } \\
\text { Specification, Test Plan, and Test Exceptions have been delivered to BNI as } \\
\text { electronic data files. Data were collected at } 20 \mathrm{~Hz} \text { or greater as required by } \\
\text { the Test Specification. }\end{array}$ \\
\hline & $\begin{array}{l}\text { Supporting data in the form of instrument and equipment descriptions, } \\
\text { dimensions, experimental conditions and run parameters are included in this } \\
\text { report. This report also provides an analysis of the confidence value data. }\end{array}$ \\
\hline & $\begin{array}{l}\text { Instrument calibrations, analysis spreadsheets and software, bench sheets and } \\
\text { laboratory record books have been documented, crosschecked, and reviewed } \\
\text { as specified in the QA requirements listed below. }\end{array}$ \\
\hline
\end{tabular}

\section{Quality Requirements}

The Pacific Northwest National Laboratory (PNNL) Quality Assurance Program is based upon the requirements defined in the United States Department of Energy (USDOE) Order 414.1C, Quality Assurance and 10 CFR 830, Energy/Nuclear Safety Management, Subpart A -- Quality Assurance Requirements (a.k.a. the Quality Rule). PNNL has chosen to implement the following consensus standards in a graded approach:

- ASME NQA-1-2000, Quality Assurance Requirements for Nuclear Facility Applications, Part 1, Requirements for Quality Assurance Programs for Nuclear Facilities.

- ASME NQA-1-2000, Part II, Subpart 2.7, Quality Assurance Requirements for Computer Software for Nuclear Facility Applications.

- ASME NQA-1-2000, Part IV, Subpart 4.2, Graded Approach Application of Quality Assurance Requirements for Research and Development.

The procedures necessary to implement the requirements are documented through PNNL's StandardsBased Management System (SBMS).

Pacific Northwest National Laboratory implements the River Protection Project - Waste Treatment Plant (RPP-WTP) quality requirements by performing work in accordance with RPP-WTP-QA-001, QAP, River Protection Project - Waste Treatment Plant Support Program (RPP-WTP) Quality Assurance Plan. Work was performed to the quality requirements of NQA-1-1989 Part I, Basic and Supplementary Requirements, NQA-2a-1990, Part 2.7, and DOE/RW-0333P, Rev 13, Quality Assurance 
Requirements and Descriptions (QARD). These quality requirements are implemented through RPP-WTP-QA-003, QAM, River Protection Project - Waste Treatment Plant Support Program (RPP-WTP) Quality Assurance Manual.

General laboratory procedures and calibration experiments were performed in accordance with RPP-WTP procedures QA-RPP-WTP-1101, Scientific Investigations, and QA-RPP-WTP-1201, Calibration Control System, ensuring that sufficient data are taken with properly calibrated measuring and test equipment to obtain quality results. The requirements of DOE/RW-0333P Rev 13were not required for this work because the work is not high-level-waste quality affecting.

Reportable measurements of distance were made using standard commercially available equipment (e.g., tape measure) and needed no traceable calibration requirements. All other test equipment generating reportable data were calibrated according to PNWD's Waste Treatment Plant Support Program Quality Assurance program.

River Protection Project - Waste Treatment Plant addresses internal verification and validation activities by conducting an Independent Technical Review of the final data report in accordance with RPP-WTP procedure QA-RPP-WTP-604. This review verifies that the reported results are traceable, that inferences and conclusions are soundly based, and the reported work satisfies the Test Plan objectives. This review procedure is part of PNNL's RPP-WTP Quality Assurance Manual.

\section{Test Conditions}

The test conditions listed in Table S.1.4 are described in detail in Sections 5.7 and 5.8.

Table S.1.4. R\&T Test Conditions

\begin{tabular}{|l|c|}
\hline \multicolumn{1}{|c|}{ List R\&T Test Conditions } & Were Test Conditions Followed? \\
\hline $\begin{array}{l}\text { See Sections 5.7, General Conditions, 5.8, Test } \\
\text { Matrix, and Table 5.3. }\end{array}$ & Yes \\
\hline
\end{tabular}

\section{Simulant Use}

Two simulants were used in this testing and were selected to bound the expected rheological properties to be encountered in the WTP. Water was used to provide a fluid with rheological properties at the lower bound. A kaolin-bentonite clay mixture was selected to provide a fluid with rheological properties at the upper bound. The clay simulant used was selected based on actual waste slurry rheology measurements that indicate the WTP, non-Newtonian waste stream can be represented by a Bingham plastic rheology model, which is represented by:

$$
\tau=\kappa \dot{\gamma}+\tau_{\mathrm{y}}
$$

where $\tau=$ shear stress, $\kappa=$ consistency factor, $\dot{\gamma}=$ shear rate or strain rate, and $\tau_{\mathrm{y}}=$ Bingham yield stress (the assumed minimum stress required to initiate fluid movement as determined by a flow curve obtained by fitting rheological data using a Bingham plastic rheological model). 
The non-Newtonian waste stream upper bounding rheological value of $\tau_{\mathrm{y}}=30 \mathrm{~Pa}$ was identified using limited data from actual waste slurries that can be represented by a Bingham plastic rheology model (Poloski et al. 2006). These values provide the basis for the simulant used for this testing. Additional information on the selection and development of the kaolin-bentonite clay simulant may be found in Poloski et al. (2004).

\section{Discrepancies and Follow-on Tests}

The experiments to determine the optimal scan rate were conducted with the water simulant, instead of the clay simulant specified in the Test Plan. The change to water was made in consultation with BNI staff after the Test Plan was written. There were no other deviations from the Test Plan. There were no equipment or instrument failures during these tests.

An unavoidable consequence of including a level probe to measure the level of the slurry inside the PJM is a reduction of the effective diameter of the airline at the top of the PJM by 0.75-inches. For 23.5-inch pulse tube diameter with a schedule 40 air-link pipe, this results in a $16 \%$ increase in the area ratio of the PJM to the air-link line. The net result is that the observed controller confidence levels, particularly for CVF, may be stronger in the present study that those which will be observed in the real plant. This is because the CVF confidence signal results from rapid change in the PJM pressure decreases due to the sudden reduction in the pipe diameter between the pulse tube and the air link line. The drive overblow detection, on the other hand, should have minimal impact since this signal is caused by a decrease in the PJM pressure as a result of the air exiting the nozzle.

The results from the present testing indicate that during normal operation, the BNI controllers are not capable of detecting overblows under all circumstances. In particular, both the ABB and Triconex controllers failed to reliably detect overblows under the scenario where a PJM overblow occurred because the pulse tube was not completely full before the start of the drive phase. Under conditions where the PJM is partially full, the amplitudes of the flush line confidence levels were small and their distribution significantly overlapped the noise distribution observed under the conditions when the PJMs were completely full. The results of the testing indicate that, in the WTP, reliable and repeatable CVF detection will be required at all times to enable reliable and repeatable overblow detection. The present testing cannot completely answer whether the BNI controllers are able to reliably and repeatedly detect CVF because the testing did not focus on conditions that can cause CVF failure (for example, conditions such as the blockage of the PJM nozzle). Additional testing is required to address issues that can lead to false CVF conditions. It is also recommended that such tests should also focus on eliminating the PJM level probe influence on the CVF results by eliminating the level probes in the air-link line.

The study of the effect of scan rate on overblow detection relied on only 20 PJM cycles at each scan rate. Although the results indicate that the scan rate has a significant effect on the controllers' ability to detect overblows, we are unable to make a firm recommendation since the amount of data collected for such purposes was insignificant. However, the controllers' confidence output at various scan rates can be simulated using the pressure data we acquired at $100 \mathrm{~Hz}$ during all of the other experiments. From such simulated controller responses, the optimal scan rate can be estimated more precisely. We recommend such simulations as an alternative to doing additional experiments on the effect of scan rate on overblow detection. 


\section{References}

Bontha JR, DE Kurath, AP Poloski, WC Buchmiller, WH Combs, ED Johnson, HC Webber and KL Herman. 2007. Pulse Jet Mixer Controller and Instrumentation Testing. WTP-RPT-146 Rev. 0 (PNWD-3828), Battelle, Pacific Northwest Division, Richland, Washington.

Poloski AP, PA Meyer, LK Jagoda, and PR Hrma. 2004. Non-Newtonian Slurry Simulant Development and Selection for Pulse Jet Mixer Testing. WTP-RPT-111 Rev. 0 (PNWD-3495), Battelle, Pacific Northwest Division, Richland, Washington.

Poloski AP, ST Arm, OP Bredt, TB Calloway, Y Onishi, RA Peterson, GL Smith, and HD Smith. 2006. Final Report: Technical Basis for HLW Vitrification Stream Physical and Rheological Property Bounding Conditions. WTP-RPT-112 Rev. 0 (PNWD-3675), Battelle, Pacific Northwest Division, Richland, Washington. 



\subsection{Introduction}

\subsection{Pulse Jet Mixers and Waste Treatment Plant Mixing}

The U.S. Department of Energy (DOE) Office of River Protection's Waste Treatment Plant (WTP) is being designed and built to pre-treat and then vitrify a large portion of the wastes in Hanford's 177 underground waste storage tanks. The WTP consists of three primary facilities - pretreatment, lowactivity waste (LAW) vitrification, and high-level waste (HLW) vitrification. The pretreatment facility receives waste piped from the Hanford tank farms and separates it into a high-volume, low-activity liquid stream stripped of most solids and radionuclides, and a much smaller volume HLW slurry containing most of the solids and most of the radioactivity.

Many of the vessels in the pretreatment facility will contain pulse jet mixers (PJM) that will provide some or all of the mixing in the vessels. Pulse jet mixer technology was selected for use in black cell regions of the WTP, where maintenance cannot be performed once hot testing and operations commence. The PJMs have no moving mechanical parts that require maintenance. The vessels with the most concentrated slurries will also be mixed with air spargers and/or steady jets in addition to the mixing provided by the PJMs.

Pulse jet mixers consist of several pulse tubes that are large, cylindrical tubes with one end tapered down to a nozzle with a diameter smaller than that of the tube. The other end of the pulse tube is connected by an airline to a Jet Pump Pair (JPP). The JPP enables the regulation of fill and discharge of the pulse tube during the PJM operation. In slurry mixing applications, several of these pulse tubes are incorporated into the mixing vessel and operated either in series or in parallel to achieve the desired mixing. Pulse jet mixing technology represents a simple method for mixing slurries using compressed air.

The WTP vessels with PJMs are expected to contain tank waste slurries with a range of solids concentrations. The dilute slurries are expected to exhibit a Newtonian rheology. The most concentrated slurries are expected to exhibit a non-Newtonian rheology, which is generally characterized with a Bingham plastic model.

\subsection{Issues Pertinent to Control of PJMs}

Figure 1.1 illustrates PJM operation in a single pulse tube system. The PJM cycle consists of three phases-1) suction, where slurry is withdrawn from the mixing vessel into the pulse tube by application of a vacuum, 2) drive, where slurry is ejected back into the mixing vessel under pressure, and 3) vent, where the compressed air inside the pulse tube is released by venting to the atmosphere. This cycle is repeated until the tank contents are adequately mixed.

Pulse jet mixer operation is controlled by opening and closing the valves supplying air to the jet pump pairs, which in turn control the air flow to the pulse tube. Of the various events associated with PJM operation, the two events that are of utmost importance when considering a control system for the PJMs are 1) charge vessel full and 2) drive overblow. These events are discussed below. 


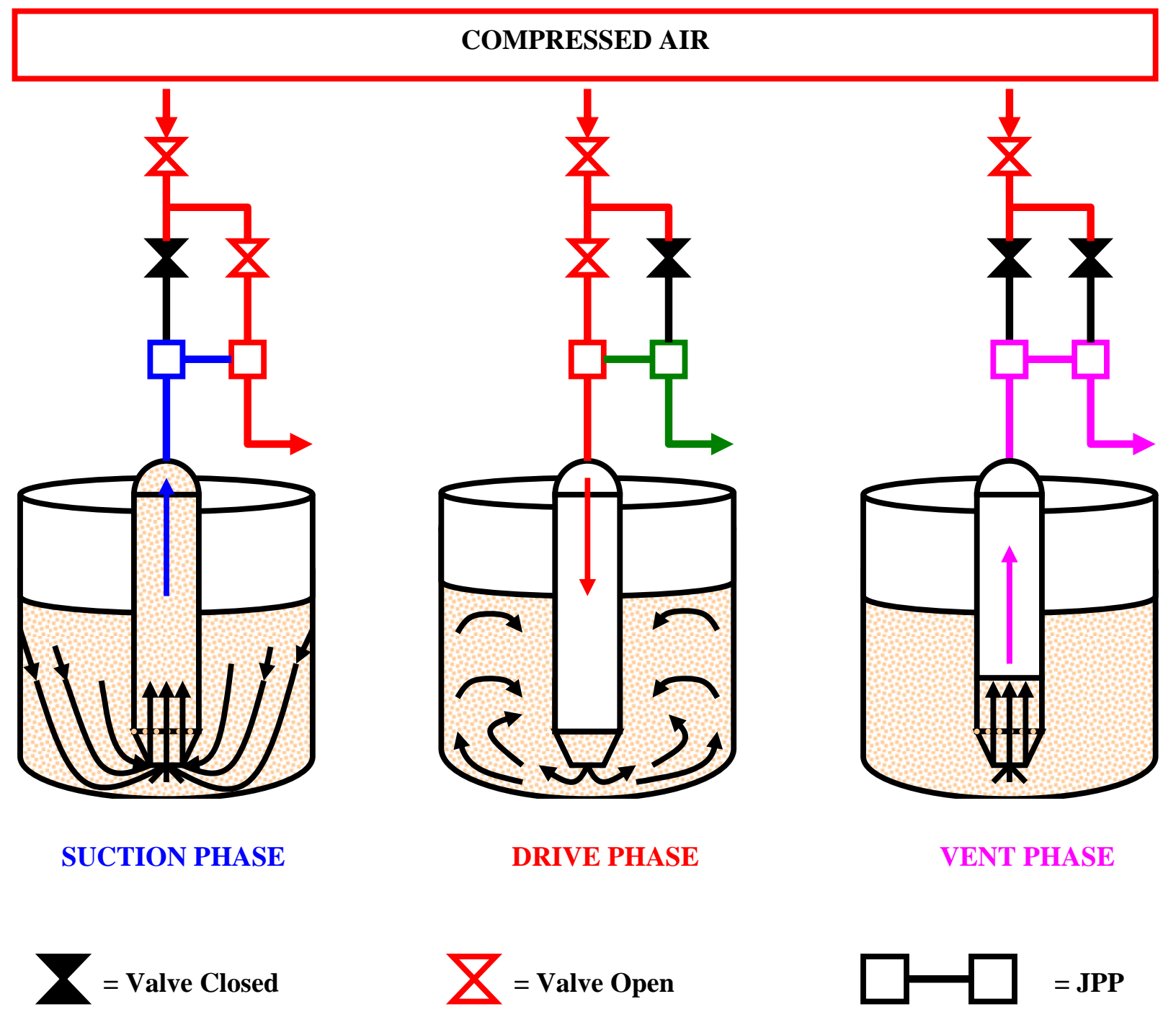

Figure 1.1. Schematic of the Different Phases in a PJM Cycle Control of PJM Operation

\subsubsection{Charge Vessel Full}

Charge vessel full (CVF) detection corresponds to the event in a PJM operational cycle when the pulse tube is full and the suction phase can be terminated. Accurate CVF detection is important in PJM operation because 1) it ensures that the PJMs are full before the drive phase begins, 2) it minimizes the amount of slurry being drawn into the air lines above the PJMs, thereby reducing slurry creep, ${ }^{1}$ (Bontha et al. 2007) and 3) it ensures that all PJMs are full prior to the drive phase. In addition to minimizing the amount of slurry in the drive/suction lines, early CVF detection also helps reduce compressed air use and maximizes the time the PJMs are engaged in mixing.

\footnotetext{
${ }^{1}$ Slurry creep represents the phenomenon of slurry slowly creeping up the air lines and eventually into the JPPs and associated vent systems. Reducing slurry creep is of critical importance to plant operation because the faster the material creeps up the air lines, the more frequently actions will need to be taken (such as washing down the air lines) to prevent the migration of waste out of the hot cells.
} 


\subsubsection{Drive Overblow}

A drive overblow (DOB) event represents the condition when a PJM is in the drive phase and the slurry and liquids are completely expelled from the pulse tube. This allows a significant volume of pressurized air to escape from the pulse tube nozzle. Drive overblow detection is critical to PJM operation because the pressurized air escaping from the PJM will create a significant pressure pulse inside the tank. Such pressure pulses have the potential to affect the lifetime of the tank internals. Consequently, it is important to have a PJM control system that minimizes the possibility of drive overblows.

There is another type of overblow event - a vent overblow. Vent overblows occur after the drive phase is complete, during the time when the controller is venting positive pressure from the PJM. The PJM continues to empty during the early part of the vent phase because of the continued elevated pressure and the downward momentum of the PJM's contents. If the drive phase ends too late, the PJM can empty completely before the pressure is relieved, resulting in a vent overblow. In general, vent overblows are less severe than drive overblows because the volume and pressure of the expelled air are both low. All of the overblows analyzed for this report were drive overblows. All references to an overblow in this report pertain to a drive overblow.

\subsection{Summary of Earlier Controller Testing Results}

In 2006, testing was done by Pacific Northwest National Laboratory (PNNL) (Bontha et al. 2007) to assess the performance of the BNI's ABB control system to detect CVF and DOB conditions during the PJM operation. The testing was conducted using the half-scale lag storage configuration that consisted of PJMs that were half the typical scale of the PJMs in the WTP. This, along with some data logging issues associated with the BNI controller, resulted in only a qualitative assessment of the controller performance. The qualitative results indicated that the controller could detect CVF under its planned configuration with the pressure transmitter located $50 \mathrm{ft}$ up the piping from the drive leg of the jet pump pair. On the other hand, the results also indicated that DOB detection was not possible using the pressure transmitter located approximately 125 feet down the suction leg of the JPP. The results also indicated that DOB detection could be achieved by the direct measurement of the pressure inside the PJMs using a pressure transmitter mounted approximately $100 \mathrm{ft}$ up the pipe used to the flush the PJMs.

The half-scale test configuration and the qualitative nature of the results obtained in 2006 combined with the need to also test the Triconex control system (that is planned for use as the backup or programmable protection system) necessitated repeating the testing using prototypic PJMs.

\subsection{Objectives of Testing}

The objectives of the PJM control system tests were to generate experimental data using a prototypic PJM configuration to:

- Establish reliability of the ABB and Triconex control systems to detect overblows.

- Establish ability of the Triconex system to control the PJMs in normal operation.

- Verify the ability to detect charge vessel full using the 4-inch nozzles. 
- Determine optimal controller scan rate for overblow detection using the WTP flush line algorithm.

- Collect data for time-to-overblow given the waste density-gravity-height (rho-g-h) characteristics for each waste type.

- Determine how long it takes for the PJM to refill at high levels of water and clay after an $80 \%$ $85 \%$ stroke with no suction (gravity re-fill). 


\subsection{Quality Requirements}

\subsection{Application of RPP-WTP Quality Assurance Requirements}

The PNNL Quality Assurance Program is based upon the requirements defined in the DOE Order 414.1C, Quality Assurance and 10 CFR 830, Energy/Nuclear Safety Management, Subpart A -- Quality Assurance Requirements (a.k.a. the Quality Rule). Pacific Northwest National Laboratory has chosen to implement the following consensus standards in a graded approach:

- ASME NQA-1-2000, Quality Assurance Requirements for Nuclear Facility Applications, Part 1, Requirements for Quality Assurance Programs for Nuclear Facilities.

- $\quad$ ASME NQA-1-2000, Part II, Subpart 2.7, Quality Assurance Requirements for Computer Software for Nuclear Facility Applications.

- ASME NQA-1-2000, Part IV, Subpart 4.2, Graded Approach Application of Quality Assurance Requirements for Research and Development.

The procedures necessary to implement the requirements are documented through PNNL's StandardsBased Management System (SBMS).

PNNL implements the RPP-WTP quality requirements by performing work in accordance with the River Protection Project - Waste Treatment Plant Support Program Quality Assurance Plan (RPP-WTP-QA-001, QAP). Work was performed to the quality requirements of NQA-1-1989 Part I, Basic and Supplementary Requirements, NQA-2a-1990, Part 2.7, and DOE/RW-0333P, Rev 13, Quality Assurance Requirements and Descriptions. These quality requirements are implemented through RPP-WTP-QA-003, QAM, Quality Assurance Manual).

The work discussed in this report was planned, executed, reviewed, and documented in accord with the above noted requirements.

\subsection{Conduct of Experimental and Analytical Work}

Test requirements specific to the controller testing are listed in Test Specification 24590-WTP-TSPRT-08-001, Pulse Jet Mixer Controller Testing, and in TP RPP-WTP-604, Test Plan for PJM Controller Testing with 4PJM System.

General laboratory procedures and calibration experiments were performed in accordance with QA-RPP-WTP-1101, Scientific Investigations, and QA-RPP-WTP-1201, Calibration Control System, ensuring that data are taken with properly calibrated measuring and test equipment to obtain quality results. The requirements of DOE/RW-0333P Rev 13 were not required for this work.

Additional equipment used included a thermometer, clock, and balances. The thermometer, for monitoring simulant temperature, and the clock were standard laboratory equipment used as indicators only. Balances are calibrated yearly by a qualified contractor, QC Services, Portland, Oregon, per quality assurance requirements. 


\subsection{Internal Data Verification and Validation}

The RPP-WTP addresses internal verification and validation activities by conducting an Independent Technical Review (ITR) of the final data report in accordance with QA-RPP-WTP-604. This review verifies that the reported results are traceable, inferences and conclusions are soundly based, and the reported work satisfies the Test Plan objectives. This review procedure is part of PNNL's RPP-WTP Quality Assurance Manual. For this project, ITRs were conducted on laboratory record books, bench data sheets, experimental checklists, and run logs. Reviews were also conducted on data acquisition computer programs and on data processing software and spreadsheets.

Electronic data are not considered records under the RPP-WTP QA Program. However, the accuracy of electronic file data transfers to portable (DVD and portable hard disk drives) media was verified. 


\subsection{PJM Control Approach}

The method used to control the operation of the PJMs was developed primarily by the Atomic Energy Authority of the United Kingdom (UKAEA). It has been adapted to meet the WTP operational and safety requirements. Also, based on the results obtained in 2006 (Bontha et al. 2007), the control method was modified to include overblow detection using the pressure measured in the PJM water flush line. This section presents the basic concepts for PJM control.

\subsection{Controls Concept}

The PJM control strategy is shown schematically in Figure 3.1. Here, depending on the stage of the PJM cycle, the controller opens or closes the drive and the suction valves, $V_{d}$ and $V_{s}$, respectively. This in turn affects the pressure measured on the drive $\left(\mathrm{P}_{\mathrm{j}}\right)$ and suction $\left(\mathrm{P}_{\mathrm{r}}\right)$ side of the JPP and in the water flush line $\left(\mathrm{P}_{\mathrm{f}}\right)$ of the $\mathrm{PJM}$, as shown below.

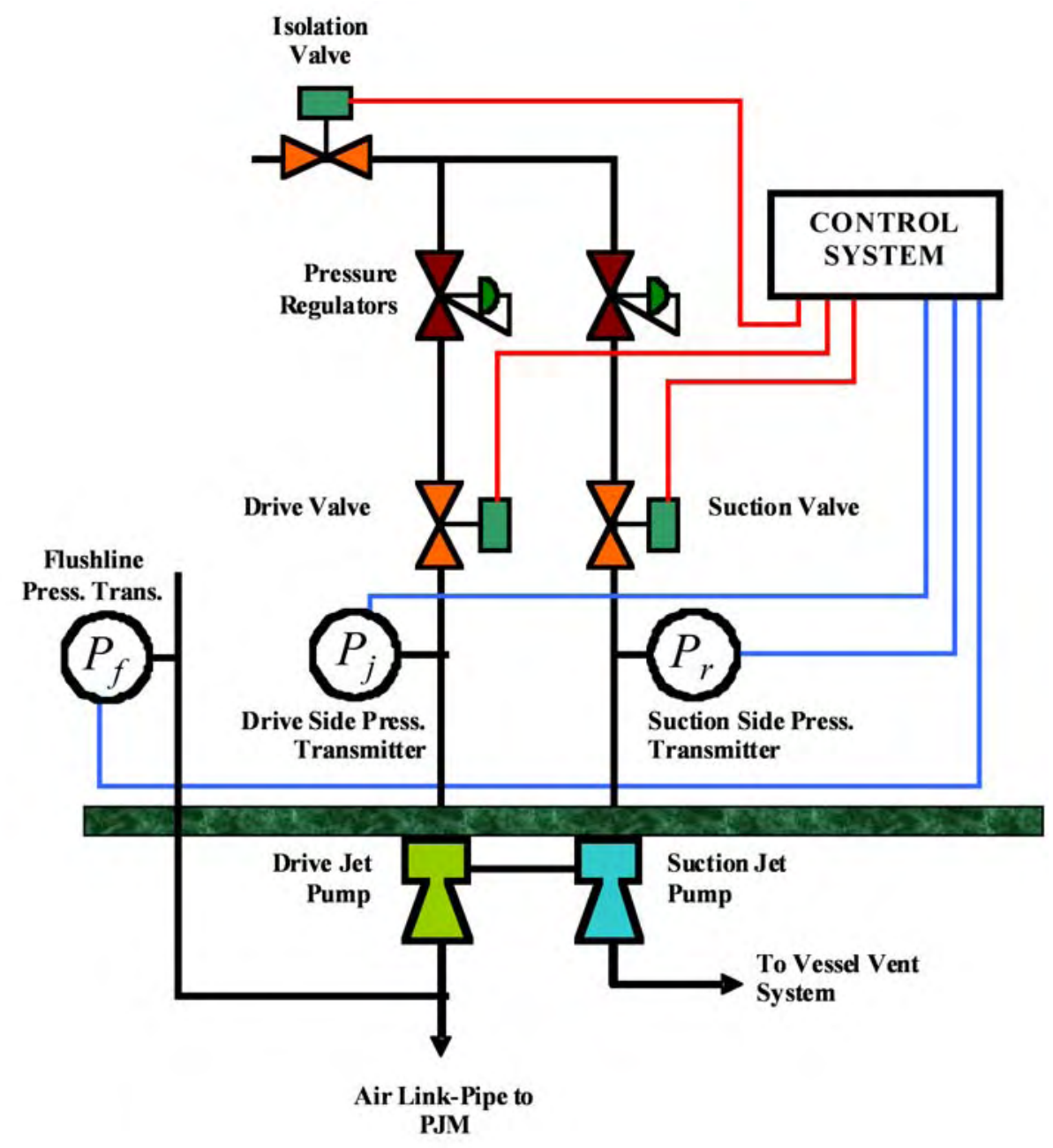

Figure 3.1. Schematic of the PJM Controller Implementation Arrangement 
During PJM operation, the transient pressures, $P_{j}$ and $P_{f}$, exhibit characteristic changes that were indicative of the occurrence of the CVF and drive overblow events, respectively. The BNI control system is designed to recognize the occurrence of these events through the use of a statistical parameter called confidence.

In the following sections, typical profiles for the suction and flush line pressures and the computed confidence during the events of CVF and DOB are presented.

\subsubsection{Suction Phase and Charge Vessel Full}

During the suction phase, the drive valve $\left(\mathrm{V}_{\mathrm{d}}\right)$ is closed, and the suction valve $\left(\mathrm{V}_{\mathrm{s}}\right)$ is open. Therefore, $P_{r}$ measures the supply pressure and $P_{j}$ detects the pressure in the air link line to the pulse tube. Figure 3.2 shows an example ${ }^{1}$ of the resultant transients, $P_{r}$ and $P_{j}$, measured during a typical PJM suction phase. The suction pressure is shown on the primary y-axis, while the drive pressure is shown on the secondary y-axis.

Figure 3.3 shows the calculated confidence profile. It can be seen that during the suction phase, the suction pressure $\left(\mathrm{P}_{\mathrm{r}}\right)$ remains fairly constant throughout, and the drive side pressure $\left(\mathrm{P}_{\mathrm{j}}\right)$ gradually decreases as a vacuum builds up in the pulse tube. As the liquid level in the pulse tube rises above the top of the pulse tube and into the air link line, the drive pressure decreases more rapidly because of a sudden reduction in the pipe diameter between the pulse tube and the air link line. This translates into a sharp increase in the calculated confidence, as shown in Figure 3.3.

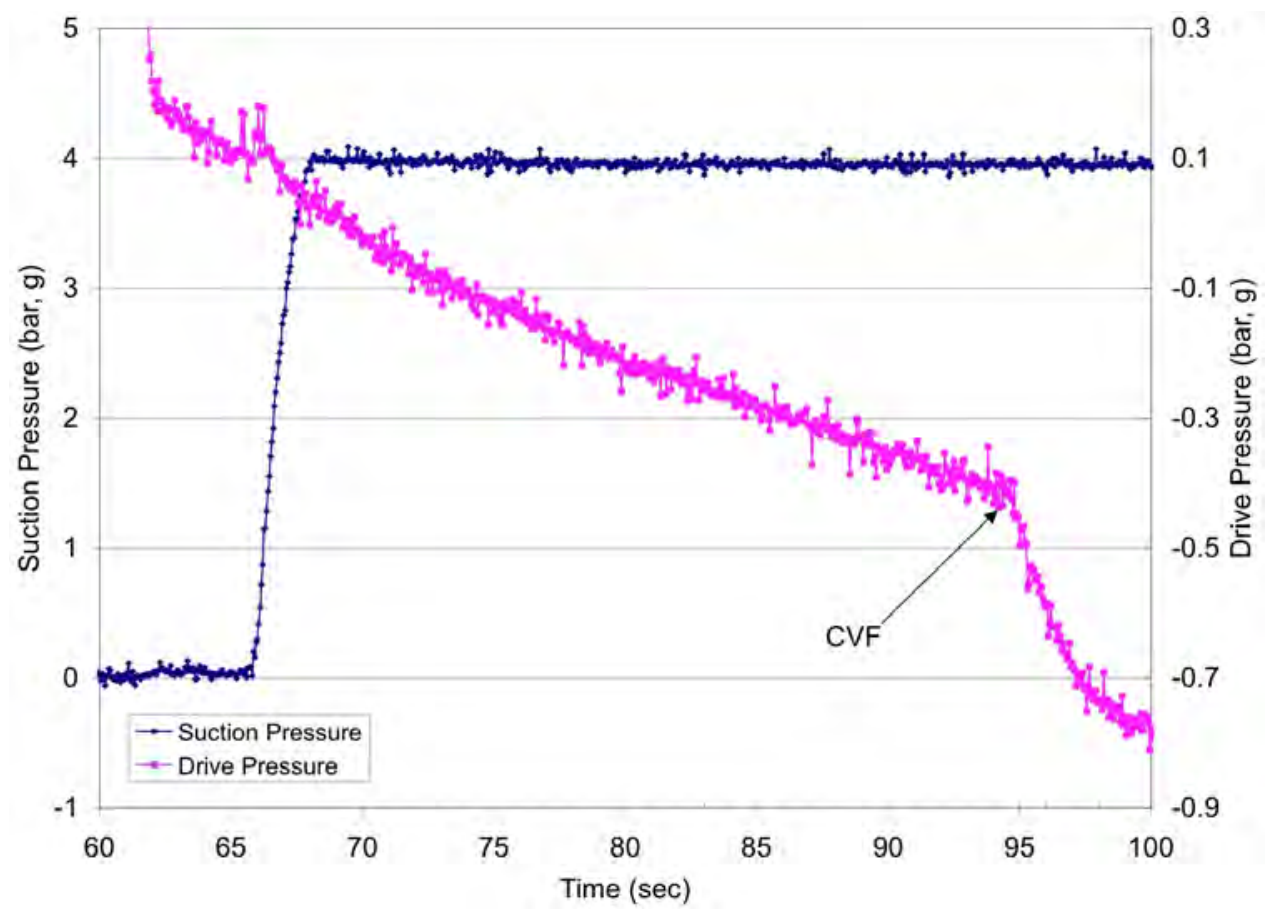

Figure 3.2. An Example of Typical Drive and Suction Pressure Profiles During the Suction Phase

\footnotetext{
${ }^{1}$ Examples used in Section 3 are taken from PRESCON Control Algorithm Design Guide, by A. Dean. 2004. 24590-QL-POA-MPEO-00002-14-01 Rev. 0.0, UKAEA, UK.
} 


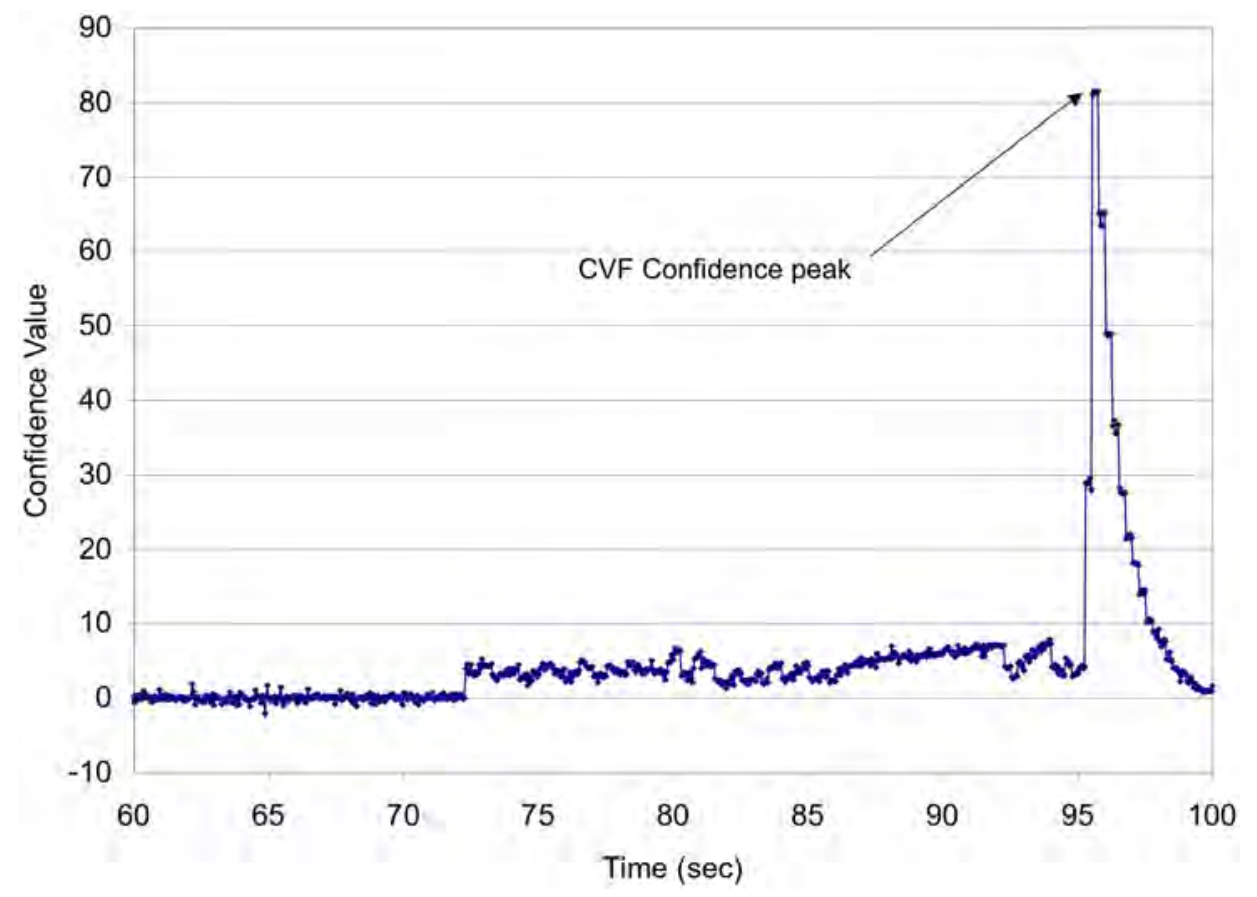

Figure 3.3. An Example of the Typical Confidence Profiles During the Suction Phase

The control algorithm looks for the peak in the confidence to determine that the charge vessel is full and to terminate the suction phase. ${ }^{2}$ Ideally, the controller would signal CVF when the slurry level in the pulse tube is at the connection between the air-supply line and top dish-head of the PJM. In this study we did not examine the correlation between the peak confidence and the level in the pulse tube and we did not estimate the lead or lag of the signal in relation to the ideal target fill level.

\subsubsection{Drive Phase and Drive Overblow Detection}

During the drive phase, the drive valve $\left(\mathrm{V}_{\mathrm{d}}\right)$ is open, and the suction valve $\left(\mathrm{V}_{\mathrm{s}}\right)$ is closed. In this situation, $\mathrm{P}_{\mathrm{j}}$ measures the supply pressure. Figure 3.4 shows an example of the resultant transient pressures on the drive side of the JPP $\left(\mathrm{P}_{\mathrm{j}}\right)$ and flush line $\left(\mathrm{P}_{\mathrm{f}}\right)$ measured during a typical drive phase. Also shown in Figure 3.4 is the pressure inside the PJM. In this figure, the drive pressure is shown on the primary y-axis while the flush line and PJM pressures are shown on the secondary y-axis. Figure 3.5 shows the calculated confidence during the same period.

As discussed in the introduction, a drive overblow refers to an overblow that occurs when the drive valve is still open when all the liquid is gone from the charge vessel. When a drive overblow occurs, there is a sharp drop in the pressure inside the PJM. Since the transmitter in the flush line measures the pressure inside the PJM (minus head loss in the line), the flush line exhibits an almost similar profile. The sudden drop in the flush line pressure during an overblow translates into a sharp increase in the

\footnotetext{
${ }^{2}$ In actuality, the confidence value is compared to a confidence threshold value determined during the PJM tuning process. If the confidence is greater than the threshold, the CVF is ascertained. Otherwise, the suction valve remains open until the confidence threshold value has been reached or the gain value reaches a percent of the maximum gain calculated during the first suction phase (i.e., a maximum gain is attained).
} 
calculated confidence, as shown in Figure 3.5. The overblow corresponds to the larger of the two peaks in the Figure. The earlier, smaller peak is a noise or false peak in the flush line confidence that typically appears during the drive phase.

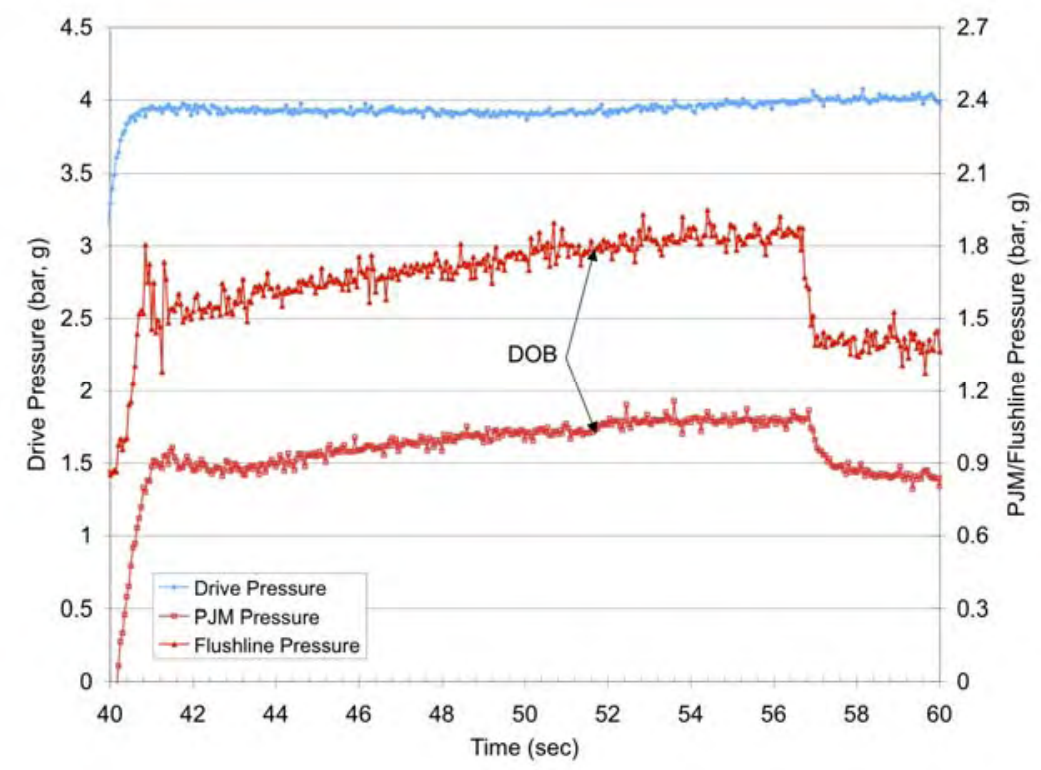

Figure 3.4. Example of Typical Drive and Suction Pressure Profiles During the Drive Phase with Drive Overblow

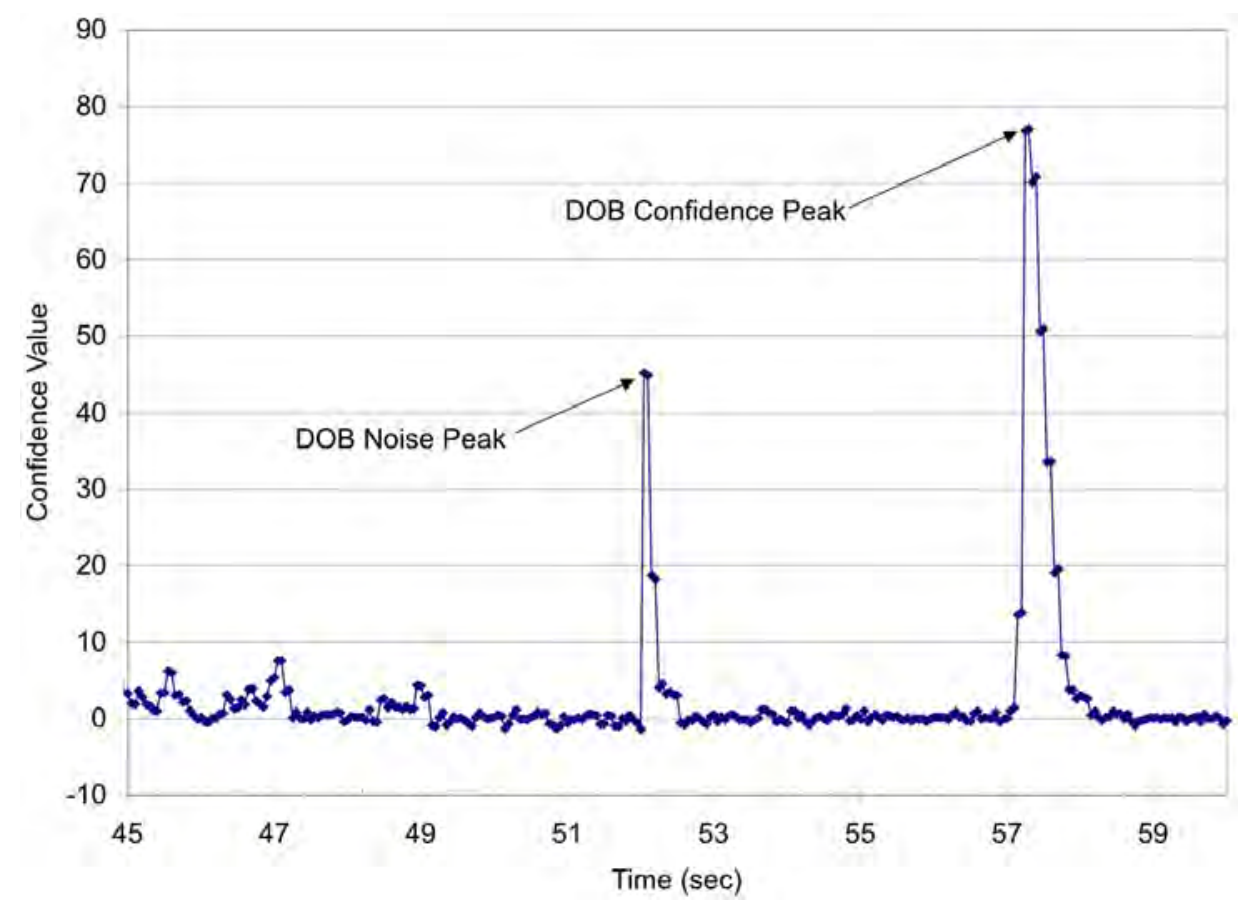

Figure 3.5. Example of Typical Flush Line Confidence Profile During Drive Phase with Drive Overblow 


\subsection{Equipment Description}

The controller tests were performed using the four PJM test stand available in PNNL's 336 Building test facility. A detailed description of the existing test equipment and configuration is presented in Bontha et al. (2003) and Pfund et al. (2008), and a brief summary is presented in this section.

\subsection{Supernate Tank and 4PJM Assembly}

The supernate tank housing the four PJM assemblies was a cylindrical, stainless steel vessel of 12.75 $\mathrm{ft}$ inner diameter (ID) and approximately $15 \mathrm{ft}$ height (H). ${ }^{1}$ The bottom of the tank was a 2:1 ellipse with minor and major IDs of approximately $3 \mathrm{ft}$ and $12.75 \mathrm{ft}$, respectively. The four PJMs were located at the center of the four quadrants of the tank as shown in Figure 4.1.

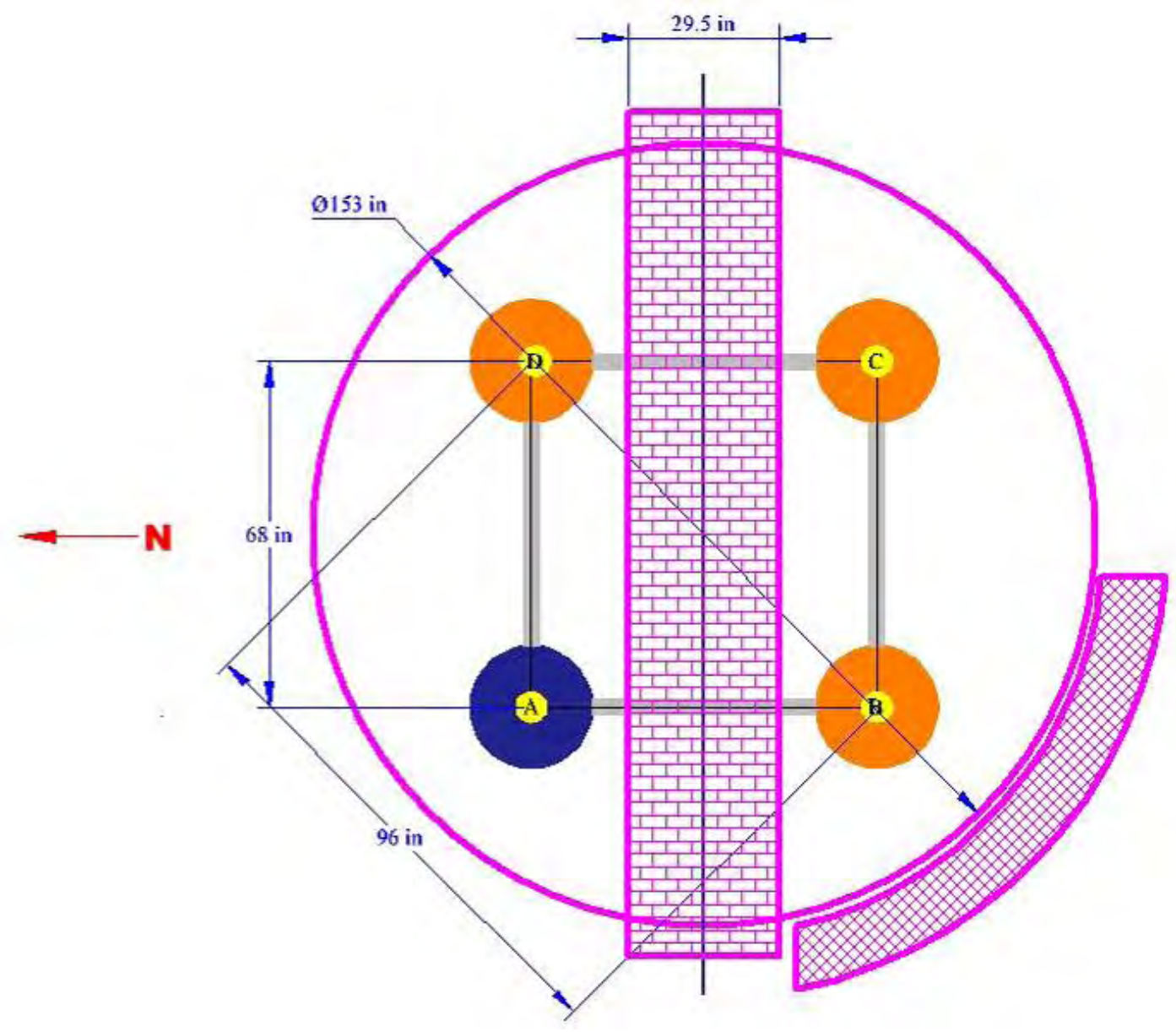

Figure 4.1. Plan View of the Four PJM Configuration (Bontha et al. 2003b)

\footnotetext{
${ }^{1}$ The actual operating height of the tank was $14 \mathrm{ft}, 10$ inches (or 178 inches) due to an approximate 2 inch wall thickness.
} 
A plan view of the vessel showing the location of the PJMs is presented in Figure 4.2. Also shown in this figure, for comparison purposes, are the high, mid, and low fill levels at which the testing with clay and water simulants were performed.

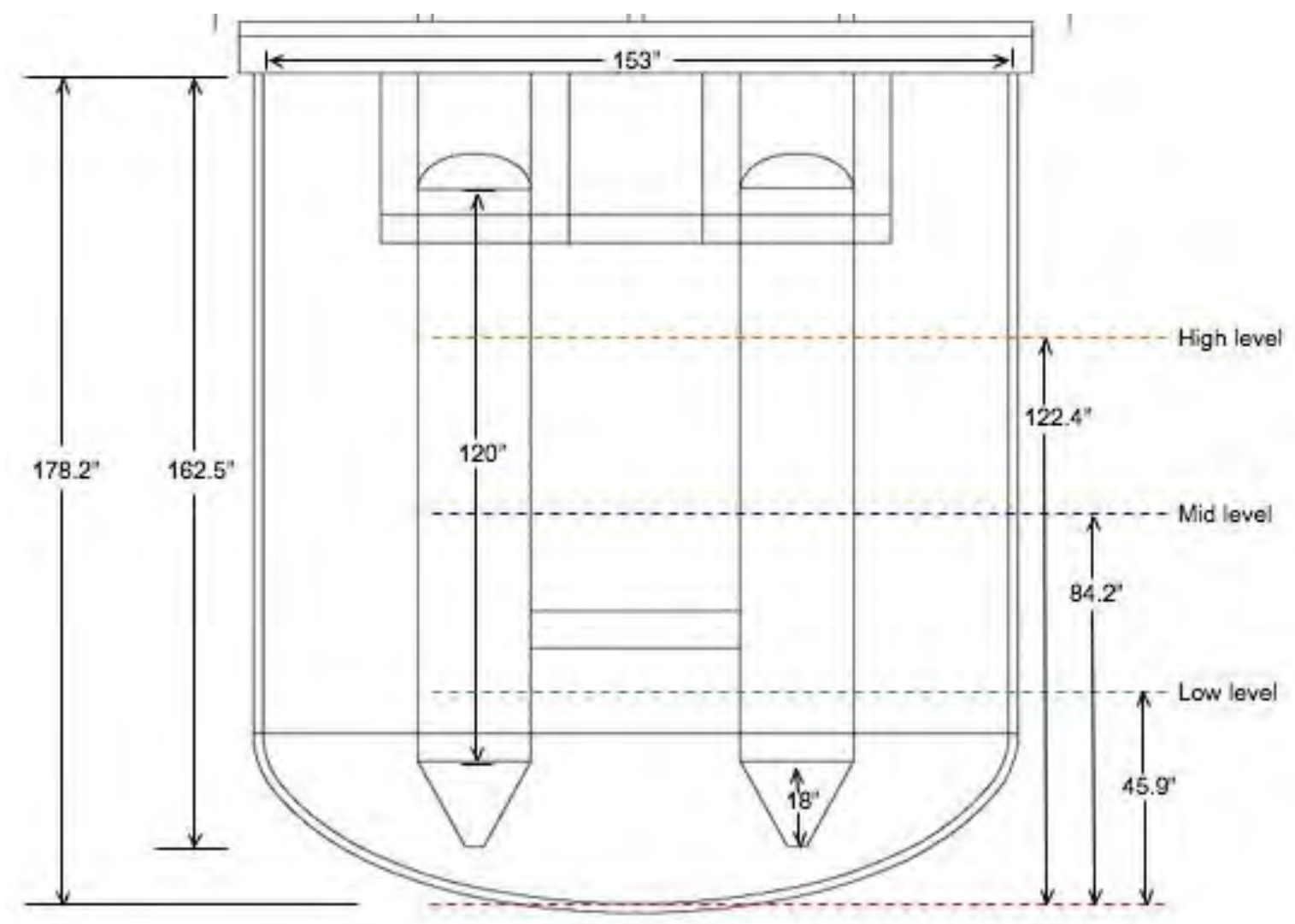

Figure 4.2. Plan View of Test Vessel with Fill Heights

A catwalk was present about $3 \mathrm{ft}$ above the top of the tank. Another catwalk approximately $40 \mathrm{ft}$ above the top of the tank supported the air hoses to the PJMs. The catwalks were not attached to the tank. There was an observation deck along a $60^{\circ}$ section of the circumference of the tank approximately $3 \mathrm{ft}$ below the rim of the tank. The tank was positioned on three load gauges to monitor the weight of the tank and its contents.

\subsection{JPP Rack Modification}

During operation of the PJMs, a venturi-created vacuum was applied to fill the pulse tubes with simulant. The slurry was then expelled from the pulse tubes with compressed air. The suction and discharge of the simulant to and from each of the four pulse tubes was regulated by a set of four JPPs mounted on a skid located at ground level beside the tank. ${ }^{2}$ In order to facilitate the prototypical representation of the extension piping between the JPP and the pressure transducers monitored by the

${ }^{2}$. In actuality, there were two racks with four JPPs per rack in the test assembly but only the bottom rack with four JPPs was used in testing. 
PJM controller, the JPP on PJM\#A was reconfigured such that $50 \pm 5$ feet of extension piping was included on the drive side and $130 \pm 5$ feet of extension piping was included on the suction side. ${ }^{3}$ The modifications are schematically shown in Figure 4.3. Both sets of extension piping consisted of 2 inch ID (nominal) wire reinforced PVC tubing. The tubing was coiled and located near the JPP rack.

\subsection{Pressure Transmitter in the Flush Line}

In addition to testing the five pressure transmitters mounted on the extension pipe of the JPP, a Druck $^{4}$ PTX-611 pressure transmitter mounted at the end of a $100 \pm 5$ feet section of 1inch ID PVC tubing connected to the air supply line of PJM \#A was used to monitor the flush line pressure. ${ }^{5}$ This is shown schematically in Figure 4.3. The flush line installation was unchanged from that reported in Bontha et al. 2007.

\subsection{Air Supply System}

The air supply system consisted of a $1600 \mathrm{cfm}$ compressor (delivering an outlet pressure of $150 \mathrm{psig}$ ) connected to six 250 gal air receiver tanks. The air from the receiver tanks passed through an air filter to feed the JPP skid. Part of the air from the filter was also routed to a $50 \mathrm{cfm}$ air dryer that fed the air actuated valves on the JPP skids and the BNI bubbler system also located in the tank (not shown in Figure 4.1).

\footnotetext{
${ }^{3}$ The $50 \mathrm{ft}$ and $125 \mathrm{ft}$ of extension tubing on the drive and suction side of the JPP were considered to represent the maximum length of tubing in the WTP plant (see Bontha et al. 2007).

${ }^{4}$ GE Sensing. Billerica, MA.

${ }^{5}$ The $100 \mathrm{ft}$ length represents the expected maximum length of the PJM water flush line in the WTP design (see Bontha et al. 2007).
} 


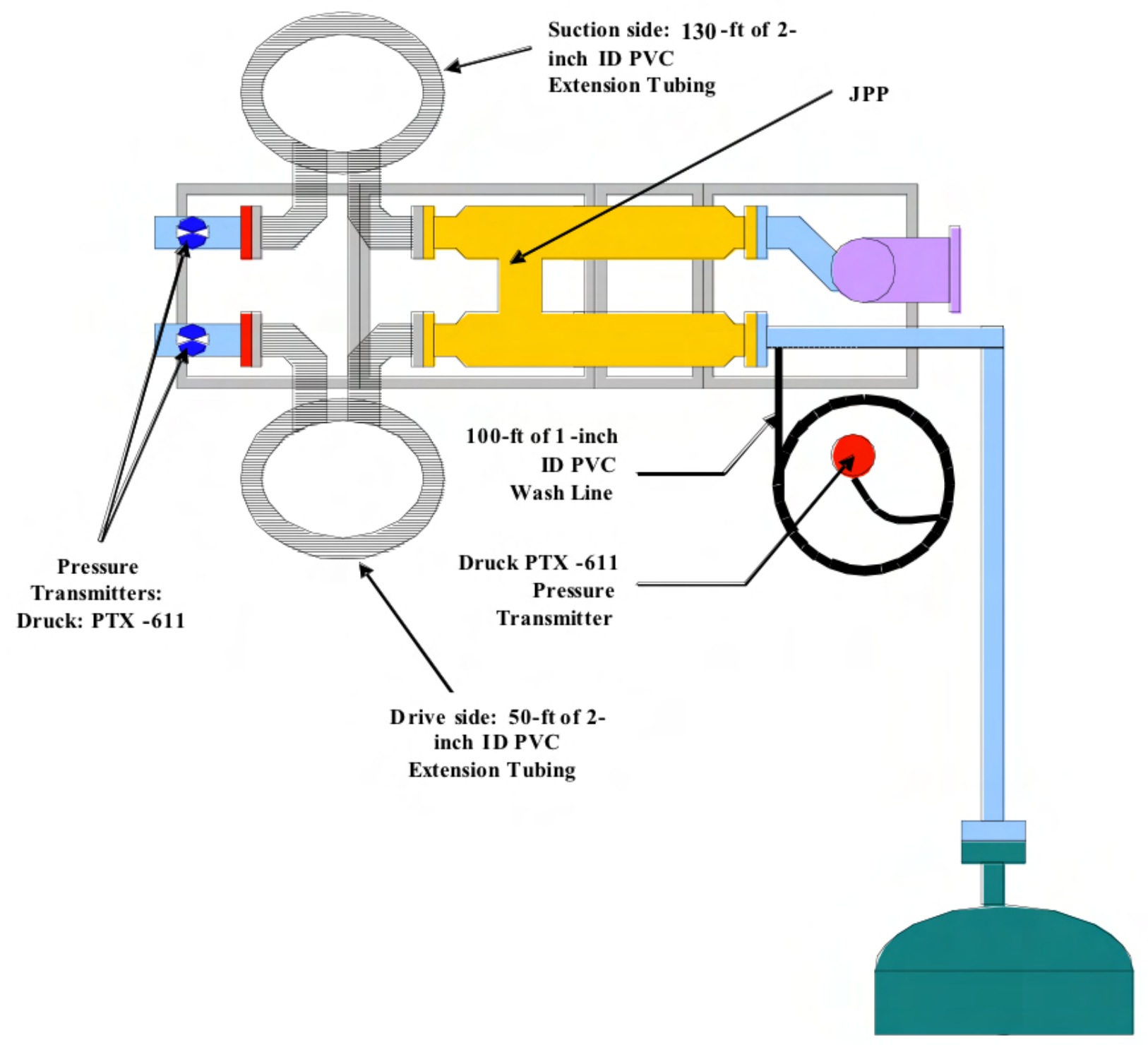

Figure 4.3. Schematic of the Modification to the JPP/Airline of PJM\#A to Include the Extension Piping and the Flush Line 


\subsection{Experimental Approach}

The controller testing was performed with clay and water simulants to encompass the upper and lower bounds of the waste streams that could be encountered in the WTP. In addition, with both simulants, tests were performed at high, mid, and low fill levels in the tank to simulate the expected operating range of the PJMs. This section describes the simulants and the various instruments and data acquisition systems (DAS) used to collect and log the experimental data.

\subsection{Clay Simulant}

The upper range of the WTP waste stream rheology was bounded using a clay simulant consisting of 80\% kaolin clay (EPK Feldspar pulverized) and 20\% bentonite clay (WYO-Ben Big Horn CH-200) mixed at a solids loading of approximately $29 \mathrm{wt} \%$. This simulant had a Bingham yield stress of $30 \pm 5 \mathrm{~Pa}$ and a consistency of approximately $30 \mathrm{cP}$. The technical basis for the development and selection of this simulant is provided in Poloski et al. (2004). This simulant mix has been used successfully in previous $\mathrm{PJM}$ /sparger testing in the Applied Process Engineering Laboratory and 336 Building test stands (Poloski et al. 2004, Bontha et al. 2005).

Before the start of a test, it was ensured that the simulant rheology had been measured at most three days prior to the test date and that the yield stress was within the target range of $30 \pm 5 \mathrm{~Pa}$, as specified in the test plan. If the simulant rheology was verified more than three days before the test, the simulant was thoroughly mixed by overblowing one PJM at a time for a few minutes. Then a sample was taken and the rheology verified. If the rheology of the sample was greater than the target range of $30 \pm 5 \mathrm{~Pa}$, the required amount of dilution water to bring the rheology to within the target range was added, and the tank was again mixed for about 30 minutes with all PJMs. ${ }^{1}$ After dilution, another sample was taken to verify that the rheology was within the target range.

The simulant rheology was measured using a TA Instruments (New Castle, DE) Model AR 2000 rheometer with a concentric cylinder sensor. This model is a controlled stress rheometer equipped with an air bearing and a Peltier plate for temperature control. All rheograms were obtained at $25^{\circ} \mathrm{C}$. The instrument was performance checked with calibration standard oils at least once a month. During controller testing, this was performed three times, and each time the instrument tested well within the required $\pm 10 \%$ of the known standard value.

\subsection{Water Simulant}

Water was used to encompass the lower range of the WTP waste stream. This water was essentially from the third rinse of the tank after the clay was removed and the tank was rinsed thoroughly with water containing small traces of clay (estimated at $<0.01 \%$ ).

\footnotetext{
1 The required amount of dilution water was determined from past experience with the same simulant and was equal to $500 \mathrm{lb}$ of water for an approximately $2 \mathrm{~Pa}$ drop in approximately 100,000 lb of clay simulant.
} 


\subsection{Analytical Instruments}

Table 5.1 lists the various analytical instruments used to collect and record data during the testing. Unless otherwise noted in the Table 5.1, all instruments that provided NQA-1 reportable data were calibrated according to PNNL's WTP Support Project QA requirements (see Section 2.0 for more details).

Table 5.1. List of the Various Analytical Instruments Used in the Controller Testing

\begin{tabular}{|c|c|c|c|c|c|}
\hline Parameter & \multicolumn{2}{|c|}{ Types \& Manufacturer } & Model & Qty & Data Quality \\
\hline JPP Drive Press. & Press. Transmitter & Druck & PTX-611 & 4 & NQA-1 ${ }^{(\mathrm{a}, \mathrm{b})}$ \\
\hline JPP Suction Press. & Press. Transmitter & Druck & \begin{tabular}{|l|} 
PTX-611 \\
\end{tabular} & 4 & NQA-1 ${ }^{(\mathrm{a}, \mathrm{b})}$ \\
\hline Flush Pressure & Press. Transmitter & Druck & PTX-611 & 1 & NQA-1 ${ }^{(\mathrm{a}, \mathrm{b})}$ \\
\hline PJM Pressure & Press. Transmitter & E+H PMP & 135-A4G01R4R & 4 & $\mathrm{NQA} 1^{\text {(a) }}$ \\
\hline Tk. Sim. Density & Bubbler & Foxboro & \begin{tabular}{|l} 
IDP10-T22B21F-M1L1B1T \\
\end{tabular} & 1 & NQA-1 $^{(a)}$ \\
\hline Tank Level & Bubbler & Foxboro & IDP10-T22C21F-M1L1B1T & 1 & $\mathrm{NQA}^{-1}{ }^{\text {(a) }}$ \\
\hline PJM Level & Cap. Level. Probe & Drexelbrook & 700-0002-057 & 4 & NQA-1 ${ }^{(a)}$ \\
\hline Tank Level & Laser Level Sensor & Optech & Sentinel 3100 & 3 & For Info Only \\
\hline Tank Temp & Type T TC & Eustis & MCT41U6 & 2 & For Info Only \\
\hline
\end{tabular}

\subsection{Instrument Description and Manufacturer Specified Accuracies}

The following is a description of the various sensors, their ranges, and the manufacturer's specified accuracy.

Note: The accuracies stated below do not include errors associated with the transmission line length, noise from the data acquisition system interfaces, etc. These errors were rolled into the acceptable tolerances (for the various sensors generating NQA-1 data) presented in Section 5.5.

\subsubsection{JPP Suction, Drive, and Flush Line Pressure}

The suction and drive pressures of the JPPs on all PJMs and the pressure in the flush line were monitored using Druck Model PTX-611 sensors. Based on a discussion with BNI’s Controls \& Instrumentation (C\&I) project leads, the Druck pressure transmitters are the WTP project approved pressure transmitters for use in all of non-safety related, PJM control systems. BNI plans on using pressure transmitters made by AMETEK - U.S. Gauge in all its backup or safety related PJM control systems. (PNNL has not evaluated the AMETEK pressure transmitters to be used in the safety related PJM control systems.) The Druck pressure transmitters have a range of 0 to 10 bar-a and an accuracy of \pm 0.008 bar. The data from this sensor were NQA-1 reportable data. Although the range of these pressure transmitters is - 1 to 9 bar-g, they were calibrated between 0 - 7 bar-a in order to maintain the 4:1 turndown ratio and still achieve the desired accuracy range of \pm 0.008 bar using the available calibration standards. The calibration range was considered sufficient since the testing was conducted with the drive and suction pressures at the JPPs set to $<5$ bar-g. 


\subsubsection{PJM Pressures}

The pressure inside each PJM was measured using an Endress+Hauser PMP Model 135-A4G01R4R ${ }^{2}$ pressure transducer having a range of 0 to 150 psia and an accuracy of \pm 0.75 psia. The data from these sensors were NQA-1 reportable.

\subsubsection{Tank Level}

The tank level was measured using a Foxboro Model IDP10-T22C21F ${ }^{3}$ differential pressure transmitter having a range of 0 to 350 inches of $\mathrm{H}_{2} \mathrm{O}$ and an accuracy of \pm 0.21 inches of $\mathrm{H}_{2} \mathrm{O}$. The data from this sensor were NQA-1 reportable data. The tank level was also measured using three Optech Model Sentinel $3100^{4}$ laser level sensors having a range of 0 to $150 \mathrm{~m}$ and an accuracy of $\pm 5 \mathrm{~mm}$. The information from these laser level sensors was for information only. The laser level sensors do not work with transparent fluids such as water.

\subsubsection{Simulant Density}

The density of the simulant in the tank was measured using a Foxboro Model IDP10-T22B21F differential pressure transmitter having a range of 15 to 40 inches of $\mathrm{H}_{2} \mathrm{O}$ and an accuracy of \pm 0.015 inches of $\mathrm{H}_{2} \mathrm{O}$. The data from this sensor were NQA-1 reportable data.

\subsubsection{PJM Level}

The level of the fluid in the PJMs were measured using a Drexelbrook Model 700-0002-057 5 capacitance level probes having a range of 0 to 144 inches and an accuracy of \pm 1.4 inches. The data from these sensors were NQA-1 reportable data.

It should be noted that the PJM level probes were inserted into the PJMs through a cross connection mounted on top of the PJM as shown in Figure 5.1. The distance from the top of the dish-head of the PJM to the top of the level probe is estimated to be $\sim 24$-inches or $\sim 2-\mathrm{ft}$. In other words, when interpreting the PJM level data presented in this report, the top of the PJM corresponds to a level probe reading of $\sim 120$ inches.

\footnotetext{
${ }^{2}$ Endress+Hauser, Inc. Greenwood, IN.

${ }^{3}$ IPS. Plano, TX.

${ }^{4}$ Optech, Inc. Vaughan, Ontario, Canada.

${ }^{5}$ AMETEK Drexelbrook, Horsham, PA.
} 


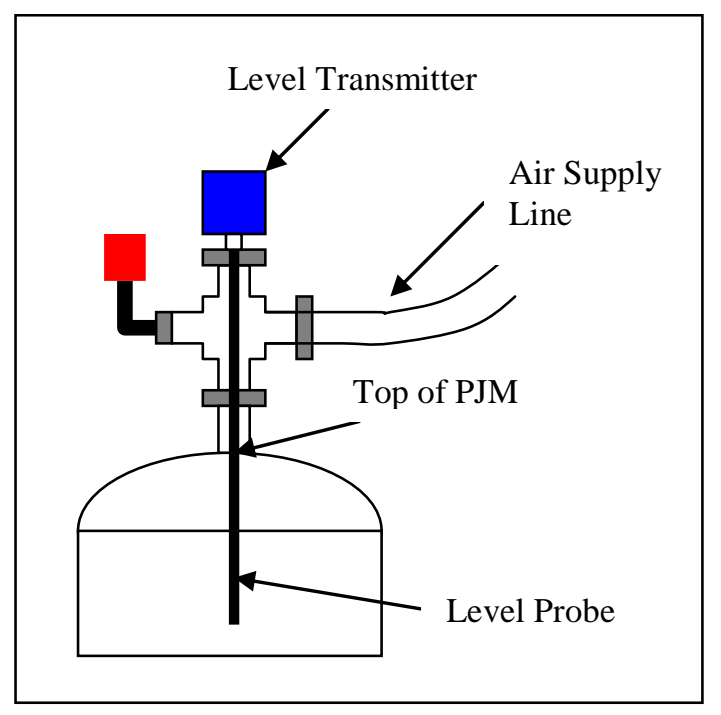

Figure 5.1. Method of Inserting Level Probe into PJM

It should also be noted that an unavoidable consequence of including a level probe to measure the level of the slurry inside the PJM is a reduction of the effective diameter of the airline at the top of the PJM by 0.75 inches. For a 23.5 inch pulse tube diameter with a Schedule 40 air-link pipe, this results in a $16 \%$ increase in the area ratio of the PJM to the air-link line. The net result is that the observed controller confidence levels, particularly for CVF, may be stronger in the present study that those which will be observed in the real plant. This is because the CVF confidence signal results from rapid change in the PJM pressure decreases due to the sudden reduction in the pipe diameter between the pulse tube and the air link line. The drive overblow detection, on the other hand, should have minimal impact since this signal is caused by a decrease in the PJM pressure as a result of the air exiting the nozzle.

\subsubsection{Tank Temperature}

The temperature of the simulant in the tank was measured using a Eustis Model MCT41U6 ${ }^{6}$ thermocouple (Type J) with a range of \pm 0 to $50^{\circ} \mathrm{C}$ and an accuracy of $\pm 2^{\circ} \mathrm{C}$. The temperature information from the thermocouple in the tank was for information only.

\subsection{PNNL Data Acquisition System}

During the testing conducted under this test plan, data from the field instruments (i.e., JPP drive and suction pressures, flush line pressure, bubbler level and density, PJM pressure, PJM level, and tank level) along with the confidence values calculated by the BNI controllers were recorded digitally on a computer using DASYLab, Version 8.0 DACS software. ${ }^{7}$

\footnotetext{
${ }^{6}$ Eustis Co., Inc. Mukilteo, WA.

${ }^{7}$ National Instruments Ireland Resources Limited. Dublin, Ireland.
} 
Table 5.2. Acceptable Tolerances for the Various NQA-1 Reportable Data Logged on the PNNL DAS Calibration

\begin{tabular}{|c|c|c|c|}
\hline Measured Variable & Sensor & Range & Acceptable Tolerance \\
\hline JPP Drive Pressure & Druck PTX-611 & -1 to 9 bar-g ${ }^{(c)}$ & \pm 0.2 bar $^{(\mathrm{a})}$ \\
\hline JPP Suction Pressure & Druck PTX-611 & -1 to 9 bar-g ${ }^{(c)}$ & \pm 0.2 bar $^{(a)}$ \\
\hline Flushline Pressure & Druck PTX-611 & -1 to 9 bar-g ${ }^{(\mathrm{c})}$ & \pm 0.2 bar $^{(a)}$ \\
\hline Tank Level & Foxboro IDP10-T22C21F & $\begin{array}{c}0 \text { to } 350 \text { in } \mathrm{H}_{2} \mathrm{O} \\
\text { differential }\end{array}$ & \pm 3.5 in $\mathrm{H}_{2} \mathrm{O}^{(\mathrm{a})}$ \\
\hline Tank Simulant Density & Foxboro IDP10-T22B21F & $\begin{array}{c}15 \text { to } 40 \text { in } \mathrm{H}_{2} \mathrm{O} \\
\text { differential }\end{array}$ & \pm 0.5 in $\mathrm{H}_{2} \mathrm{O}^{(\mathrm{a})}$ \\
\hline Confidence Level & Output from BNI Controller & -10 to 100 & $\pm 2.0^{(\mathrm{a})}$ \\
\hline PJM Pressure & E+H 135-A4G01R4R & 0 to 150 psia & \pm 3.0 psia $^{(\mathrm{b})}$ \\
\hline PJM Level & Drexelbrook 700-0002-057 & 0 to 144 in & \pm 2 in \\
\hline \multicolumn{4}{|c|}{$\begin{array}{l}\text { (a) Tolerance ranges provided by BNI. } \\
\text { (b) Tolerance range estimated based on the } \pm 2 \% \text { uncertainty used by BNI in determining the acceptable tolerance } \\
\text { for the Druck and Foxboro transmitters and the controller generated confidence values. } \\
\text { (c) The Druck transmitters are used in the study measure the absolute pressure. This pressure was converted to } \\
\text { gauge pressure by the BNI controllers. }\end{array}$} \\
\hline
\end{tabular}

Before the start of reportable data collection, the DAS software was verified and validated according to procedures approved by BNI (in Bechtel memoranda CCN 191725 and CCN 191726 and their attachments). The verification and validation included ensuring that the signal from the field transmitters and the confidence values from the BNI controllers were being accurately logged on the PNNL DAS. Table 5.2 lists the accuracy ranges that were used for the ensuring the logged data were within the acceptable tolerance limits. This information was provided by BNI’s C\&I staff prior to the start of the testing.

All data were sampled at a rate of $100 \mathrm{~Hz}$ and logged at a rate of $20 \mathrm{~Hz}$ (i.e., one out of every five data points was logged). In addition to the $20 \mathrm{~Hz}$ data files, data were also logged at a sampling rate of $100 \mathrm{~Hz}$; this data was for information only and was not used in any of the analysis presented in this report. All data logged on PNNL DAS were time stamped with the date and time of sampling.

\subsection{Testing Approach}

The following approach was used for determining the performance of the BNI controllers:

- Repeatability was determined by analyzing the controller generated confidence data under a given set of conditions to establish whether the true event (CVF or DOB) can be clearly distinguished from the false event arising from the noise associated with the pressure transducer signals.

- Reliability was determined by conducting multiple cycles of the PJM operation at several test conditions to ensure that a threshold confidence level can be clearly identified to enable CVF or DOB detection over the range of conditions tested.

The number of repeated cycles of data collected during each test condition are listed with the experimental results in Sections 6 - 10 below. 


\subsection{General Conditions}

The following general conditions applied to the various tests discussed in this report.

1. All tests were performed with $50 \pm 5$ feet of 2 inch reinforced PVC tubing on the drive leg of the JPP of PJM\#A, $130 \pm 5$ feet of 2 inch reinforced PVC tubing on the suction leg of the JPP of PJM\#A, and $100 \pm 5$ feet of 1 inch flush line reinforced PVC tubing on the air supply line of PJM\#A. No extension piping and flush line piping was used with any of the other PJMs.

2. The focus of all testing and analysis presented in this report was PJM\#A, which has the prototypic piping included between the JPP \& pressure transmitter on the drive and suction legs, and on the flush line.

3. All tests presented in this report were conducted at a single set point for the JPP drive and suction pressures of $4 \pm 0.2$ bar-g as specified by BNI.

4. All tests were conducted at ambient conditions.

5. There were no spargers present in the four PJM configuration.

\subsection{Test Matrix}

The test parameters that were investigated to determine the ability of the ABB and Triconex controllers to detect CVF and DOB are shown in Table 5.3. The parameters investigated included simulant type (clay/water), fill height (high/mid/low), number of PJMs operating, PJM fill level (only for DOB tests). In addition to these, tests were also performed to determine the time to gravity fill the PJMs and the effect of density-gravity-height on the time to overblow. The list of the various data files generated for the different tests performed are listed in Appendix A.

Table 5.3. Controller Test Matrix

\begin{tabular}{|c|c|c|c|c|}
\hline Test & System & Simulant & Fill Level (H/D) & Description \\
\hline $\begin{array}{l}\text { System } \\
\text { Tuning }\end{array}$ & $\begin{array}{l}\text { ABB } \\
\text { Triconex }\end{array}$ & Clay $(30 \pm 5 \mathrm{~Pa})$ & High (0.80) & $\begin{array}{l}\text { Tune algorithm to detect } \\
\text { overblows, charge vessel full, etc. }\end{array}$ \\
\hline $\begin{array}{l}\text { Drive } \\
\text { Overblow } \\
\text { Scan Times }\end{array}$ & $\begin{array}{l}\text { ABB } \\
\text { Triconex }\end{array}$ & $\begin{array}{l}\text { Water }(30 \pm 5 \\
\text { Pa) }\end{array}$ & High (0.80) & $\begin{array}{l}\text { Detect drive overblow using the } \\
\text { WTP flush line algorithm at 50ms, } \\
100 \mathrm{~ms}, 150 \mathrm{~ms} \text {, and } 250 \mathrm{~ms} \\
\text { controller scan periods to } \\
\text { determine optimal controller scan } \\
\text { rate for overblow detection. }\end{array}$ \\
\hline $\begin{array}{l}\text { Drive } \\
\text { Overblow } \\
\text { Detection }\end{array}$ & $\begin{array}{l}\text { ABB } \\
\text { Triconex }\end{array}$ & $\begin{array}{l}\text { Clay }(30 \pm 5 \mathrm{~Pa}) \\
\text { Water }\end{array}$ & $\begin{array}{l}\text { High (0.80) } \\
\text { Mid (0.55) } \\
\text { Low }(0.30)\end{array}$ & $\begin{array}{l}\text { Detect overblows at all three levels } \\
\text { (low, mid, high) using both } \\
\text { simulant types. Tests run for single } \\
\text { PJM and multiple PJM operations } \\
\text { using both the flush line algorithm } \\
\text { and normal PRESCON control } \\
\text { algorithm (as designed by } \\
\text { NuVision Engineering). }\end{array}$ \\
\hline
\end{tabular}




\begin{tabular}{|l|l|l|c|l||}
\hline \multicolumn{1}{|c|}{ Test } & System & \multicolumn{1}{c|}{ Simulant } & Fill Level (H/D) & \multicolumn{1}{c||}{ Description } \\
\hline $\begin{array}{l}\text { CVF } \\
\text { Detection }\end{array}$ & $\begin{array}{l}\text { ABB } \\
\text { Triconex }\end{array}$ & $\begin{array}{l}\text { Clay (30 } \pm 5 \mathrm{~Pa}) \\
\text { Water }\end{array}$ & $\begin{array}{l}\text { High (0.80) } \\
\text { Mid (0.55) } \\
\text { Low (0.30) }\end{array}$ & $\begin{array}{l}\text { Verify no change in charge vessel } \\
\text { full indication with 4 nozzles (as } \\
\text { opposed to the 2 nozzles). }\end{array}$ \\
\hline $\begin{array}{l}\text { Rho-g-h Data } \\
\text { Collection }\end{array}$ & ABB & $\begin{array}{l}\text { Clay }(30 \pm 5 \mathrm{~Pa}) \\
\text { Water }\end{array}$ & $\begin{array}{l}\text { High (0.80) } \\
\text { Mid (0.55) } \\
\text { Low (0.30) }\end{array}$ & $\begin{array}{l}\text { Collect time-to-overblow given } \rho \text { - } \\
\text { g-h waste characteristics at all three } \\
\text { levels (low, mid, high) using both } \\
\text { simulant types. }\end{array}$ \\
\hline Gravity Re-fill & ABB & $\begin{array}{l}\text { Clay (30 } \pm 5 \mathrm{~Pa}) \\
\text { Water }\end{array}$ & High (0.8) & $\begin{array}{l}\text { Determine how long it takes for the } \\
\text { PJM to refill at high level water } \\
\text { and clay with no suction (gravity } \\
\text { re-fill). }\end{array}$ \\
\hline
\end{tabular}





\subsection{Drive Overblow Detection}

The ability of BNI's primary (ABB) and safety (Triconex) control systems to detect drive overblows was evaluated at multiple vessel fill levels using clay and water simulants to bound the upper and lower rheological limits of the waste streams that could be encountered in the WTP. In addition, the PJM operation conditions were chosen to encompass the anticipated scenarios for PJM overblow to occur. These included, 1) an overblow occurring due to a stuck drive valve, 2) an intentional overblow during the scout mode of PJM operation where each PJM is operated by itself to determine the tuning parameters for the controller, and 3) an overblow occurring due to a PJM not completely filling during the suction phase.

In Scenarios 1 and 2, both controllers provided reliable overblow detection. For Scenario 3, neither controller could detect overblows over drive phase background noise peaks. Reliable detection of overblows is therefore contingent on avoiding an incompletely filled PJM condition.

\subsection{Experimental Conditions}

The PJM operation for the different scenarios was achieved in the following manner:

- Scenario 1, PJM overblow caused by a stuck valve. Simulated by setting the drive time of one of the PJMs to a value such that the PJM overblew while the rest operated normally during the cycle. This case is also referred to as the 4PJM-Full case.

- Scenario 2, single PJM operation with overblow. Simulated by turning off the other PJMs on the controller and setting the drive time for the one PJM such that it overblew during the drive phase. This case is also referred to as the 1PJM-Full case.

- Scenario 3, overblow of an incompletely filled PJM. Simulated by setting the CVF detection parameters of the controller such that the controller detects CVF before the pulse tube is actually full. This case is also referred to as the 4PJM-Partial case.

The overblow tests with Scenarios 1, 2, and 3 were performed with both clay and water simulants. In all cases, only PJM\#A, with the prototypic tubing, was overblown. Scenarios 1 and 2 were performed at three simulant fill levels corresponding to Height to Diameter (H/D) ratios of 0.8, 0.55, and 0.3. ${ }^{1}$ For Scenario 3, however, due to difficulty in preventing PJM filling during the refill phase at the low H/D ratio of 0.3 , testing was only conducted at $\mathrm{H} / \mathrm{D}$ ratios of 0.8 and 0.55 . During testing, the clay simulant rheology was tested frequently and adjusted, if necessary, to keep it within the target range of $30 \pm 5 \mathrm{~Pa}$.

Each experiment consisted of between 100 and 300 PJM cycles. The recorded confidence levels obtained from each experiment were examined and the peak values near overblow and the peak noise values during the pre-overblow drive were identified for every cycle. The distributions of true and false (noise) peak values are displayed in the sections below in the form of histograms for each experiment. As confidence levels ranged between 0 and 100 (dimensionless), we divided the recorded confidence

\footnotetext{
${ }^{1}$ For the 336 test vessel with an internal diameter of 153 inches, these H/Ds correspond to fill levels of 122.4, 84, and 46 inches, respectively, as measured from the tank centerline. During testing, the fill level in the tank was maintained within \pm 2 inches of the target.
} 
values into 80 bins that were 1.25 confidence units wide and counted the number of cycles for which the true confidence peak value fell within each bin. We did likewise for the false peak values. The histograms presented below are plots of those frequencies versus confidence value. In each such plot the sum of bar heights in a distribution equals 1 .

We consider the detection of DOB to be repeatable for a given experiment if there is a clear separation between the true and false peak histograms. Under such conditions a threshold confidence level for DOB detection could have been set for that experiment such that a large percentage of the cycles had false peak confidences below the threshold value and another large percentage had true peak values above the threshold. We consider DOB detection to be reliable if such a conclusion holds for all three scenarios with both simulants at all three levels.

The ability of the ABB and Triconex controllers to detect drive overblows is discussed in Sections 6.2 and 6.3, respectively. The responses of the two systems to overblows were different. As tested, the ABB system sampled pressures every 50ms. The Triconex sampled pressures every $250 \mathrm{~ms}$. The differing scan rates resulted in differing distributions of confidence levels for the two systems. The effect of scan rate is discussed in more detail in Section 10.

\subsection{Drive Overblow Detection with the ABB Controller}

The results of DOB testing with the ABB controller for Scenarios 1, 2, and 3 are presented in the following sections.

\subsubsection{Scenario 1: Clay Simulant}

Figure 6.1 shows the histograms for the true (Light shaded) ${ }^{2}$ and false (Dark shaded) ${ }^{3}$ peaks of flush line confidence levels for DOB detection with clay simulant under Scenario 1 where all PJMs are full prior to the start of the drive phase. The upper, middle, and lower plots in this figure show the data for the high, mid, and low fill level of the simulant. Each plot in this figure represents a minimum of 101 cycles for a total of 314 cycles for the three fill heights.

It can be seen in Figure 6.1 that for the high, mid, and low fill level in clay simulant, the true overblow confidence peak range is 69 - 89 while the false peak range is 18 - 47. Also, for the clay simulant, the fill level seemed to have minor impact on the ranges of the true and false peaks observed. Finally, the true and false peaks appear to be well separated over the entire range of fill levels as shown in Figure 6.2. This lack of overlap of the peaks indicates that a detection threshold value can be set for this simulant that will ensure a high probability that a drive overblow will be detected when one occurs and a low probability of a false detection when one doesn't.

Modeling the true and false overblow peaks under the assumption of normal distributions allows thresholds for overblow detection to be estimated for Scenario 1 with clay. False alarms can be limited to $1 \%$ or less with a threshold of 47.8 or greater. The probability of overblow detection will be $99 \%$ or

\footnotetext{
${ }^{2}$ A "true" peak corresponds to the peak (or maximum) value of the confidence anytime after the PJM overblow has occurred.

${ }^{3}$ A "false" peak corresponds to the peak (or maximum) value of the confidence anytime during the drive phase prior to the PJM overblow.
} 
greater with a threshold of 70.2 or less. A working threshold for clay can be chosen anywhere within the range of 47.8 to 70.2 .

An example segment of the time series of flush line confidence levels for Scenario 1 with clay simulant is plotted in Figure 6.3. The data shown were obtained at the high liquid level. The plot clearly shows the false peaks during the drive phase and the true peaks near overblow. The ABB controller often produced baseline shifts during the suction phase as shown on the graph. The baseline shifts in the controller values for the ABB controller at the end of a drive phase are attributed to the fact that the controller resets the confidence values to a preset value during the vent and refill phases.
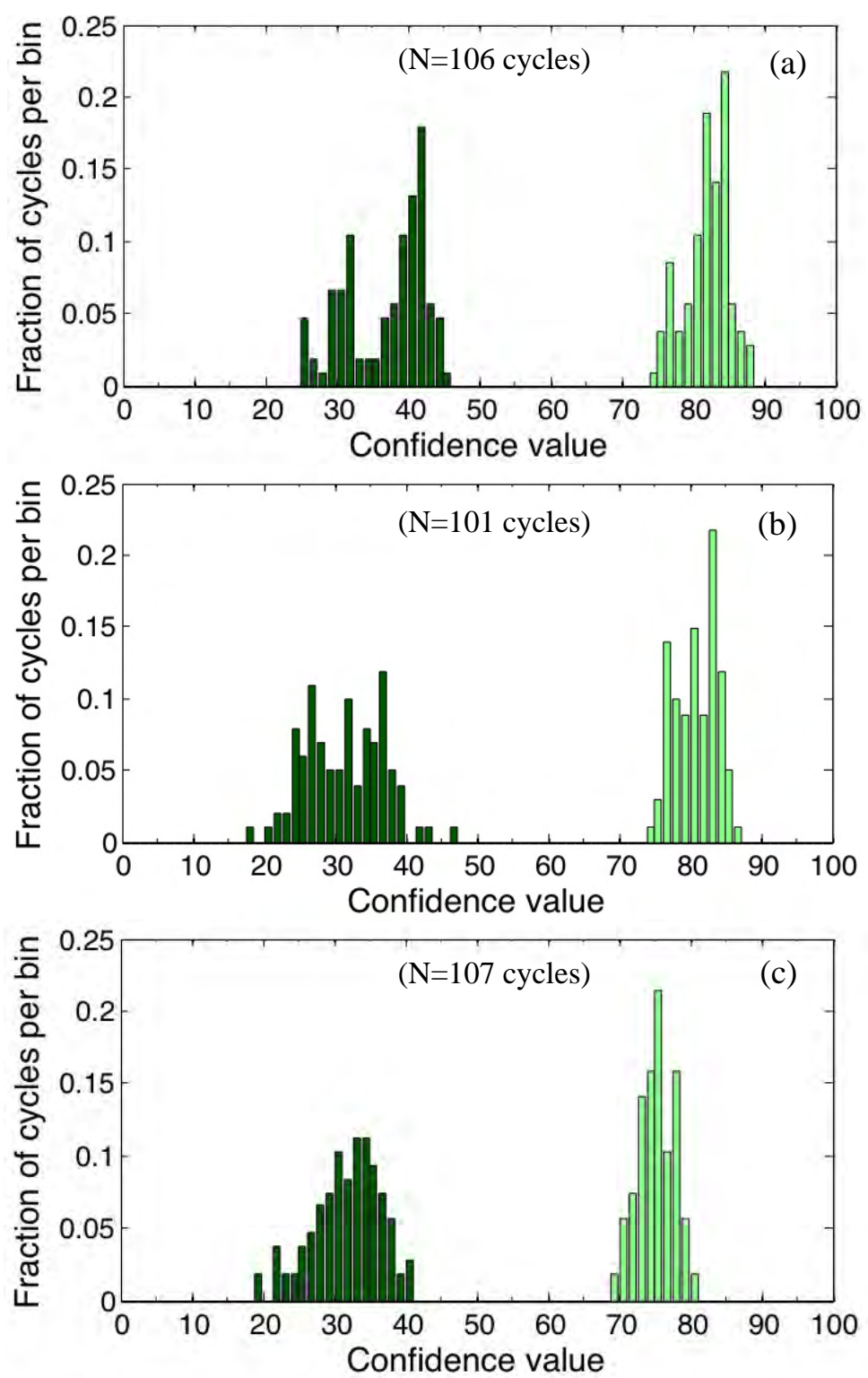

Figure 6.1. Histograms of the True and False Overblow Peaks for DOB Detection Scenario 1 (4PJM-Full Case) with ABB Controller in Clay Simulant at (a) High, (b) Mid, and (c) Low Fill Levels (Light shaded - true peaks. Dark shaded - false peaks.) 


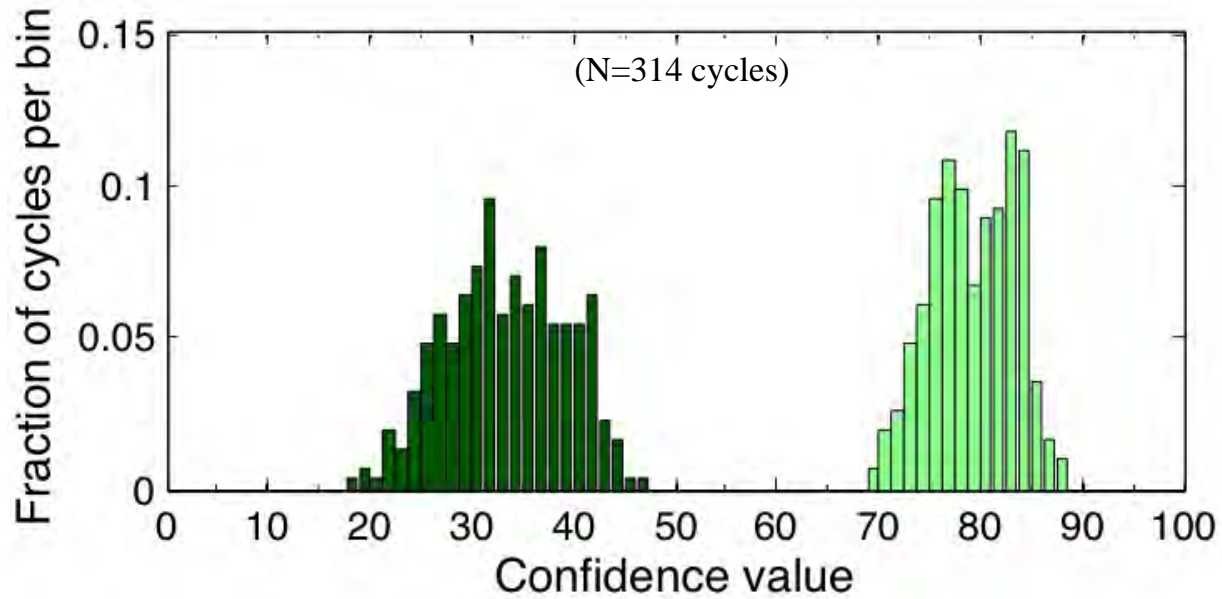

Figure 6.2. Histograms Over All Fill Levels of the True and False Overblow Peaks for DOB Detection Scenario 1 (4PJM-Full Case) with ABB Controller in Clay Simulant (Light shaded - true peaks. Dark shaded - false peaks.)

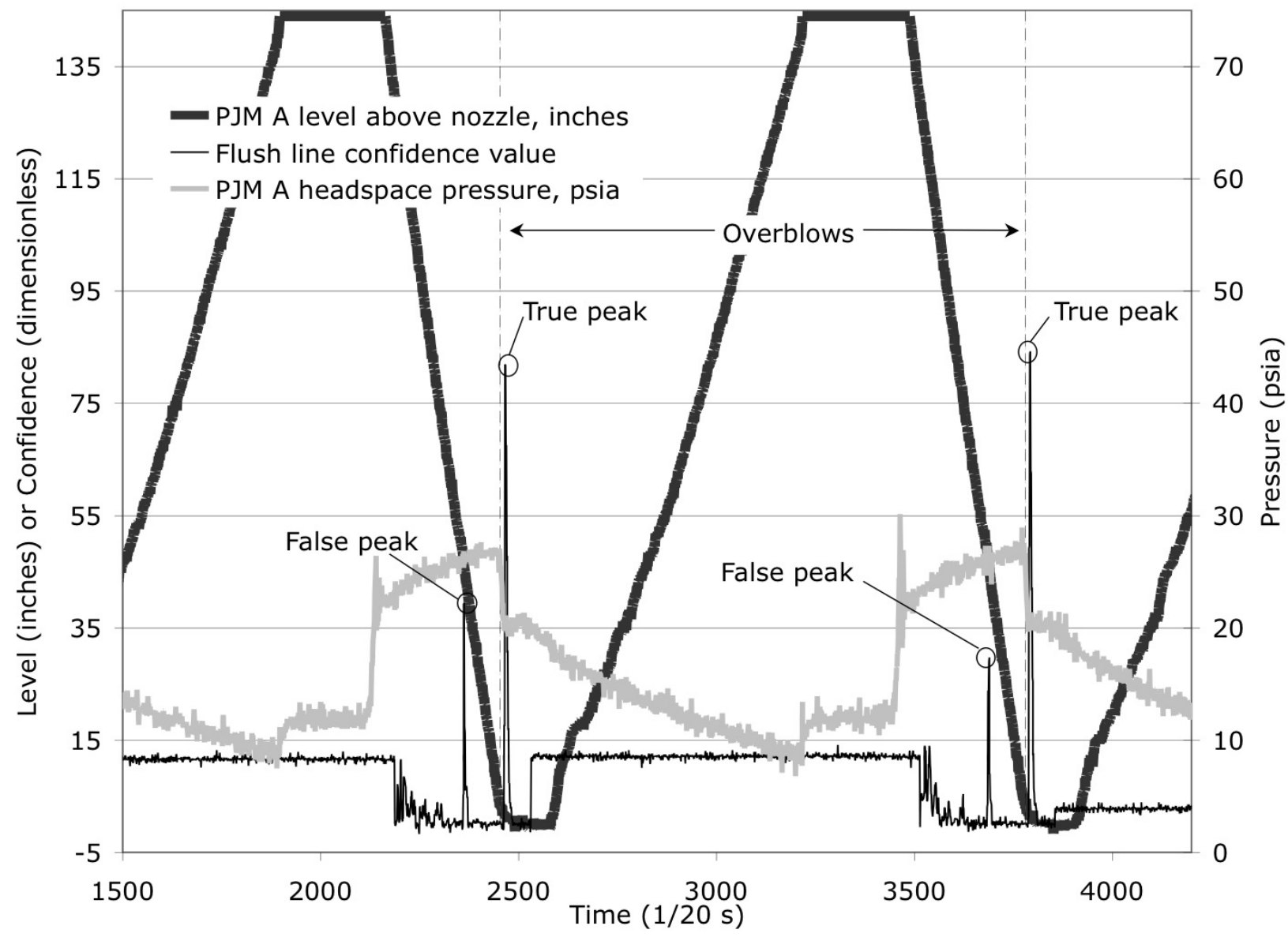

Figure 6.3. Flush Line Confidence Values for DOB Detection Scenario 1 (4PJM-Full Case) with ABB Controller in Clay Simulant at the High Fill Level 


\subsubsection{Scenario 1: Water Simulant}

Figure 6.4 shows the histograms for the true and false peaks for DOB detection with water simulant under Scenario 1 where all PJMs were full prior to the start of the drive phase. The upper, middle, and lower plots in this figure show the data for the high, mid, and low fill level of the simulant. Similar to the clay data, each plot in this figure represents a minimum of 104 cycles and a total 513 cycles for the three fill heights.

It can be seen in Figure 6.4 that for the high, mid, and low fill level in water simulant, the true overblow confidence peak range is 66 - 94 while the false peak range is 18 - 50. Additionally, the simulant fill level seemed to have a more pronounced effect than that observed with the clay simulant. The true and false overblow confidence peaks are still well separated for all three fill levels, as shown in Figure 6.5. This, once again, indicates that a detection threshold value can be set for water simulant that will ensure a high probability of true overblow detection and a low probability of false detections. 

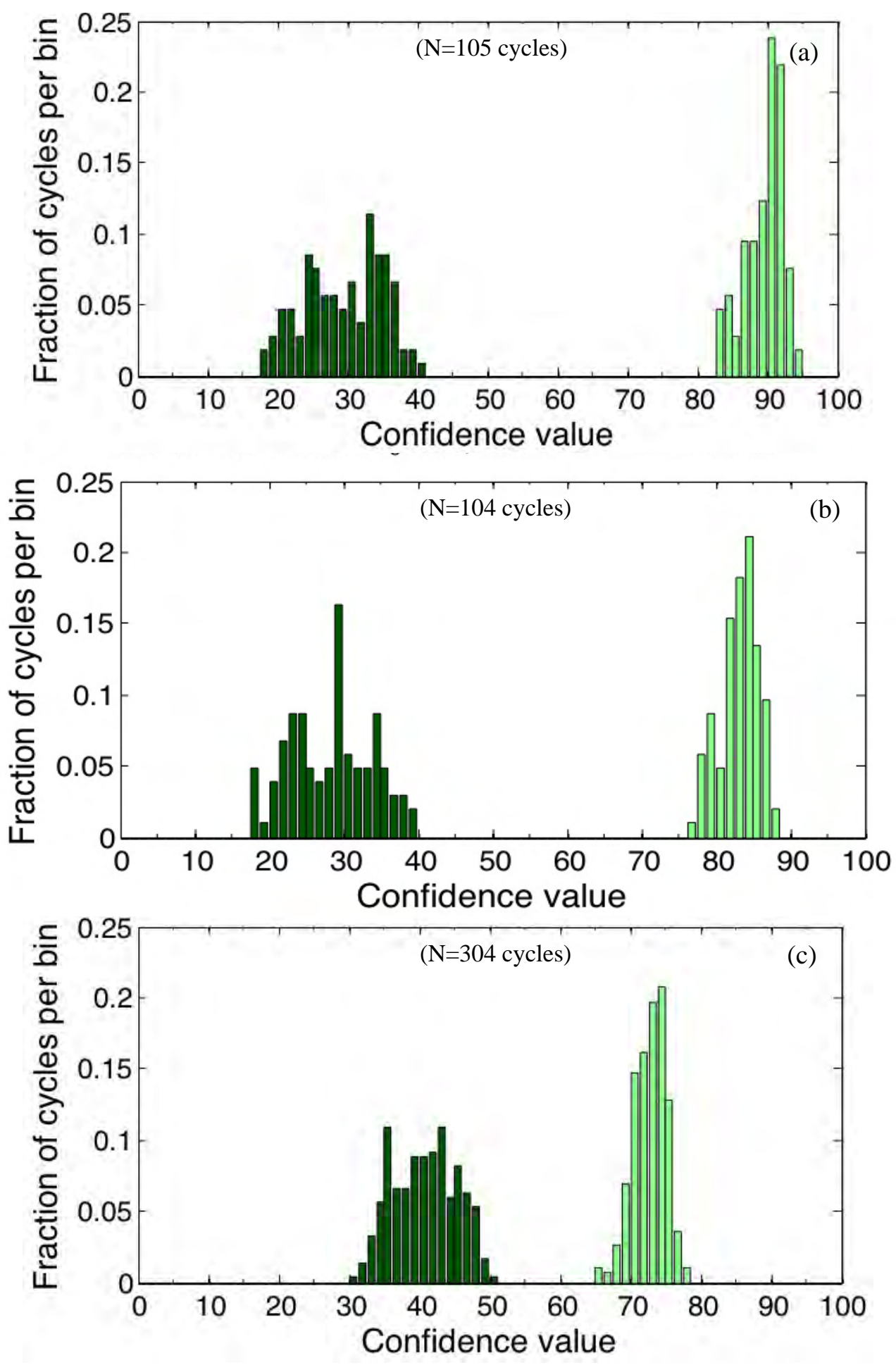

Figure 6.4. Histograms of the True and False Overblow Peaks for DOB Detection Scenario 1 (4PJM-Full Case) with ABB Controller in Water Simulant at (a) High, (b) Mid, and (c) Low Fill Levels (Light shaded - true peaks. Dark shaded - false peaks.)

Modeling the true and false overblow peaks under the assumption of normal distributions allows thresholds for overblow detection to be estimated for Scenario 1 with water. False alarms can be limited 
to $1 \%$ or less with a threshold of 50.2 or greater. The probability of overblow detection will be $99 \%$ or greater with a threshold of 67.9 or less. A working threshold for water can be chosen anywhere within the range of 50.2 to 67.9 .

An example segment of the time series of flush line confidence levels for Scenario 1 with water simulant is plotted in Figure 6.6. The true and false peaks and baseline noise during the drive phase are similar to the results obtained with clay.

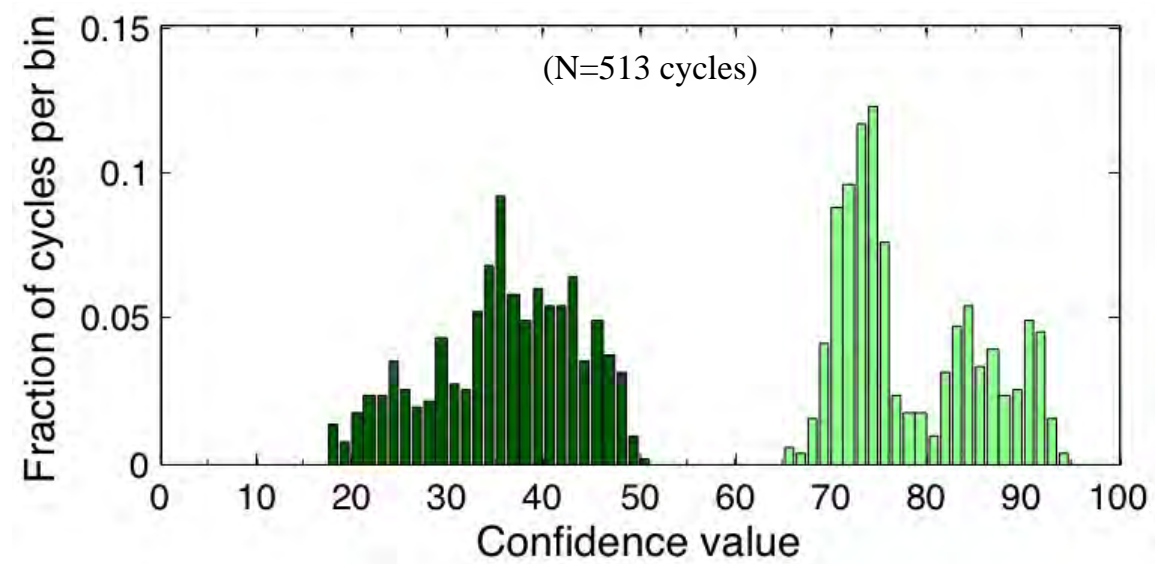

Figure 6.5. Histograms Over All Fill Levels of the True and False Overblow Peaks for DOB Detection Scenario 1 (4PJM-Full Case) with ABB Controller in Water Simulant

(Light shaded - true peaks. Dark shaded - false peaks.)

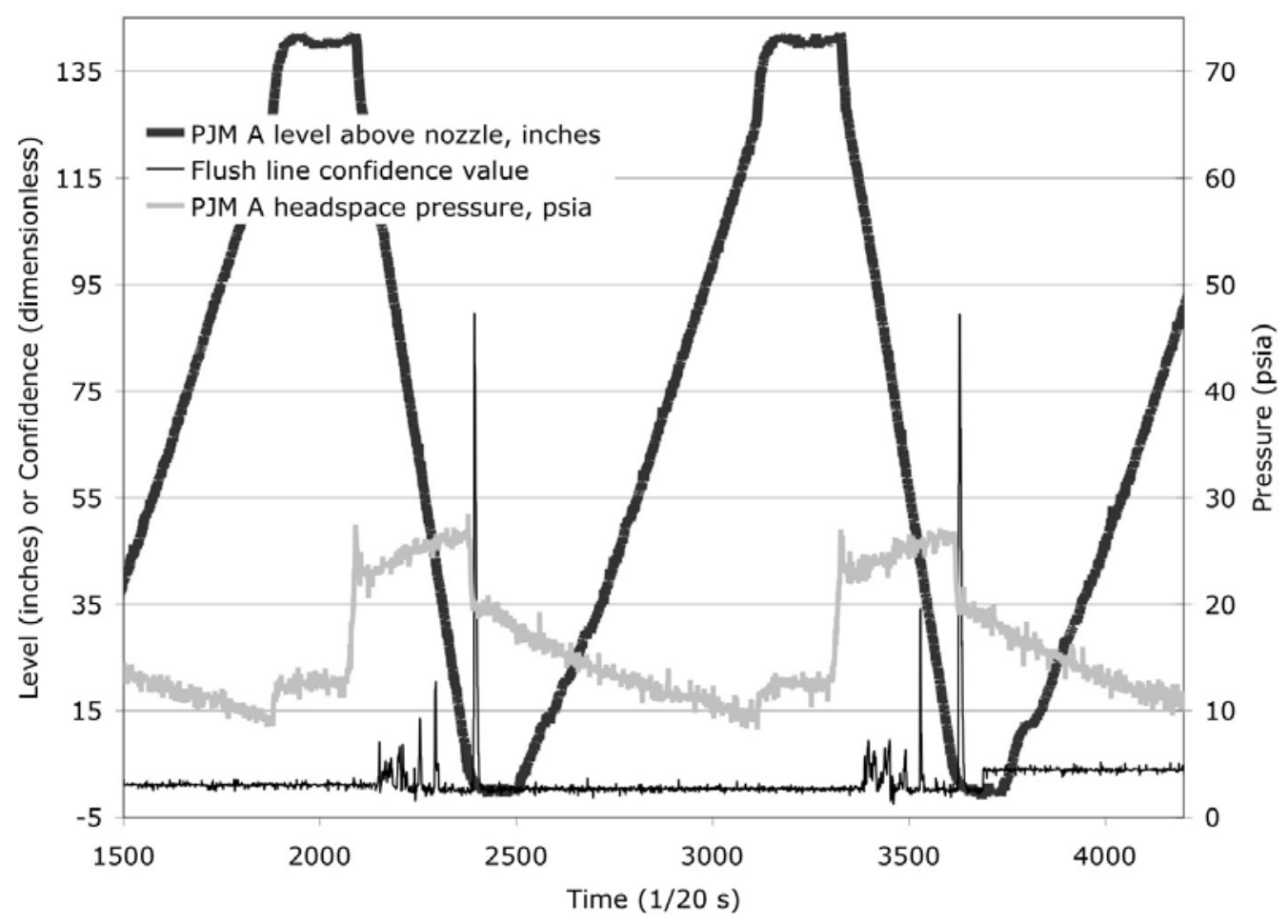

Figure 6.6. Flush Line Confidence Values for DOB Detection Scenario 1 (4PJM-Full Case) with ABB Controller in Water Simulant at the High Fill Level 


\subsubsection{Scenario 2: Clay Simulant}

Figure 6.7 shows the histograms for the true and false peaks of flush line confidence levels for DOB detection with clay simulant under Scenario 2 where only PJM\#A was operating. The upper, middle, and lower plots in this figure show the data for the high, mid, and low fill level of the simulant. Each plot in this figure represents a minimum of 306 cycles for a total of 924 cycles for the three fill heights.
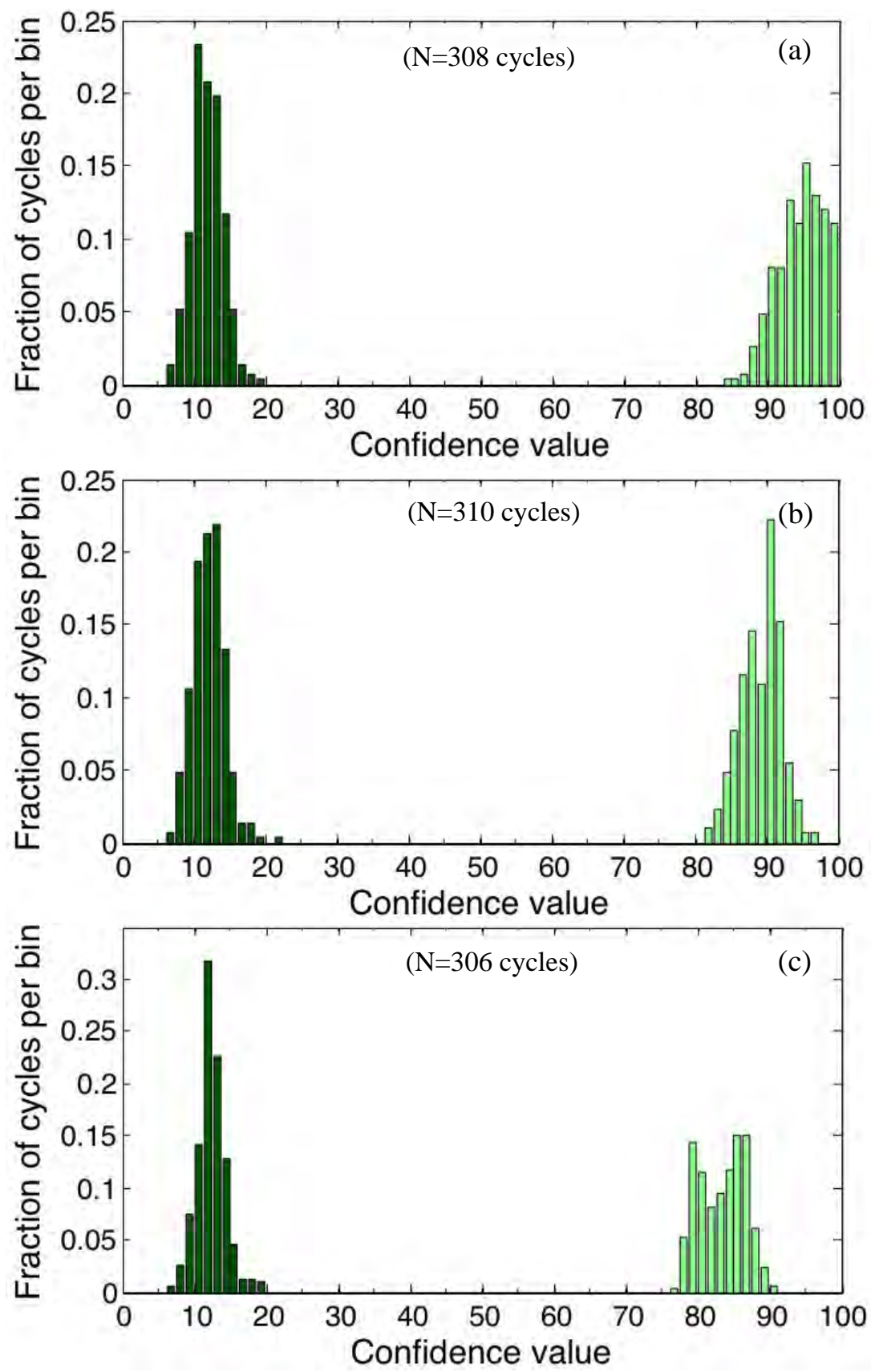

Figure 6.7. Histograms of the True and False Overblow Peaks for DOB Detection Scenario 2 (1PJMFull Case) with ABB Controller in Clay Simulant at (a) High, (b) Mid, and (c) Low Fill Levels (Light shaded - true peaks. Dark shaded - false peaks.) 
It can be seen in Figure 6.7 that for the high, mid, and low fill level in clay simulant, the true overblow confidence peak range is 77 - 100 while the false peak range is $7-22$. Also, for the clay simulant, the fill level seemed to have minor impact on the ranges of the true and false peaks observed. Finally, the true and false peaks appear to be well separated over the entire range of fill levels as shown in Figure 6.8. This lack of overlap of the peaks indicates that a detection threshold value can be set for this simulant that will ensure a high probability of correct overblow detections.

Modeling the true and false overblow peaks under the assumption of normal distributions allows thresholds for overblow detection to be estimated for Scenario 2 with clay. False alarms will be limited to $1 \%$ or less with a threshold of 16.7 or greater. The probability of overblow detection will be $99 \%$ or greater with a threshold of 76.9 or less. A working threshold for clay can be chosen anywhere within the range of 16.7 to 76.9 .

An example segment of the time series of flush line confidence levels for Scenario 2 with clay simulant is plotted in Figure 6.9.

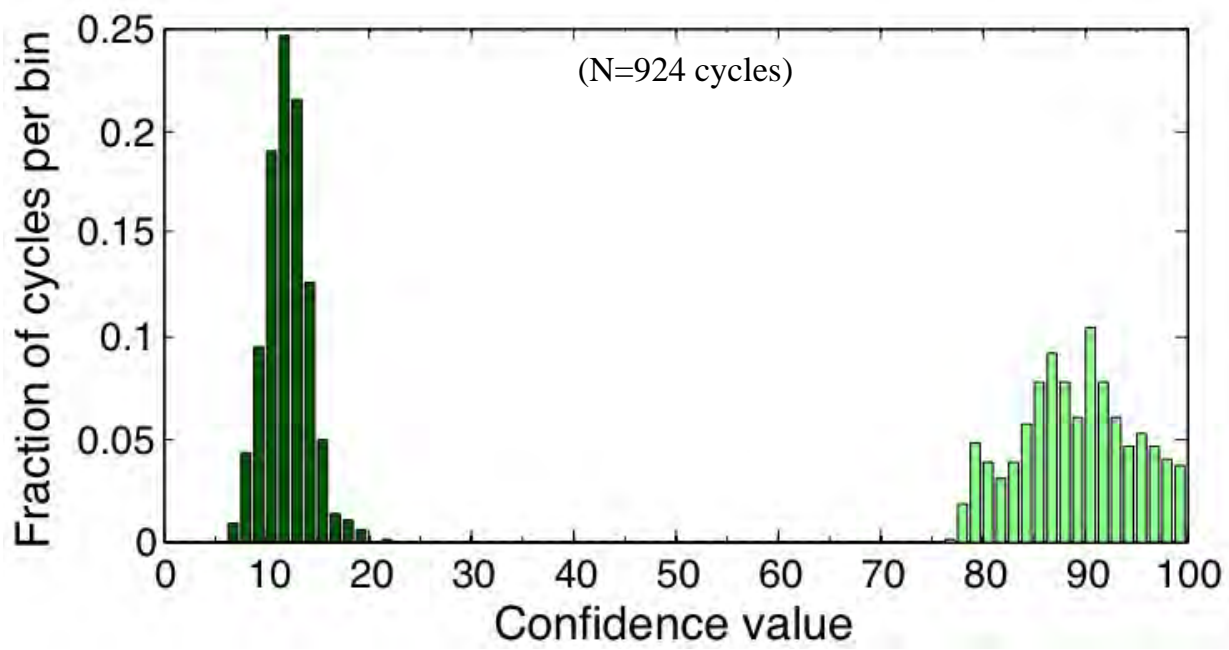

Figure 6.8. Histograms Over All Fill Levels of the True and False Overblow Peaks for DOB Detection Scenario 2 (1PJM-Full Case) with ABB Controller in Clay Simulant

(Light shaded - true peaks. Dark shaded - false peaks.) 


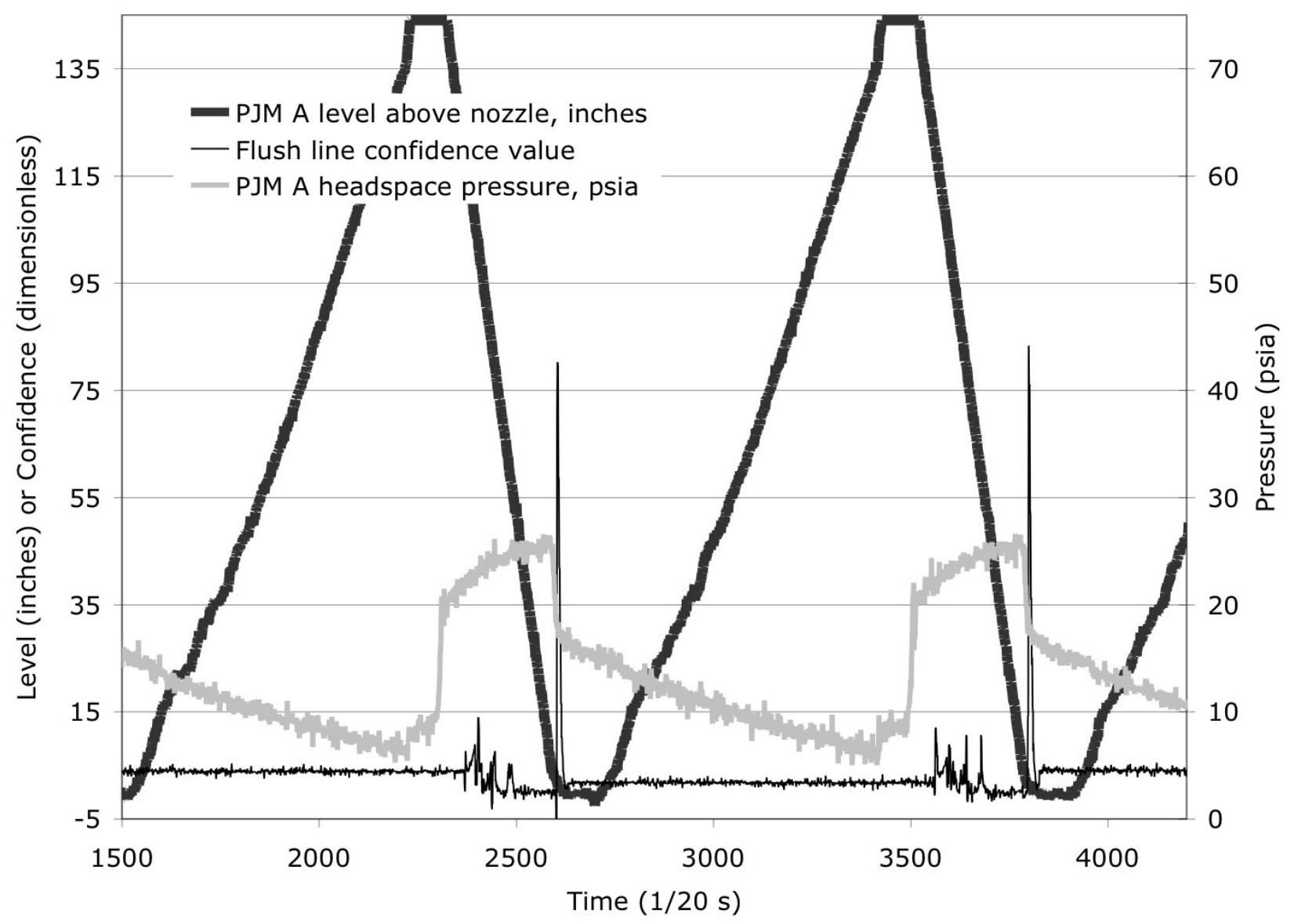

Figure 6.9. Flush Line Confidence Values for DOB Detection Scenario 2 (1PJM-Full Case) with ABB Controller in Clay Simulant at the Low Fill Level 


\subsubsection{Scenario 2: Water Simulant}

Figure 6.10 shows the histograms for the true and false peaks for DOB detection with water simulant under Scenario 2 where only PJM A is operating. The upper, middle, and lower plots in this figure show the data for the high, mid, and low fill level of the simulant. Each plot in this figure represents a minimum of 305 cycles for a total of 916 cycles for the three fill heights.
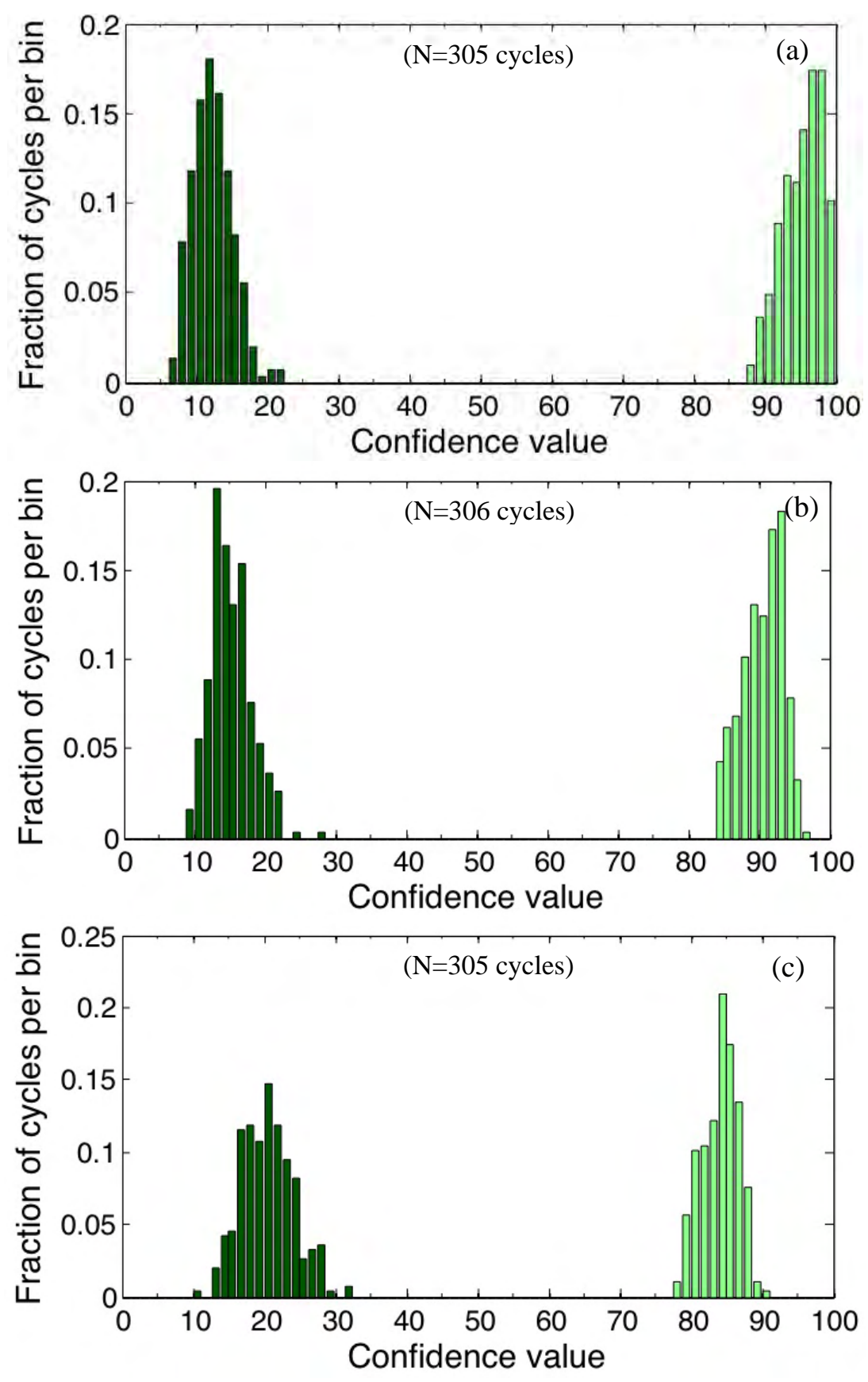

Figure 6.10. Histograms of the True and False Overblow Peaks for DOB Detection Scenario 2 (1PJM-Full Case) with ABB Controller in Water Simulant at (a) High, (b) Mid, and (c) Low Fill Levels (Light shaded - true peaks. Dark shaded - false peaks.) 
It can be seen in Figure 6.10 that for the high, mid, and low fill level in water simulant, the true overblow confidence peak range is 78 to 100 while the false peak range is 7 to 32 . The true and false overblow confidence peaks are again well separated for all three fill levels, as shown in Figure 6.11. This, once again, indicates that a detection threshold value can be set for water simulant that will ensure a high probability of true overblow detection and a low probability of false detections.

Modeling the true and false overblow peaks under the assumption of normal distributions allows thresholds for overblow detection to be estimated for Scenario 2 with water. False alarms will be limited to $1 \%$ or less with a threshold of 28.1 or greater. The probability of overblow detection will be $99 \%$ or greater with a threshold of 78.9 or less. A working threshold for clay can be chosen anywhere within the range of 28.1 to 78.9 .

An example segment of the time series of flush line confidence levels for Scenario 2 with water simulant is plotted in Figure 6.12.

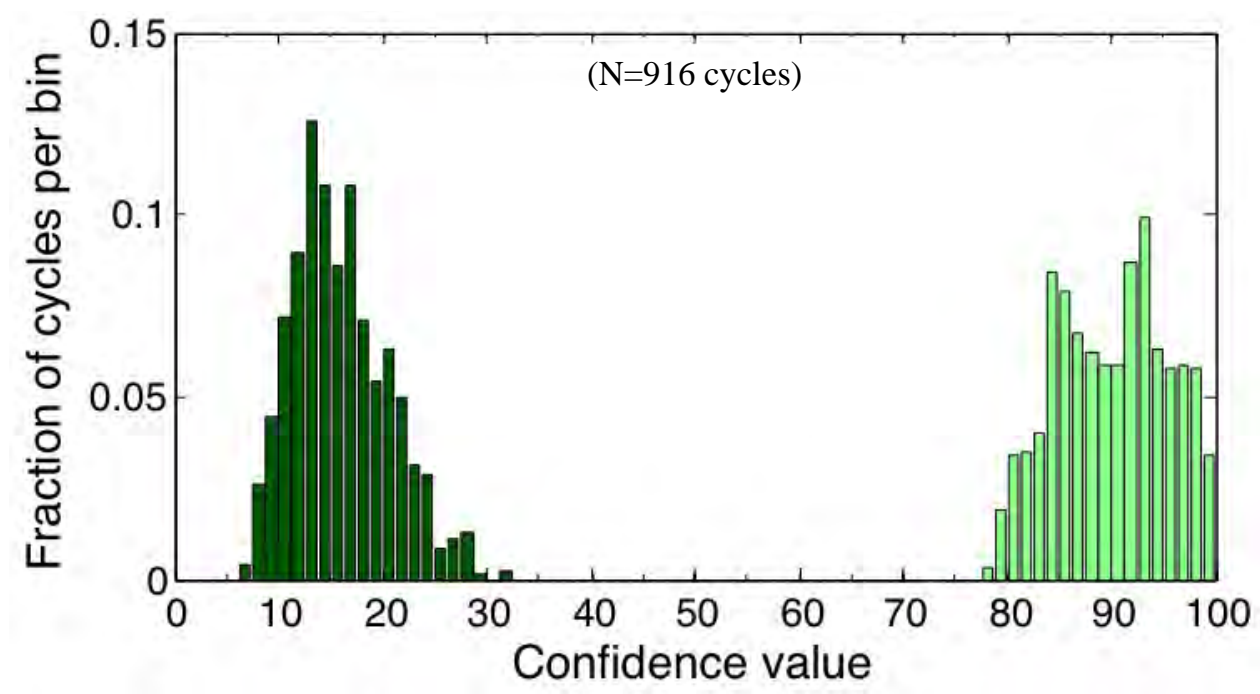

Figure 6.11. Histograms Over All Fill Levels of the True and False Overblow Peaks for DOB Detection Scenario 2 (1PJM-Full Case) with ABB Controller in Water Simulant (Light shaded - true peaks. Dark shaded - false peaks.) 


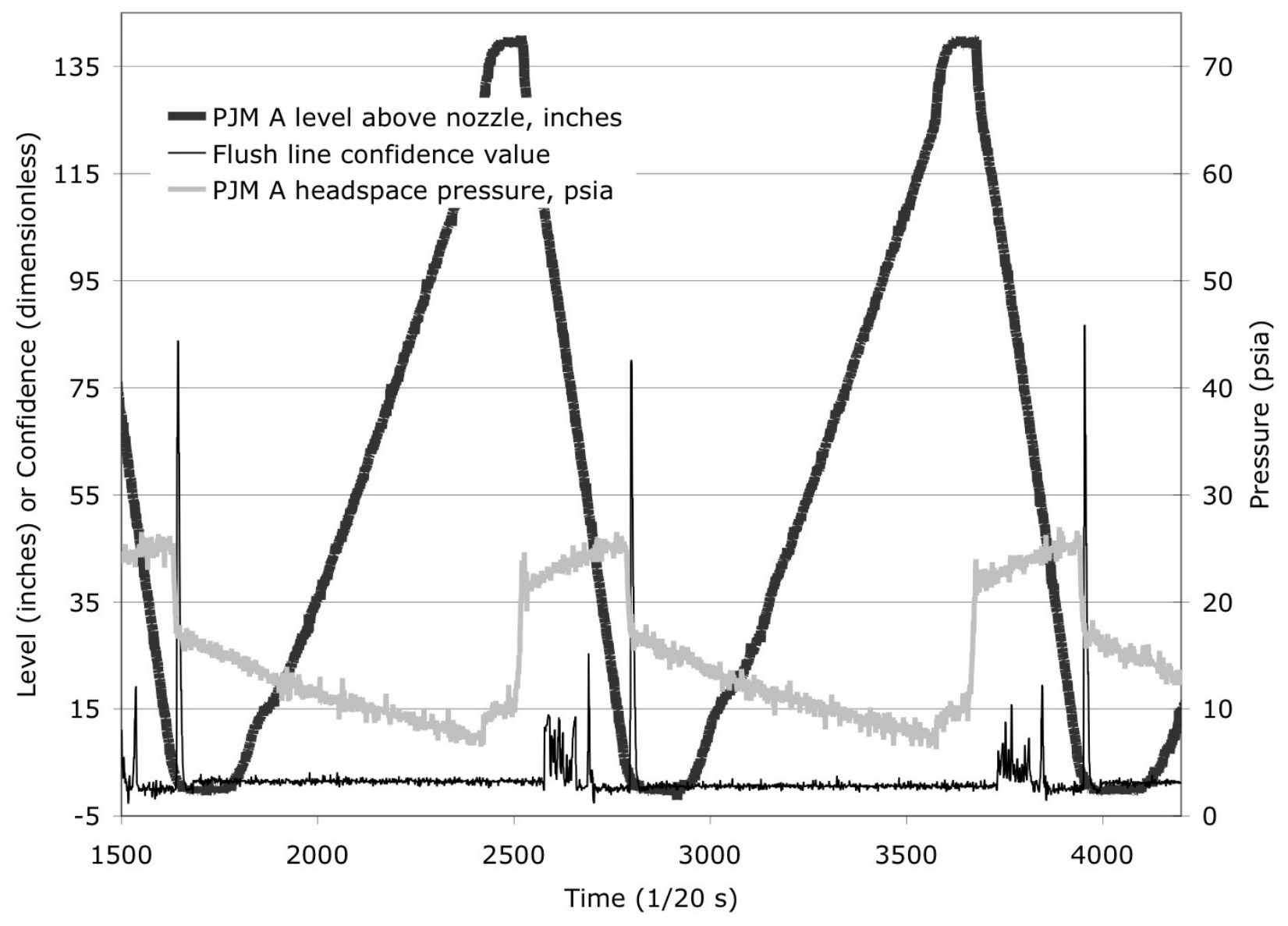

Figure 6.12. Flush Line Confidence Values for DOB Detection Scenario 2 (1PJM-Full Case) with ABB Controller in Water Simulant at the Low Fill Level 


\subsubsection{Scenario 3: Clay Simulant}

For Scenario 3, overblow of PJM\#A occurred because it was allowed to fill only partially before the start of the drive phase. The other PJMs were operated normally. Figure 6.13 shows the histograms for the true and false peaks for DOB detection with clay simulant under Scenario 3. The upper and lower plots in this figure show the data for the high and mid fill levels of the simulant, respectively. (As noted in Section 6.1 above, the lower fill level was not used with Scenario 3.) The high level data were collected over 305 cycles and the mid level data were collected over 288 cycles.
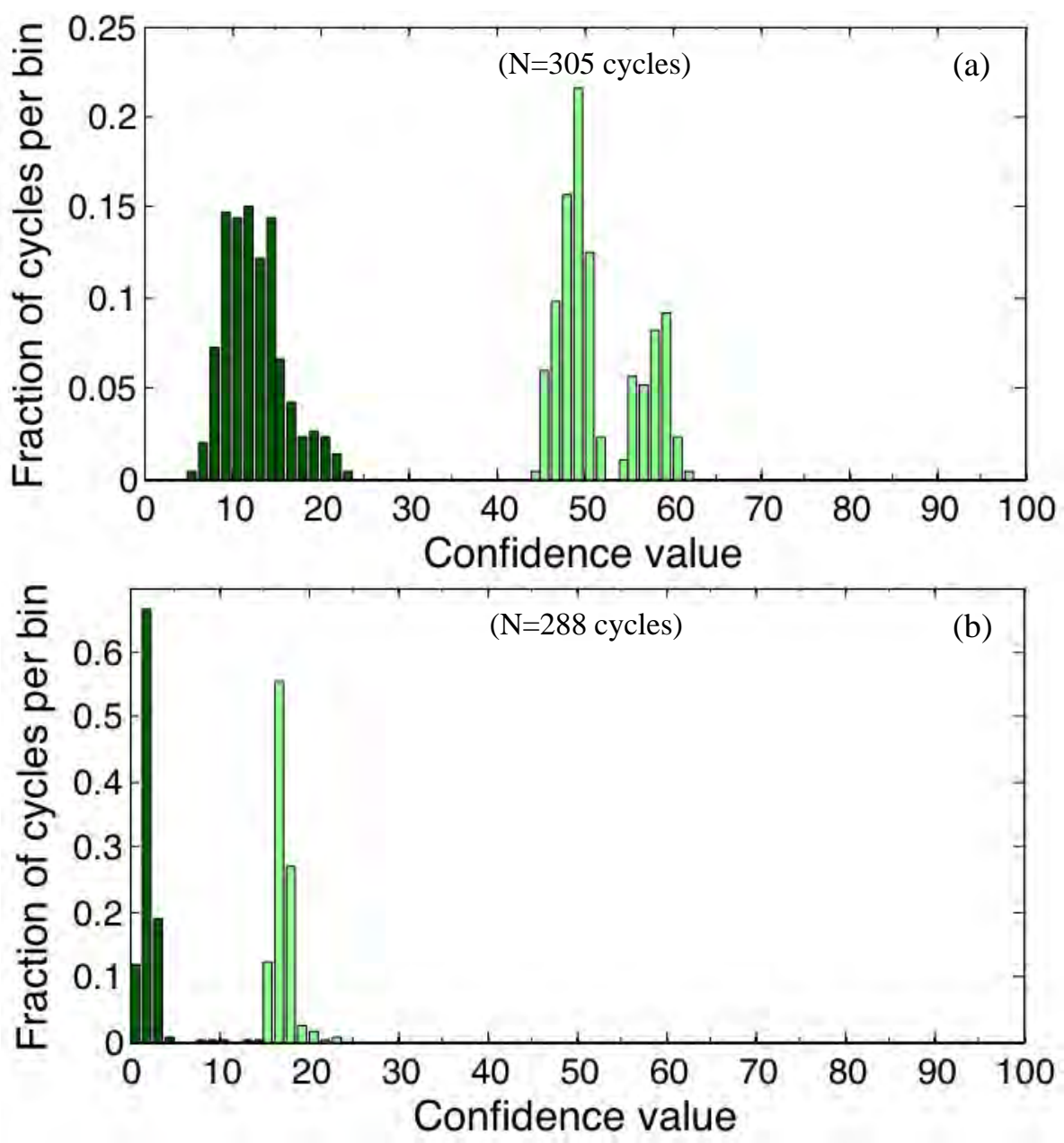

Figure 6.13. Histograms of the True and False Overblow Peaks for DOB Detection Scenario 3 (4PJM-Partial Case) with ABB Controller in Clay Simulant at (a) High and (b) Mid Fill Levels

(Light shaded - true peaks. Dark shaded - false peaks.)

It can be seen in Figure 6.13 that the true overblow confidence peak range is 15 - 62 while the false peak range is 0 - 23. In this case, the fill level had a great impact on the magnitudes of the true peaks. The true and false peaks were not separated over the range of fill levels as shown in Figure 6.14. It was not possible to set a general detection threshold for Scenario 3 that would separate the true and false peaks. Also, it was not possible to estimate the probabilities of various degrees of PJM underfilling in the 
WTP application, thus it is impossible to truly assess false alarm probabilities versus threshold.

Therefore, it is not possible to have reliable detection of overblows in this case.

Example segments of the time series of flush line confidence levels for Scenario 3 with clay simulant are plotted in Figure 6.15. The values at high liquid level are plotted in the upper half of the figure and the values at mid level in the lower half. The false peaks during the drive phase had similar magnitudes to those observed for the other scenarios (for example, see Figure 6.9). The true peaks, however, had a greatly reduced magnitude. Perhaps this was caused by the relatively low PJM pressures just before overblows, resulting in much lower or less abrupt dips in pressure when overblows occurred. At mid level, the noise in the confidence level early in the drive blended with the reduced response at overblow, yielding a broad indistinct overblow peak. Flush line pressures are also plotted in Figure 6.15. At mid level, the flush pressure did not reach its ultimate value for the drive phase before each overblow occurred.

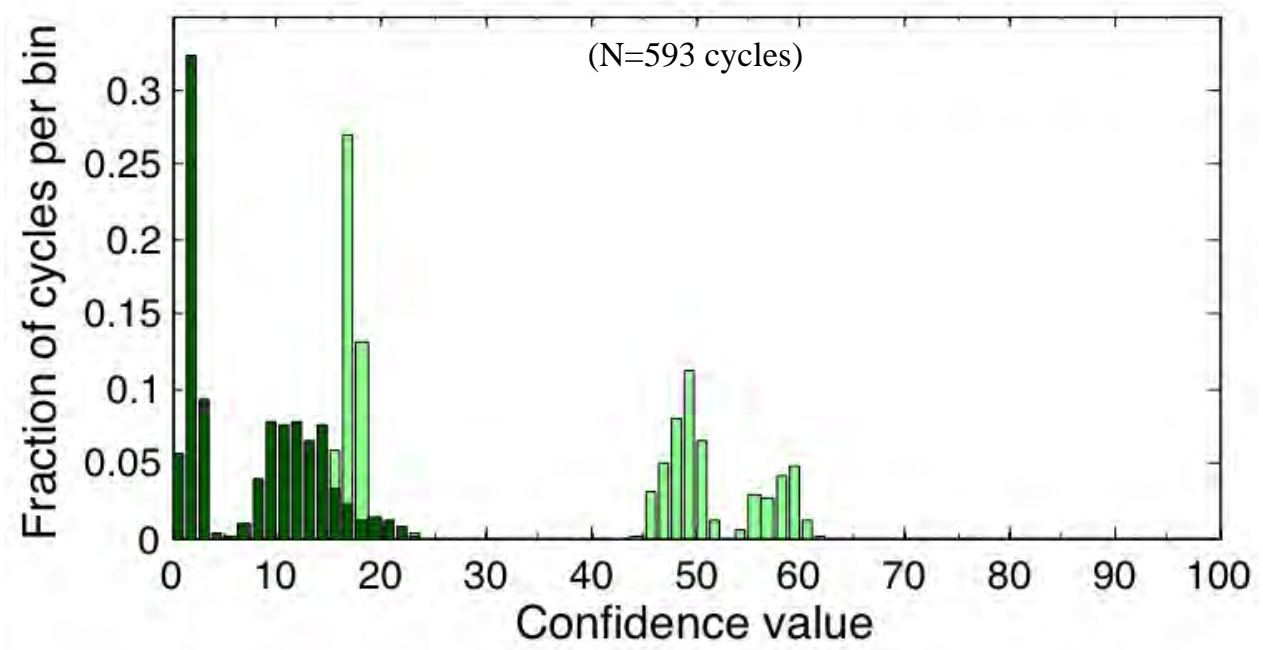

Figure 6.14. Histograms Over High and Mid Level Data Combined for the True and False Overblow Peaks for DOB Detection Scenario 3 (4PJM-Partial Case) with ABB Controller in Clay Simulant (Light shaded - true peaks. Dark shaded - false peaks.)

\subsubsection{Scenario 3: Water Simulant}

For Scenario 3, overblow of PJM\#A occurred because it was allowed to fill only partially before the start of the drive phase. The other PJMs were operated normally. Figure 6.16 shows the histograms for the true and false peaks for DOB detection with water simulant under Scenario 3. The upper and lower plots in this figure show the data for the high and mid fill levels of the simulant, respectively. (As noted in Section 6.1 above, the lower fill level was not used with Scenario 3.) Data were collected for 306 cycles at both the high and mid simulant levels.

It can be seen in Figure 6.16 that the true overblow confidence peak range is 11 - 44 while the false peak range is 0 - 23. Again, the fill level had a great impact on the magnitudes of the true peaks. The true and false peaks were not separated over the range of fill levels as shown in Figure 6.17. It was not possible to set a general detection threshold for Scenario 3 that would separate the true and false peaks and so it was not possible to have reliable detection of overblows in this case. 
Example segments of the time series of flush line confidence levels for Scenario 3 with water simulant are plotted in Figure 6.18. The values at high liquid level are plotted in the upper half of the figure and the values at mid level in the lower half. The false peaks during the drive phase again had similar magnitudes to those observed for the other scenarios. As with the clay simulant, the true peaks had a greatly reduced magnitude. With water, the true confidence peaks tended to be even lower than the values obtained under Scenario 3 with clay.
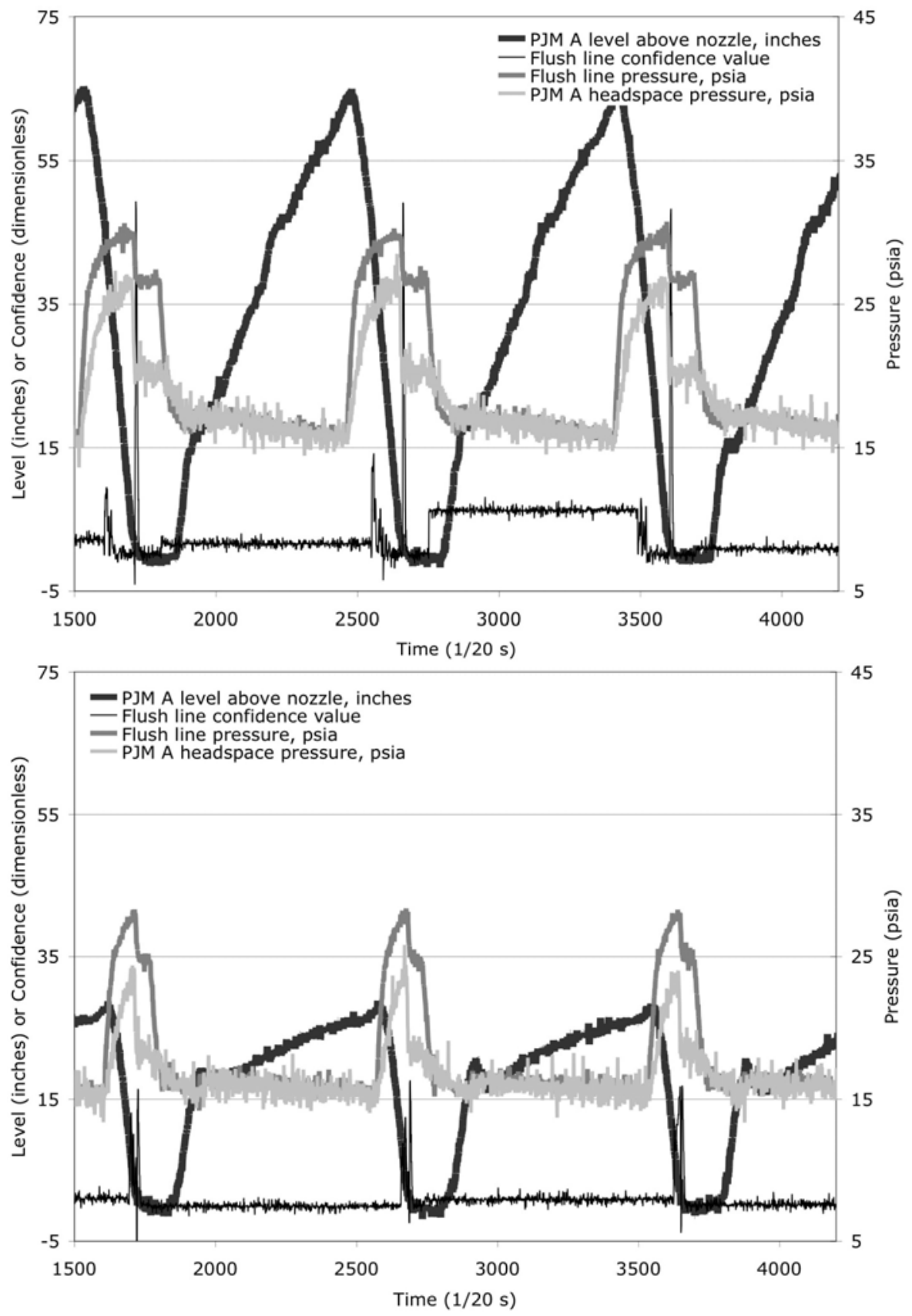

Figure 6.15. Flush Line Confidence Values for DOB Detection Scenario 3 (4PJM-Partial Case) with ABB Controller in Clay Simulant at the High Fill (top) and Mid (bottom) Levels 

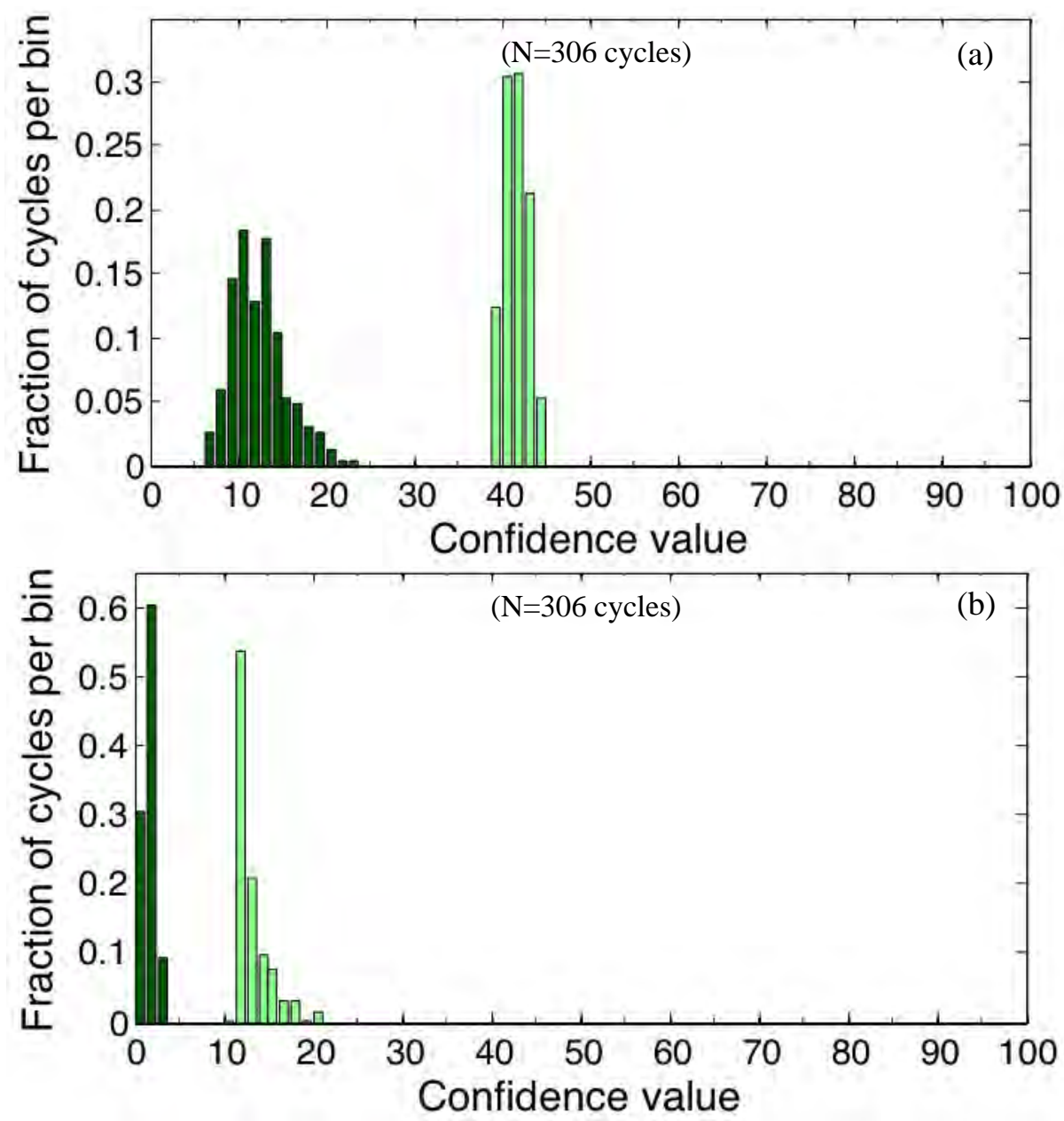

Figure 6.16. Histograms of the True and False Overblow Peaks for DOB Detection Scenario 3 (4PJM-Partial Case) with ABB Controller in Water Simulant at (a) High and (b) Mid Fill Levels (Light shaded - true peaks. Dark shaded - false peaks.)

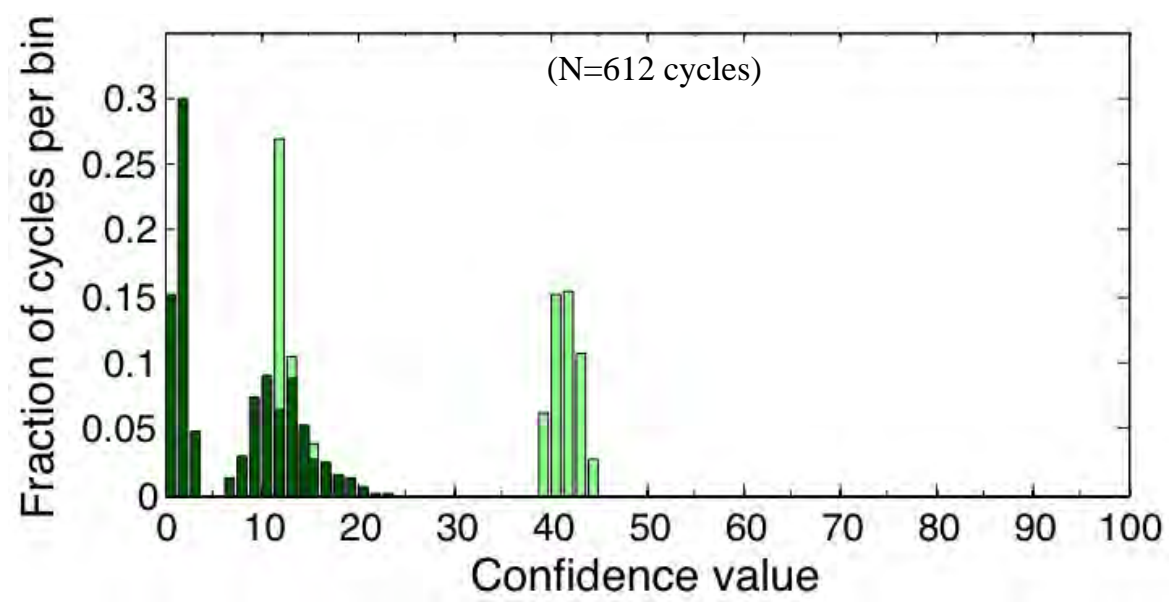

Figure 6.17. Histograms Over High and Mid Level Data Combined for the True and False Overblow Peaks for DOB Detection Scenario 3 (4PJM-Partial Case) with ABB Controller in Water Simulant (Light shaded - true peaks. Dark shaded - false peaks.) 

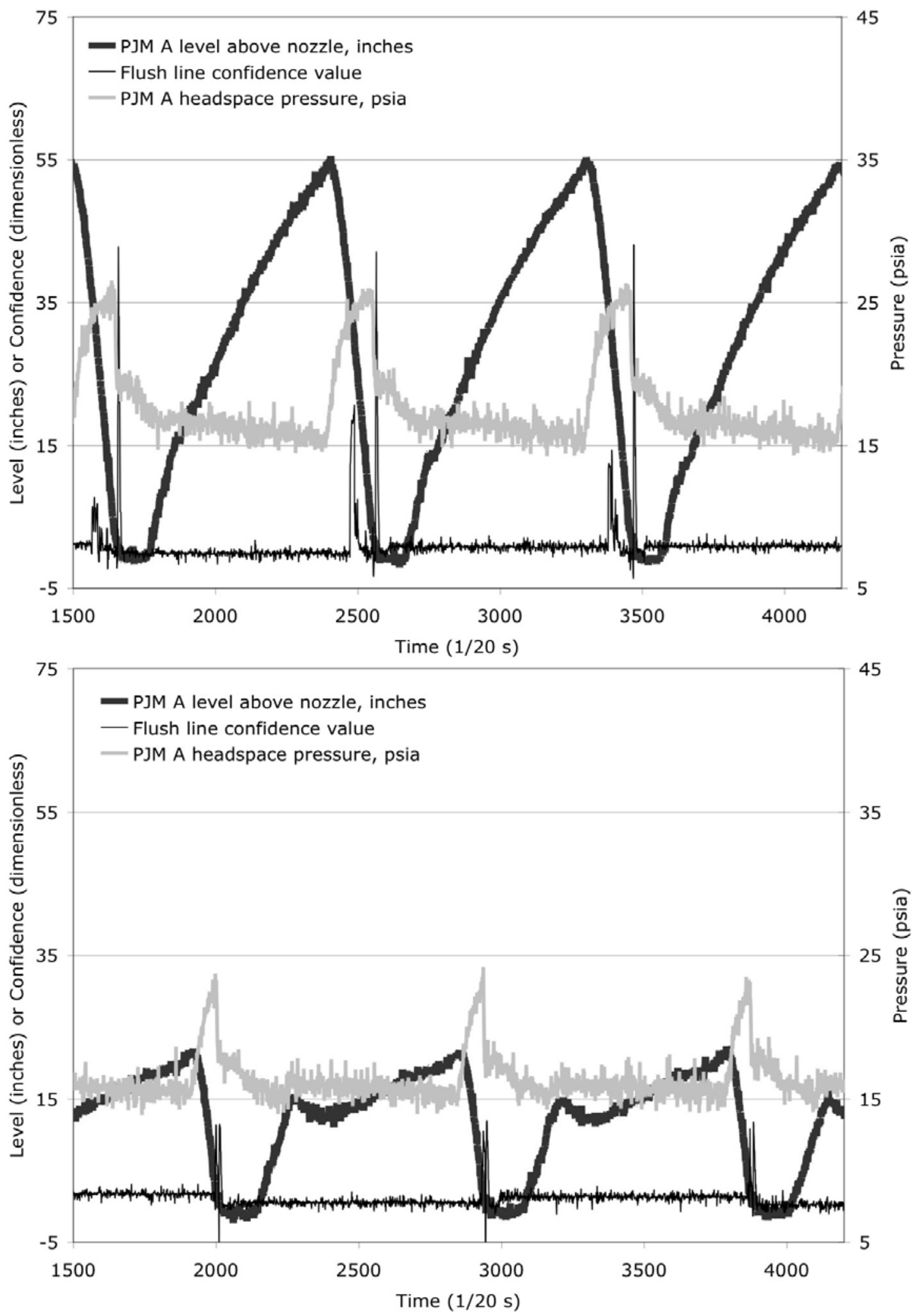

Figure 6.18. Flush Line Confidence Values for DOB Detection Scenario 3 (4PJM-Partial Case) with ABB Controller in Water Simulant at the High Fill (top) and Mid (bottom) Levels 


\subsubsection{Overall Results for DOB Detection with the ABB Controller}

If we ignore scenario 3, where overblow detection was not reliable, we can set reliable detection thresholds for operation with either simulant at any level, under the assumption that CVF will be guaranteed by other means. Plotted in Figure 6.19 are true peak and false peak histograms for all Scenario 1 and 2 cases combined. The distributions for the true and false peaks are significantly separated, so a detection threshold can be set to give a high probability of detection and a low false alarm rate.

In determining the lower and upper limits of the true and false confidence peaks, here and in other sections of this report, we used only the data set from the worst case scenario. For the ABB controller the maximum likely (at frequencies at least than 1\%) false confidence values occurred during Scenario 1 with water at the low liquid level (see Figure 6.4 (c) above). The minimum true confidences (at frequencies at most 1\%) were also occurred Scenario 1 with water at low level, which was therefore the worst case scenario that resulted in the minimum separation between the distributions. The histograms for that case are plotted again below in Figure 6.20, overlaid with approximating normal distributions. From those normal distributions, it was estimated that approximately $99 \%$ of false peaks would fall under a confidence level of 50.2 (marked by the dashed line in the upper half of the figure), and approximately $99 \%$ of true peaks would be above a confidence level of 67.9 (marked by the dashed line in the lower half). A reliable detection threshold for ABB operation under most conditions (excluding failure to completely fill a PJM) could be anywhere between 50.2 and 67.9.

As discussed above, we set tolerance limits based on worst case scenarios. Alternatively, we could have combined all the data from all the experimental conditions. Including cycles run under relatively benign experimental conditions in the analysis does increase the overall variability of the data, but this doesn't really change by a significant amount the upper tail of false peaks, or the lower tail of true peaks. Including more benign cycles has the effect of somewhat artificially increasing statistical sample sizes that estimate the tails of the distributions and could lead to less conservative statements about separation than were made using the current approach. For this reason only the worst case distributions are used to derive the tolerance limits.

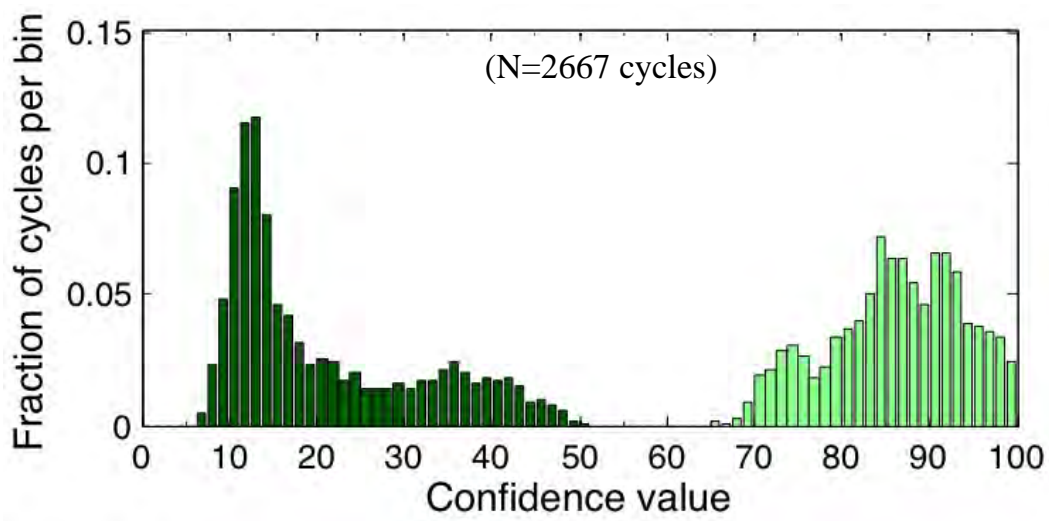

Figure 6.19. Combined Histograms for the True and False Overblow Peaks Over All Scenario 1 (4-PJM Full) and Scenario 2 (1PJM-Full) Cases (both simulants, all levels) for DOB Detection with ABB Controller (Light shaded - true peaks. Dark shaded - false peaks.) 


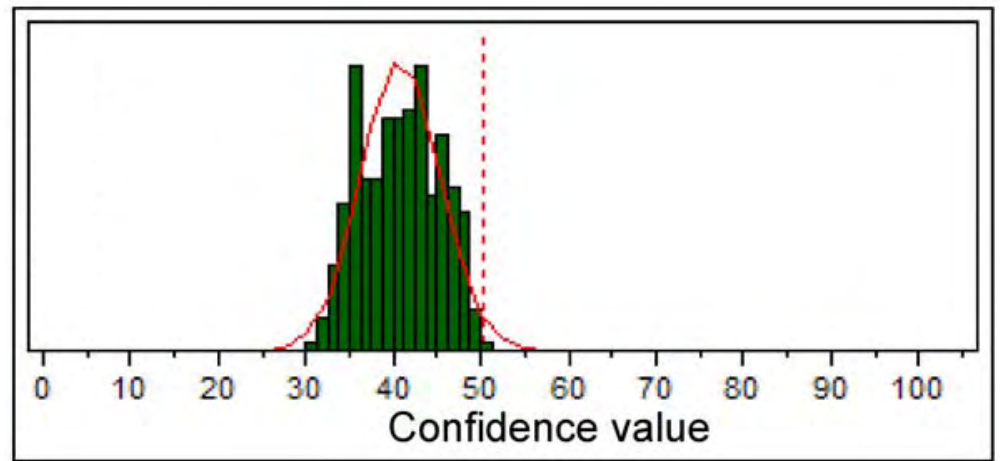

Peak $=$ False

Number of cycles: $\quad 304$ Mean confidence level: 40.805763 Standard deviation: 4.503538

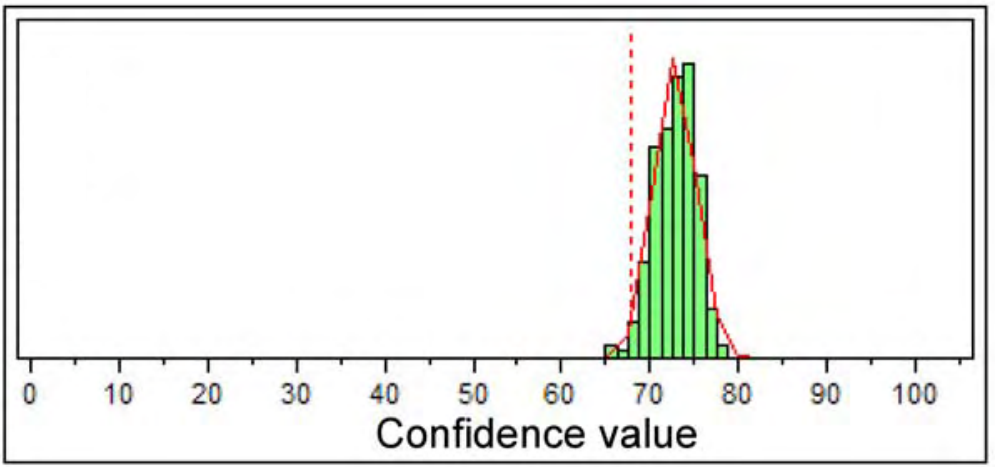

Peak $=$ True

Number of cycles: $\quad 304$ Mean confidence level: 72.797877 Standard deviation: 2.3515439

Figure 6.20. Limiting Case Histograms for True and False Overblow Peaks for DOB Detection with ABB Controller and Approximating Normal Distributions

(Light shaded - true peaks. Dark shaded - false peaks.)

\subsection{DOB Detection with the Triconex Controller}

The results of DOB testing with the Triconex controller for Scenarios 1, 2, and 3 are presented in the following sections.

\subsubsection{Scenario 1: Clay Simulant}

Figure 6.21 shows the histograms for the true and false peaks of flush line confidence level for DOB detection with clay simulant under Scenario 1 where all PJMs were full prior to the start of the drive phase. The upper, middle, and lower plots in this figure show the data for the high, mid, and low fill level of the simulant. Each plot in this figure represents a minimum of 105 cycles for a total of 517 cycles for the three fill heights.

It can be seen in Figure 6.21 that for the high, mid, and low fill level in clay simulant, the true overblow confidence peak range is 34 - 50 while the false peak range is $2-24$. The true and false peaks appear to be well separated over the entire range of fill levels as shown in Figure 6.22. This lack of overlap of the peaks indicates that a detection threshold value can be set for this simulant that will ensure 
a high probability that a drive overblow will be detected when one occurs and a low probability of a false detection when one doesn't.
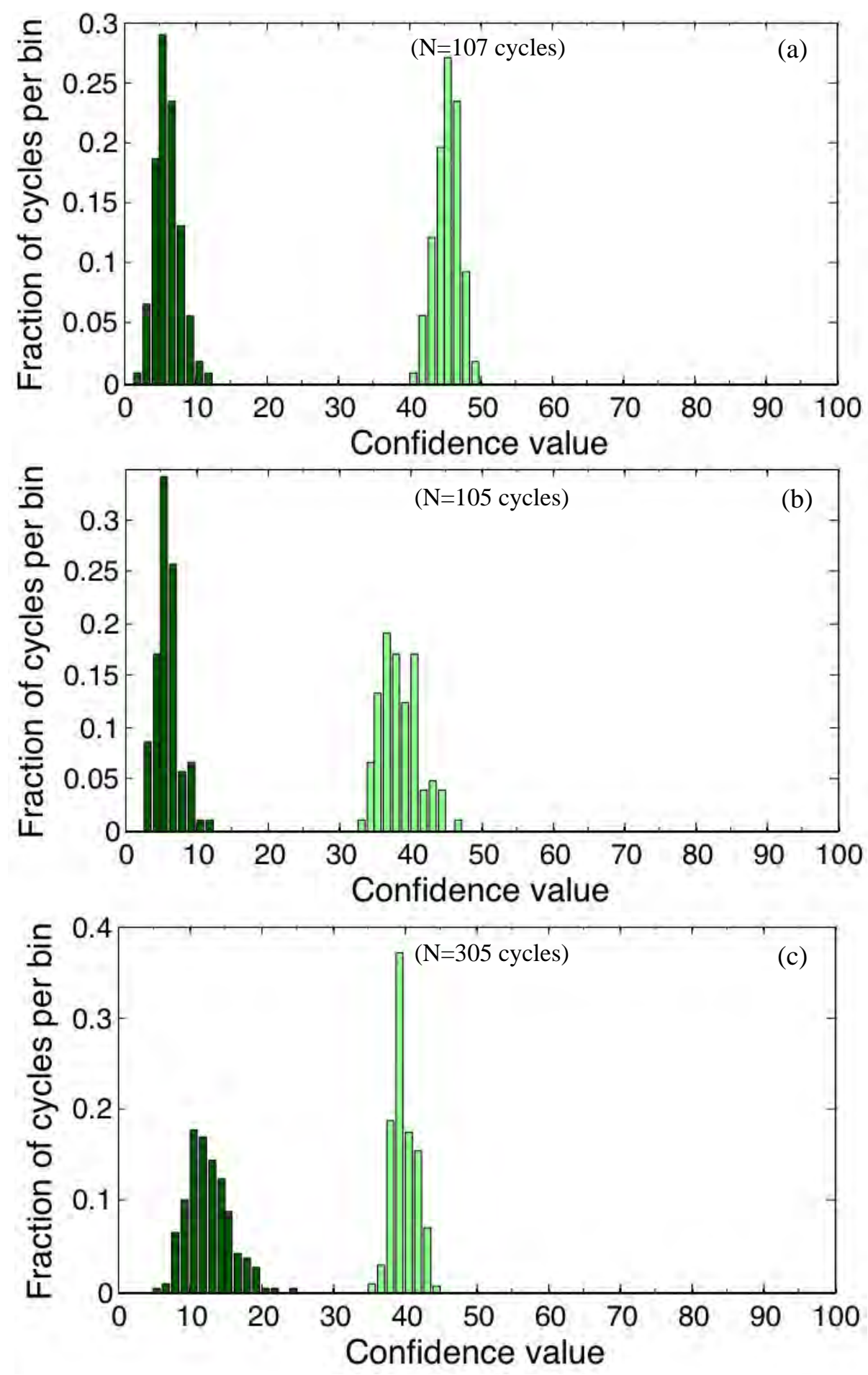

Figure 6.21. Histograms of the True and False Overblow Peaks for DOB Detection Scenario 1 (4-PJM Full) with Triconex Controller in Clay Simulant at (a) High, (b) Mid, and (c) Low Fill Levels (Light shaded - true peaks. Dark shaded - false peaks.) 


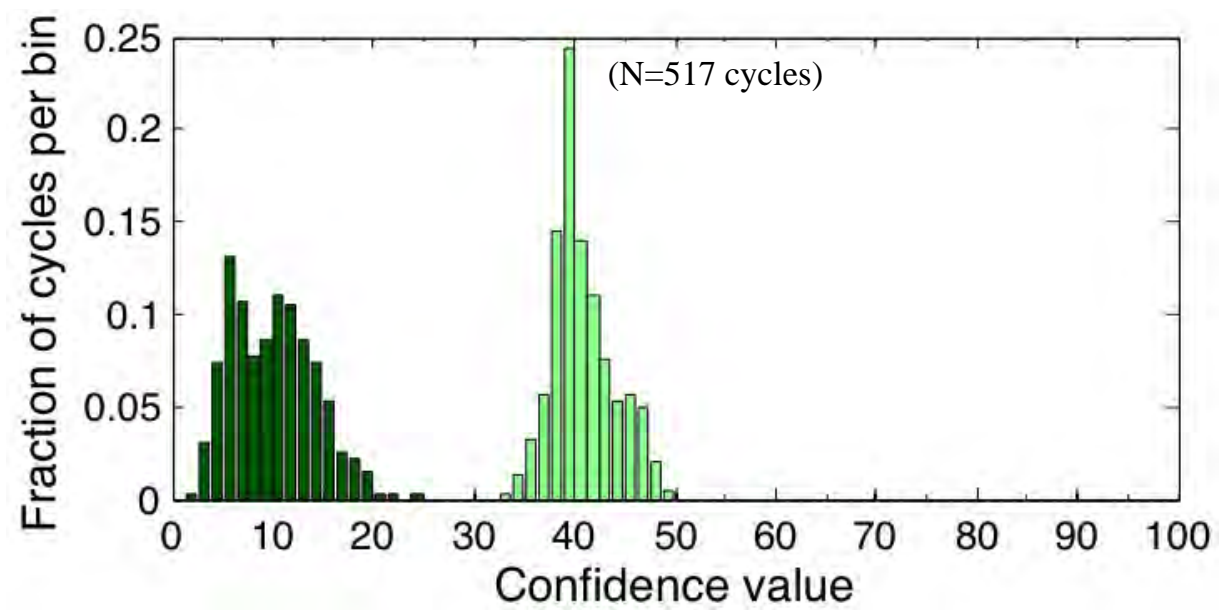

Figure 6.22. Histograms Over All Fill Levels of the True and False Overblow Peaks for DOB Detection Scenario 1 (4-PJM Full) with Triconex Controller in Clay Simulant

(Light shaded - true peaks. Dark shaded - false peaks.)

The separation in the true and noise confidence distributions for DOB detection was less for the Triconex controller than for the ABB controller under Scenario 1 with clay simulant (see Figure 6.21). Similar is the case with the water simulant and all of the DOB conditions tested. The difference in the amplitude of the confidence peaks and the separation of the true and false distributions is attributed primarily to the fact that the Triconex controller scans the pressure transmitter data at $250 \mathrm{~ms}$ intervals as opposed to the scan time of $50 \mathrm{~ms}$ for the ABB controller. As shown in Section 10, the decrease in scan time (and the increase in scan rate) resulted in an increase in both the peak magnitudes and the separation of the true and noise distributions.

Modeling the true and false overblow peaks under the assumption of normal distributions allows thresholds for overblow detection to be estimated for Scenario 1 with clay. False alarms can be limited to $1 \%$ or less with a threshold of 18.8 or greater. The probability of overblow detection will be $99 \%$ or greater with a threshold of 33.3 or less. A working threshold for clay can be chosen anywhere within the range of 18.8 to 33.3 .

An example segment of the time series of flush line confidence levels for Scenario 1 with clay simulant are plotted in Figure 6.23. The values at high, mid, and low liquid levels are plotted in the upper, middle, and bottom sections of the figure, respectively. The plots clearly show the very large CVF detection peaks near the end of the suction phase, one or two false peaks during each drive phase, and the true overblow detection peaks near overblow. The Triconex controller often produced high, decaying baseline shifts at mid liquid level during the suction phase—a behavior that does not harm overblow detection. That behavior at mid level may have been a function of the gain used for those cases. 

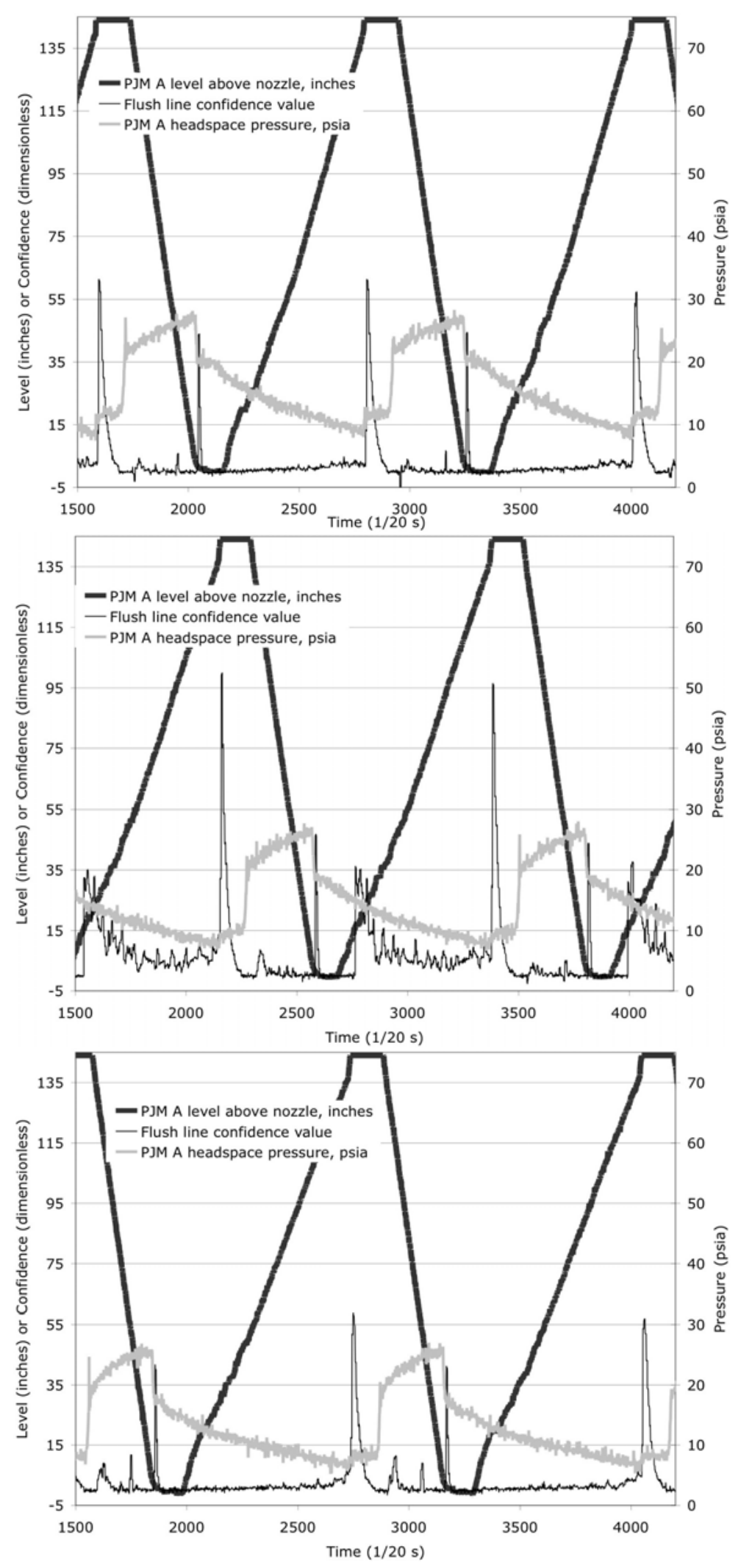

Figure 6.23. Flush Line Confidence Values for DOB Detection Scenario 1 (4-PJM Full) with Triconex Controller with Clay Simulant at the High (top), Mid (middle), and Low (bottom) Levels 


\subsubsection{Scenario 1: Water Simulant}

Figure 6.24 shows the histograms for the true and false peaks for DOB detection with water simulant under Scenario 1 where all PJMs were full prior to the start of the drive phase. The upper, middle, and lower plots in this figure show the data for the high, mid, and low fill level of the simulant. Similar to the clay data, each plot in this figure represents a minimum of 107 cycles and a total 533 cycles for the three fill heights.
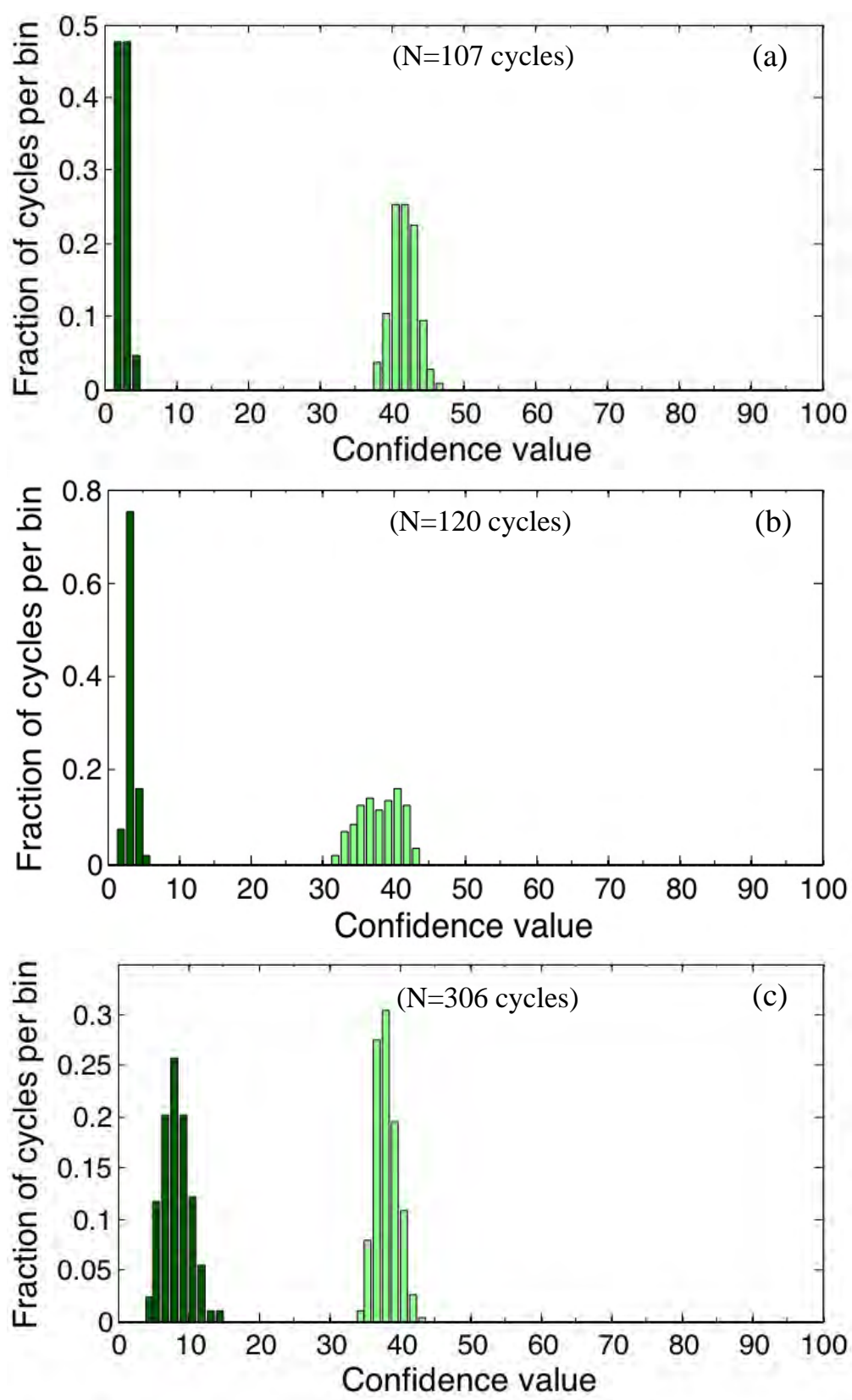

Figure 6.24. Histograms of the True and False Overblow Peaks for DOB Detection Scenario 1 (4-PJM Full) with Triconex Controller in Water Simulant at (a) High, (b) Mid, and (c) Low Fill Levels (Light shaded - true peaks. Dark shaded - false peaks.) 


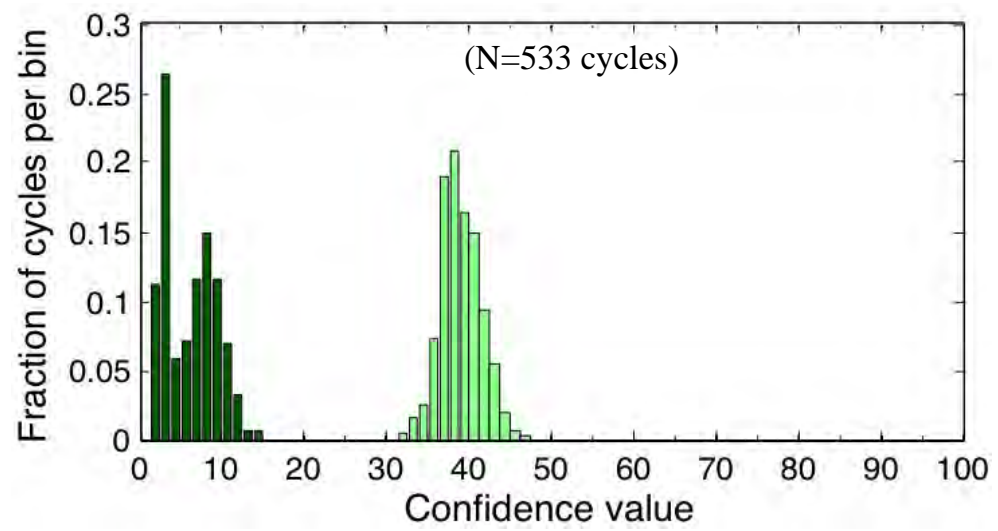

Figure 6.25. Histograms Over All Fill Levels of the True and False Overblow Peaks for DOB Detection Scenario 1 (4-PJM Full) with Triconex Controller in Water Simulant (Light shaded - true peaks. Dark shaded - false peaks.)
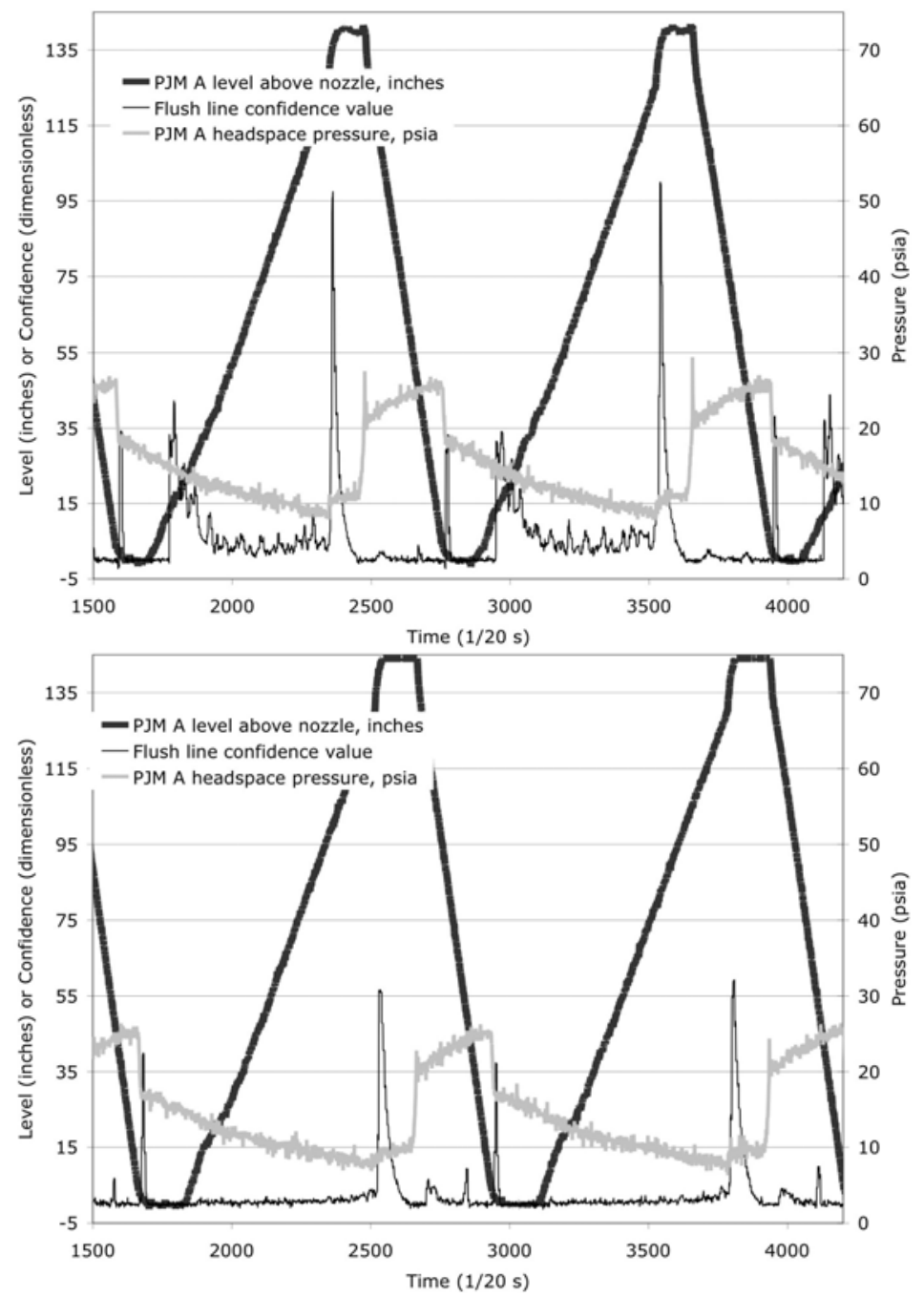

Figure 6.26. Flush Line Confidence Values for DOB Detection Scenario 1 (4-PJM Full) with Triconex Controller with Water Simulant at the Mid (top) and Low (bottom) Levels 


\subsubsection{Scenario 2: Clay Simulant}

Figure 6.27 shows the histograms for the true and false peaks of flush line confidence levels for DOB detection with clay simulant under Scenario 2 where only PJM\#A is operating. The upper, middle, and lower plots in this figure show the data for the high, mid, and low fill level of the simulant. Each plot in this figure represents a minimum of 303 cycles for a total of 913 cycles for the three fill heights.
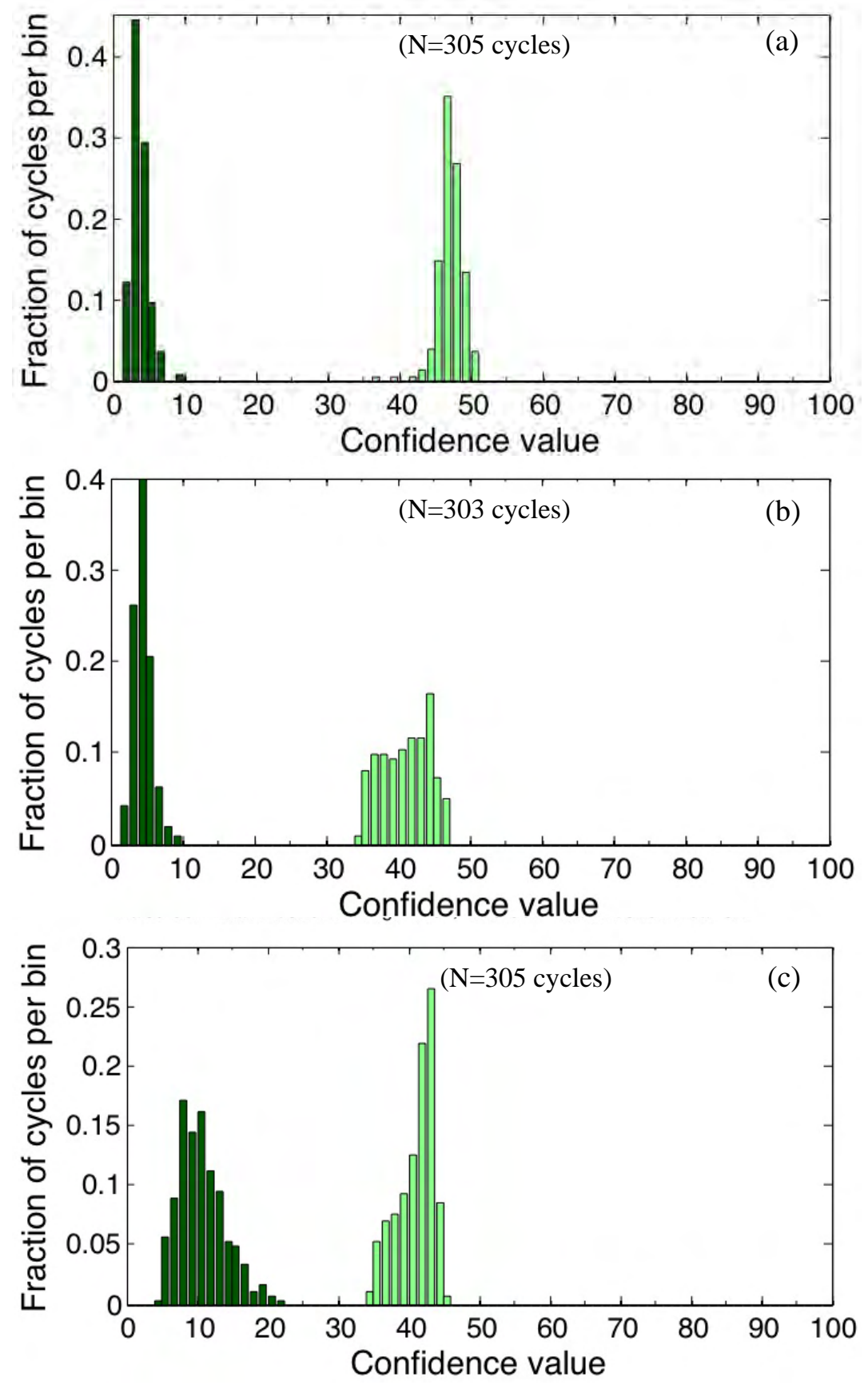

Figure 6.27. Histograms of the True and False Overblow Peaks for DOB Detection Scenario 2 (1-PJM Full) with Triconex Controller in Clay Simulant at (a) High, (b) Mid, and (c) Low Fill Levels

(Light shaded - true peaks. Dark shaded - false peaks.) 
It can be seen in Figure 6.27 that for the high, mid, and low fill level in clay simulant, the true overblow confidence peak range is 34 - 51 while the false peak range is 2 - 22. The true and false peaks appear to be sufficiently separated over the entire range of fill levels as shown in Figure 6.28. This lack of overlap of the peaks indicates that a detection threshold value can be set for this simulant that will ensure a high probability of correct overblow detections.

Modeling the true and false overblow peaks under the assumption of normal distributions allows thresholds for overblow detection to be estimated for Scenario 2 with clay. False alarms can be limited to $1 \%$ or less with a threshold of 17.6 or greater. The probability of overblow detection will be $99 \%$ or greater with a threshold of 34.2 or less. A working threshold for clay can be chosen anywhere within the range of 17.6 - 34.2. An example segment of the time series of flush line confidence levels for Scenario 2 with clay simulant is plotted in Figure 6.29.

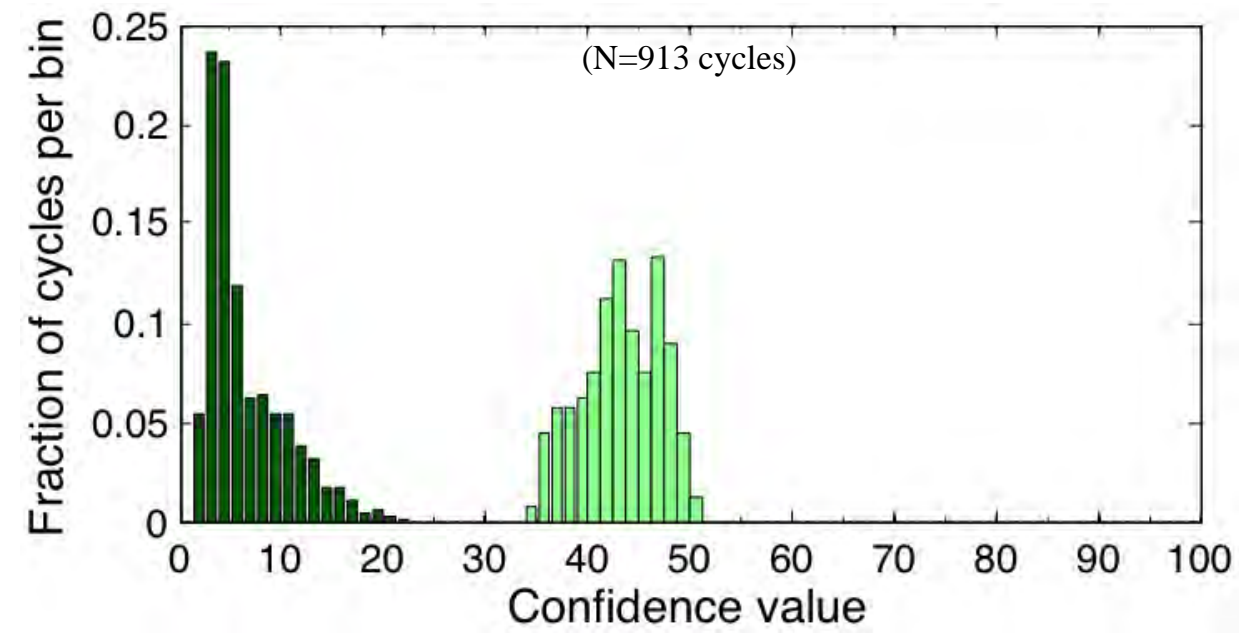

Figure 6.28. Histograms Over All Fill Levels of the True and False Overblow Peaks for DOB Detection Scenario 2 with Triconex Controller in Clay Simulant

(Light shaded - true peaks. Dark shaded - false peaks.) 


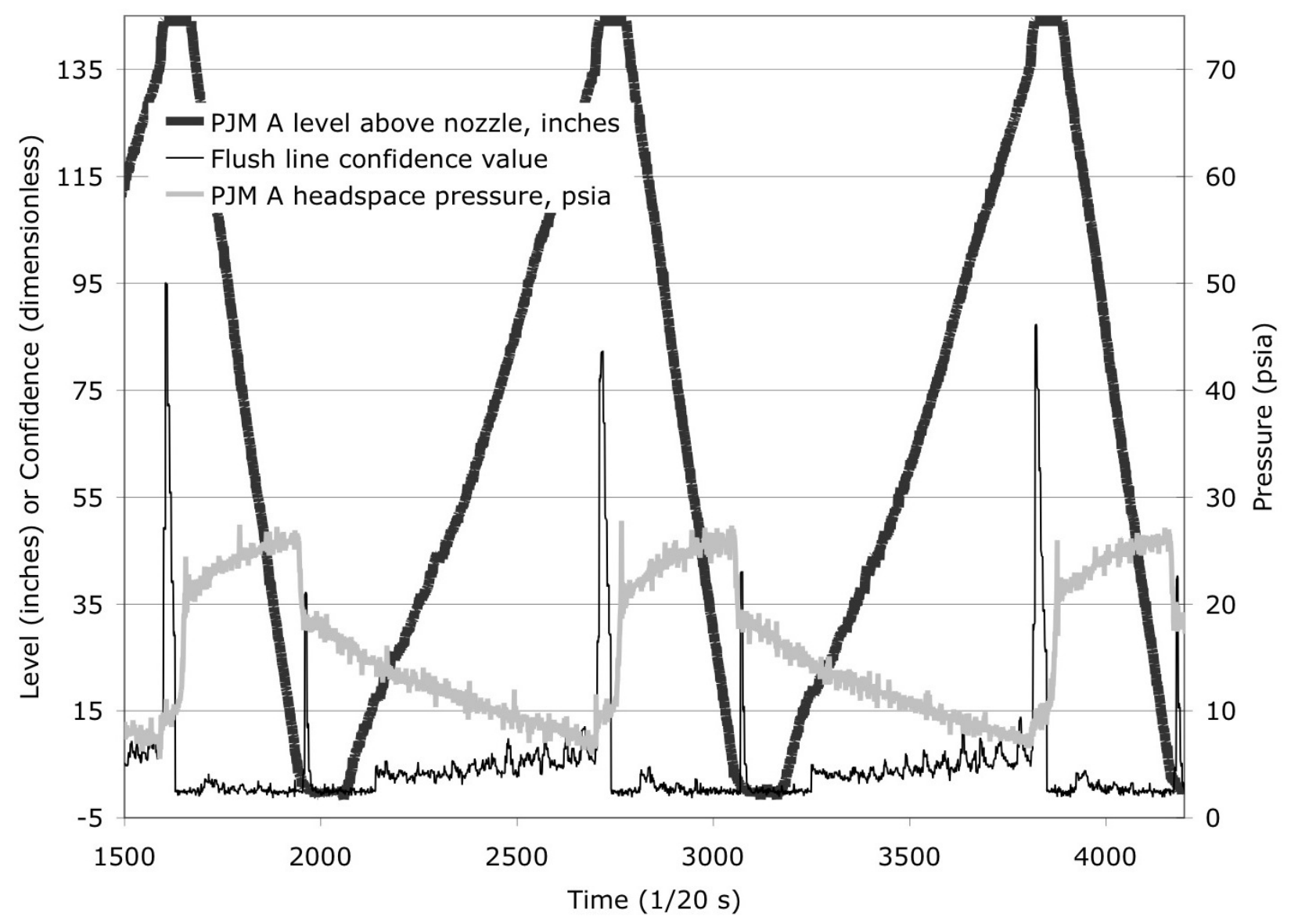

Figure 6.29. Flush Line Confidence Values for DOB Detection Scenario 2 (1-PJM Full) with Triconex Controller in Clay Simulant at the Mid Fill Level 


\subsubsection{Scenario 2: Water Simulant}

Figure 6.30 shows the histograms for the true and false peaks for DOB detection with water simulant under Scenario 2 where only PJM\#A is operating. The upper, middle, and lower plots in this figure show the data for the high, mid, and low fill level of the simulant. Each plot in this figure represents a minimum of 304 cycles for a total of 916 cycles for the three fill heights.
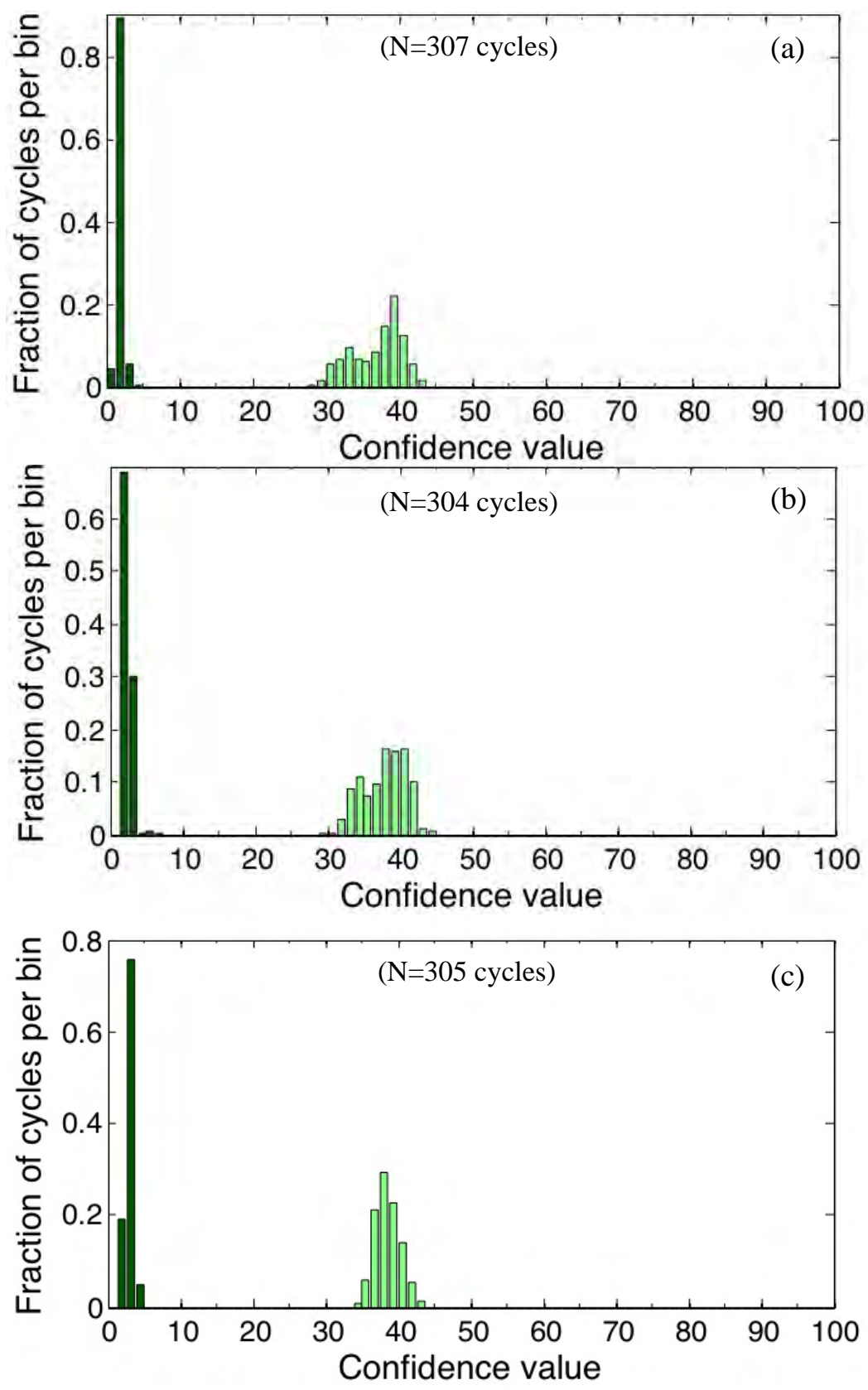

Figure 6.30. Histograms of the True and False Overblow Peaks for DOB Detection Scenario 2 (1-PJM Full) with Triconex Controller in Water Simulant at (a) High, (b) Mid, and (c) Low Fill Levels (Light shaded - true peaks. Dark shaded - false peaks.) 
It can be seen in Figure 6.30 that for the high, mid, and low fill level in water simulant, the true overblow confidence peak range is 28 - 45 while the false peak range is 1 - 6 . The true and false overblow confidence peaks are again well separated for all three fill levels, as shown in Figure 6.31. This, once again, indicates that a detection threshold value can be set for water simulant that will ensure a high probability of true overblow detection and a low probability of false detections.

Modeling the true and false overblow peaks under the assumption of normal distributions allows thresholds for overblow detection to be estimated for Scenario 2 with water. False alarms can be limited to $1 \%$ or less with a threshold of 3.8 or greater. The probability of overblow detection will be $99 \%$ or greater with a threshold of 29.8 or less. A working threshold for clay can be chosen anywhere within the range of 3.8 - 29.8. An example segment of the time series of flush line confidence levels for Scenario 2 with water simulant is plotted in Figure 6.32. Significant false peaks before the overblow peaks were not present.

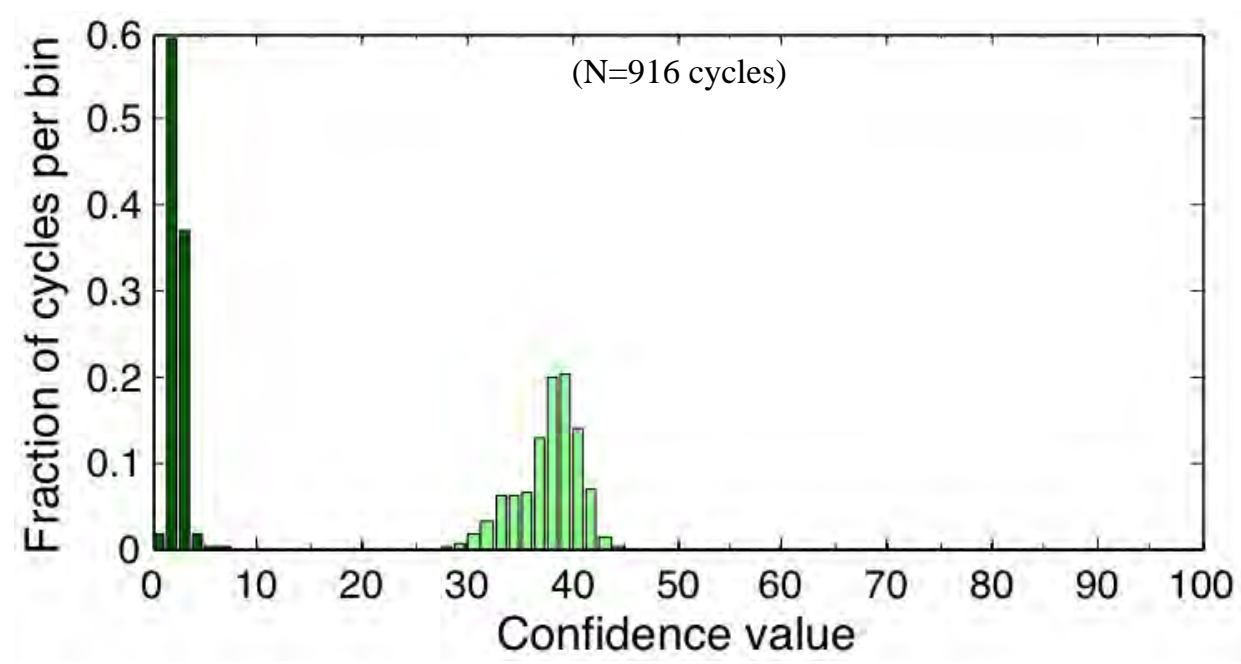

Figure 6.31. Histograms Over All Fill Levels of the True and False Overblow Peaks for DOB Detection Scenario 2 (1-PJM Full) with Triconex Controller in Water Simulant

(Light shaded - true peaks. Dark shaded - false peaks.) 


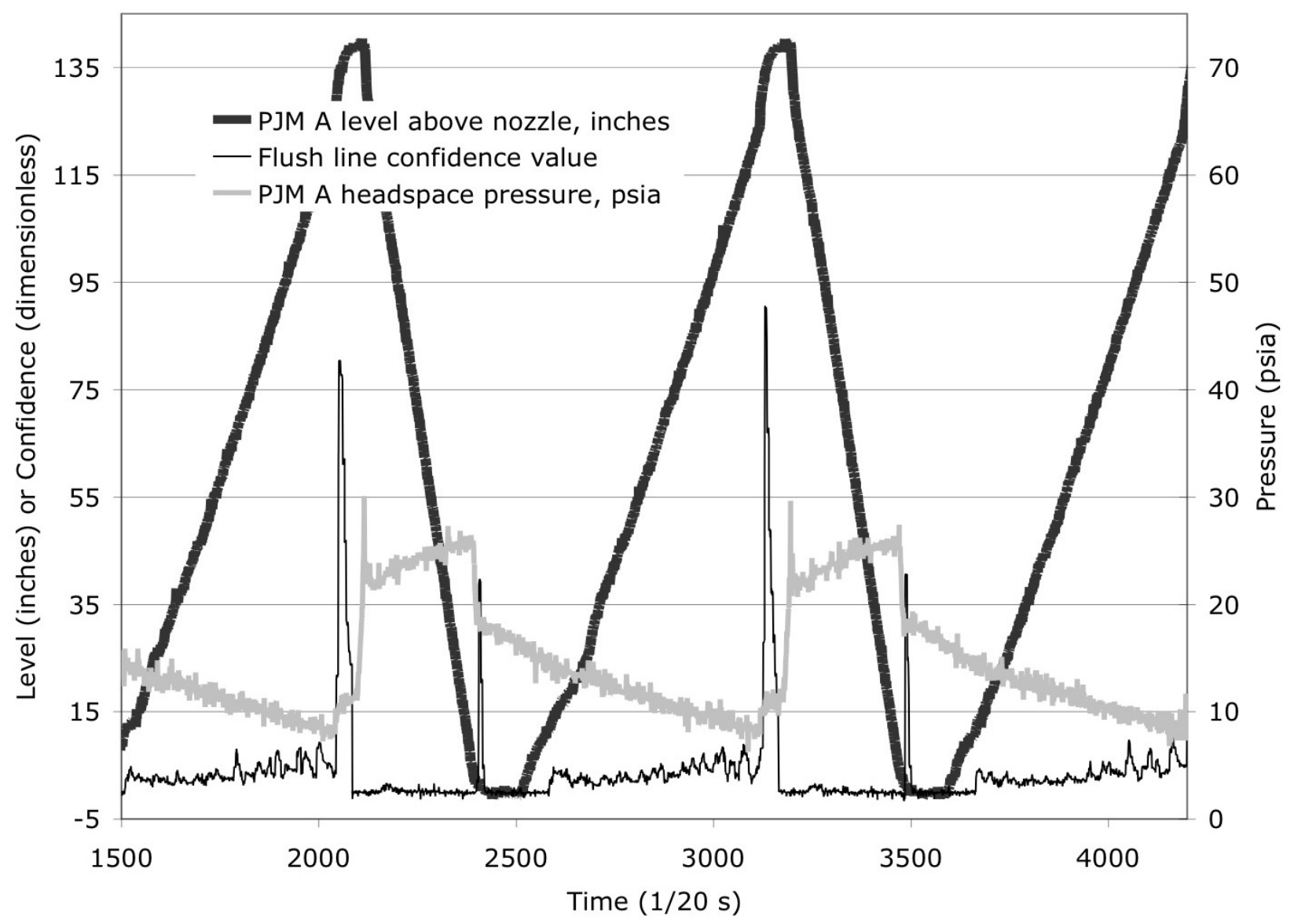

Figure 6.32. Flush Line Confidence Values for DOB Detection Scenario 2 (1-PJM Full) with Triconex Controller in Water Simulant at the Mid Fill Level

\subsubsection{Scenario 3: Clay Simulant}

For Scenario 3, overblow of PJM\#A occurred because it was allowed to only partially fill before the start of the drive phase. The other PJMs were operated normally. Figure 6.33 shows the histograms for the true and false peaks for DOB detection with clay simulant under Scenario 3. The upper and lower plots in this figure show the data for the high and mid fill levels of the simulant, respectively. (As noted in Section 6.1 above, the lower fill level was not used with Scenario 3.) The high level data were collected over 327 cycles and the mid level data were collected over 305 cycles.

It can be seen in Figure 6.33 that the true overblow confidence peak range is 9 - 29 while the false peak range is 3 - 13. In this case, the fill level had a great impact on the magnitudes of the true peaks. The true and false peaks were not separated over the range of fill levels as shown in Figure 6.34. It was not possible to set a general detection threshold for Scenario 3 that would separate the true and false peaks and so it was not possible to have reliable detection of overblows in this case.

Example segments of the time series of flush line confidence levels for Scenario 3 with clay simulant at the mid level are plotted in Figure 6.35. The overblow peak was not distinct from the false peak and its amplitude was small. 

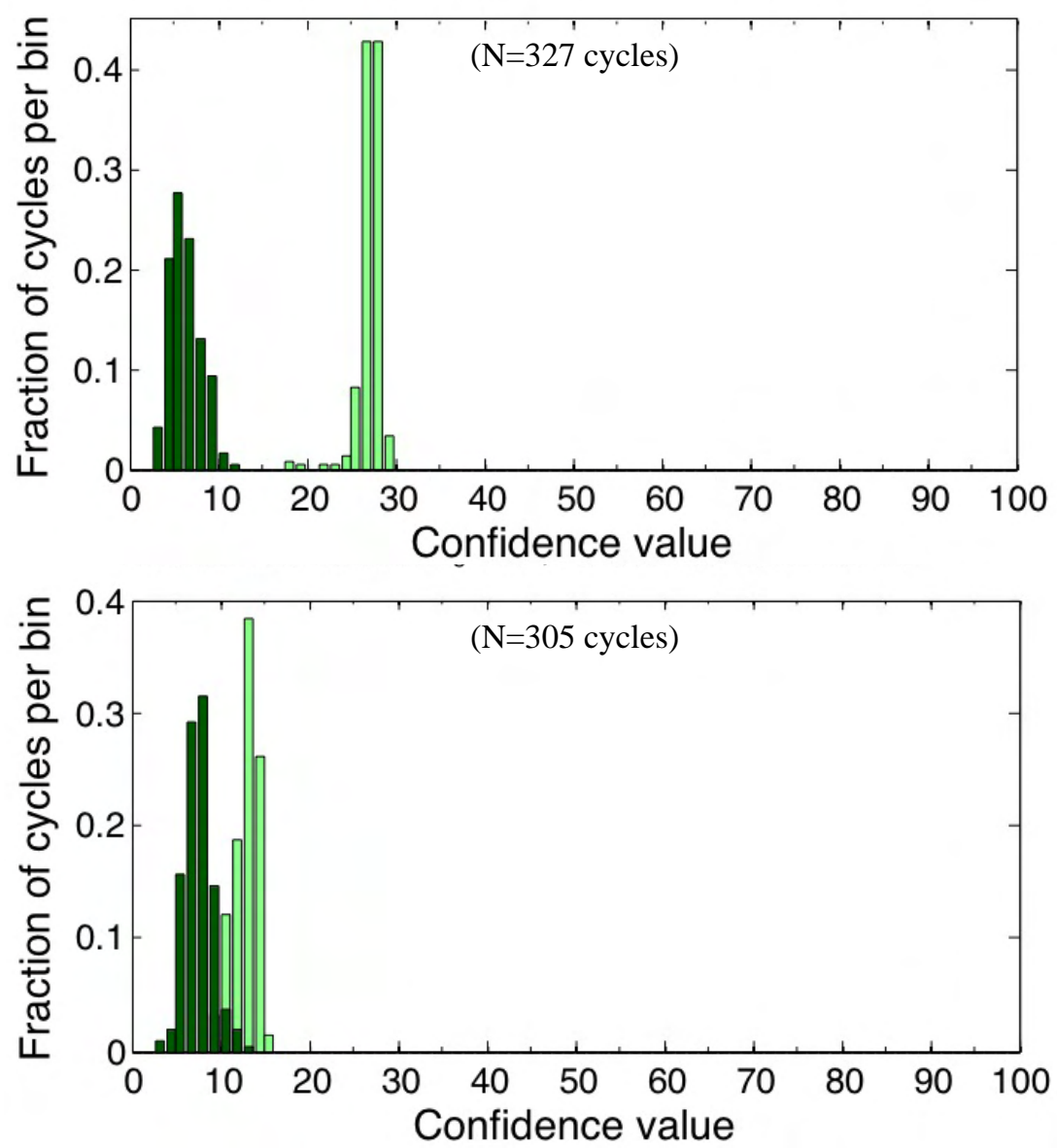

Figure 6.33. Histograms of the True and False Overblow Peaks for DOB Detection Scenario 3 (4-PJM Partial) with Triconex Controller in Clay Simulant at (a) High and (b) Mid Fill Levels (Light shaded - true peaks. Dark shaded - false peaks.)

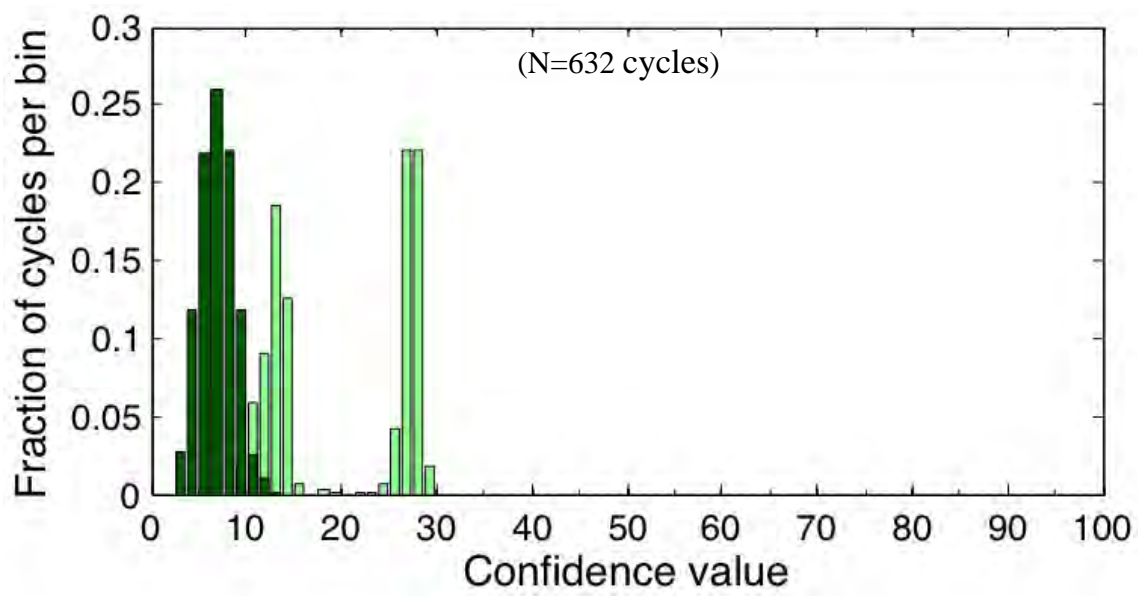

Figure 6.34. Histograms Over High and Mid Level Data Combined for the True and False Overblow Peaks for DOB Detection Scenario 3 (4-PJM Partial) with Triconex Controller in Clay Simulant (Light shaded - true peaks. Dark shaded - false peaks.) 


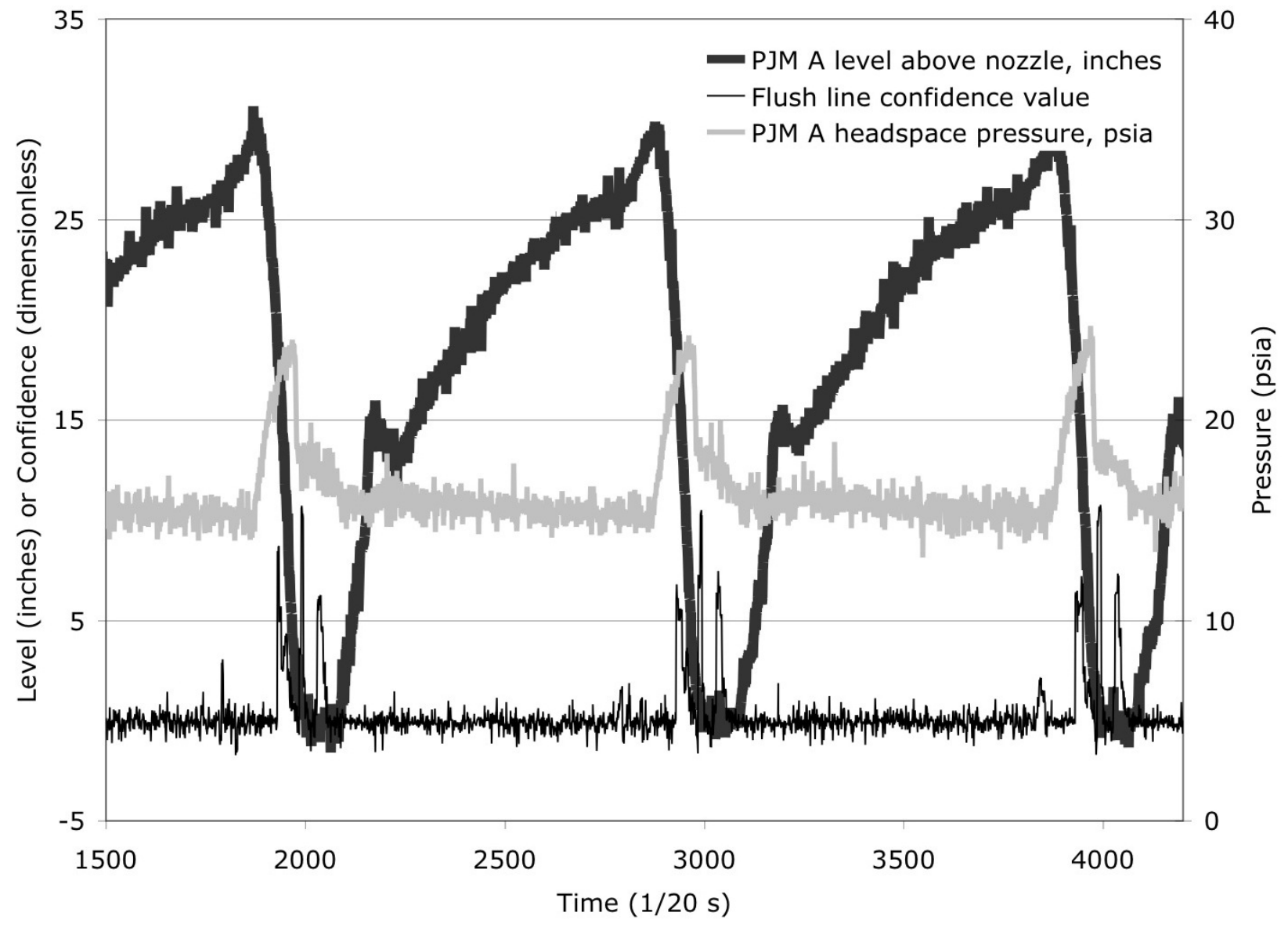

Figure 6.35. Flush Line Confidence Values for DOB Detection Scenario 3 (4-PJM Partial) with Triconex Controller in Clay Simulant at the Mid Level

\subsubsection{Scenario 3: Water Simulant}

For Scenario 3, overblow of PJM\#A occurred because it was allowed to only partially fill before the start of the drive phase. The other PJMs were operated normally. Figure 6.36 shows the histograms for the true and false peaks for DOB detection with water simulant under Scenario 3. The upper and lower plots in this figure show the data for the high and mid fill levels of the simulant, respectively. (As noted in Section 6.1 above, the lower fill level was not used with Scenario 3.) Data were collected for 306 cycles at the high simulant level and for 305 cycles at the mid level.

It can be seen in Figure 6.36 that the true overblow confidence peak range is 8 - 25 while the false peak range is 3 - 12. Again, the fill level had a great impact on the magnitudes of the true peaks. The true and false peaks were not separated over the range of fill levels as shown in Figure 6.37. It was not possible to set a general detection threshold for Scenario 3 that would separate the true and false peaks and so it was not possible to have reliable detection of overblows in this case. 

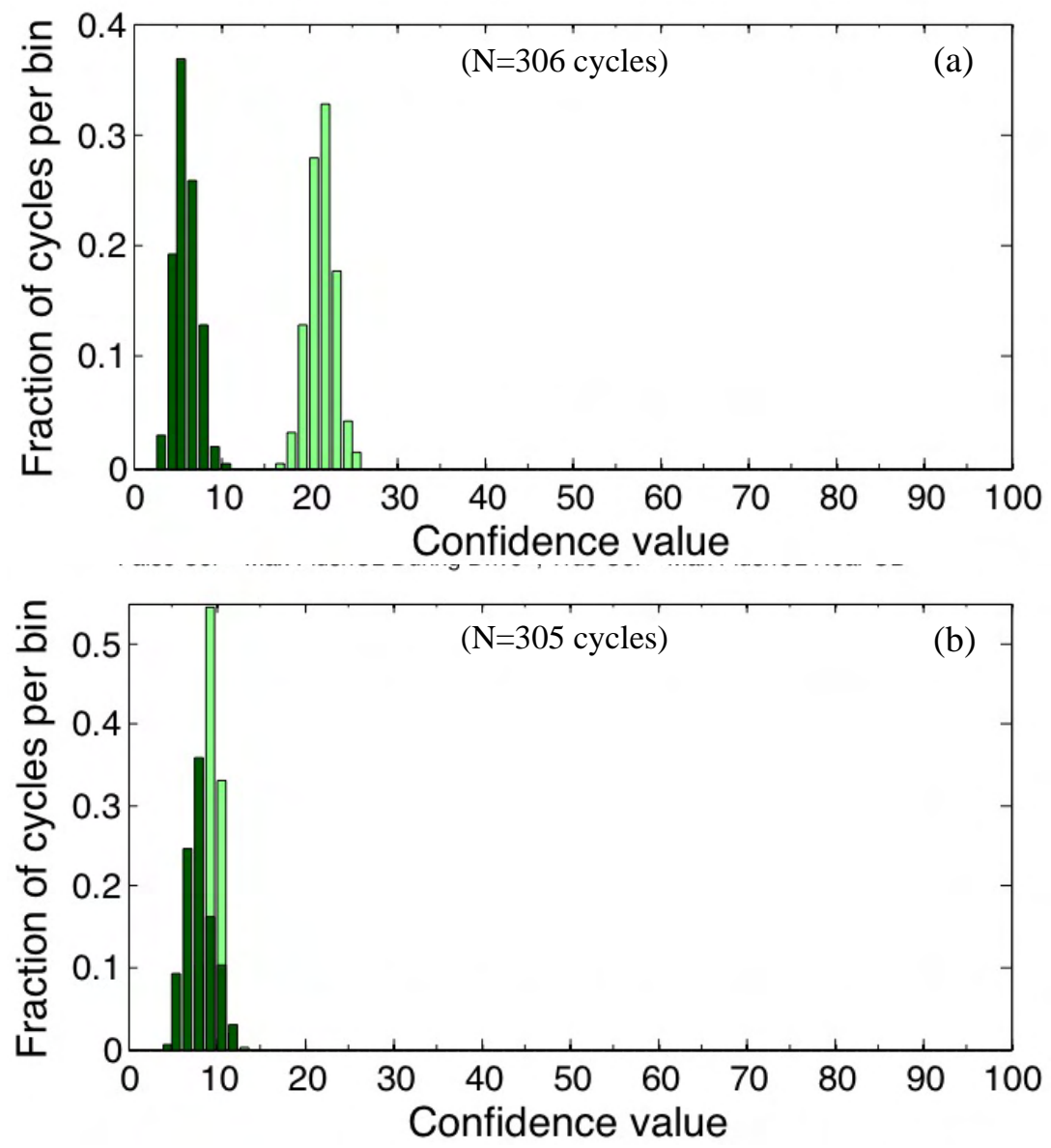

Figure 6.36. Histograms of the True and False Overblow Peaks for DOB Detection Scenario 3 with Triconex Controller in Water Simulant at (a) High and (b) Mid Fill Levels (Light shaded - true peaks. Dark shaded - false peaks.)

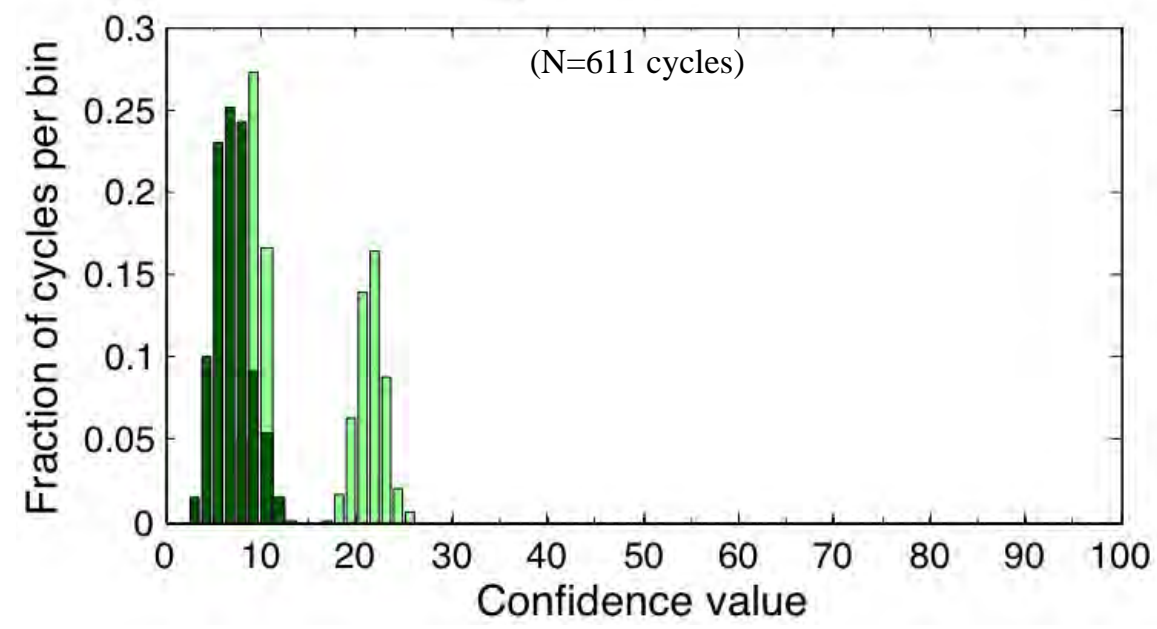

Figure 6.37. Histograms over High and Mid Level Data Combined for the True and False Overblow Peaks for DOB Detection Scenario 3 with Triconex Controller in Water Simulant (Light shaded - true peaks. Dark shaded - false peaks.) 
An example segment of the time series of flush line confidence levels for Scenario 3 with water simulant at mid level is plotted in Figure 6.38. The false peaks during the drive phase again had similar magnitudes to those observed for the other scenarios. As with the clay simulant, the true peaks had a greatly reduced magnitude. With water, the true confidence peaks tended to be even lower than the values obtained under Scenario 3 with clay.

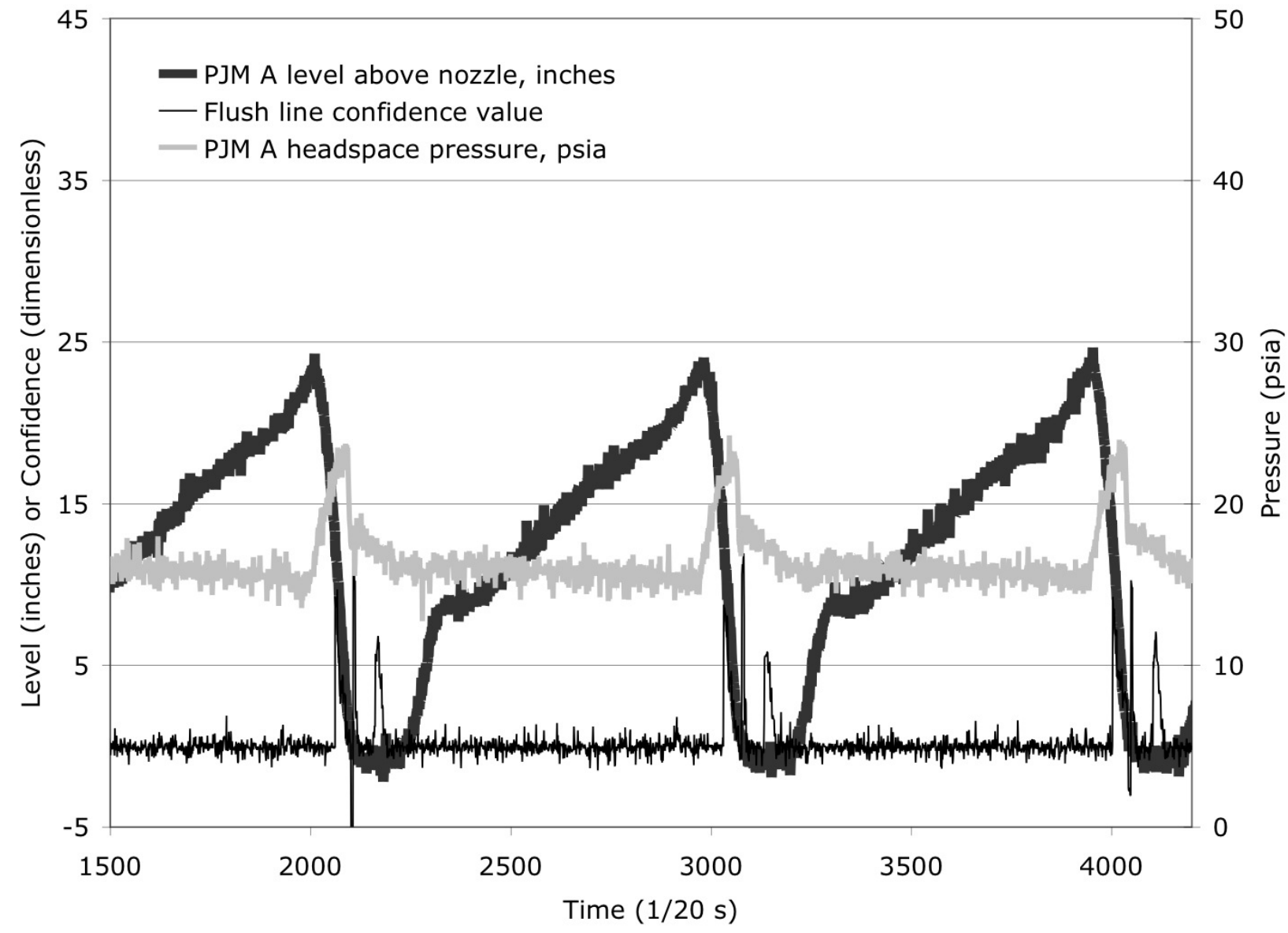

Figure 6.38. Flush Line Confidence Values for DOB Detection Scenario 3 with Triconex Controller in Water Simulant at the Mid Fill Level

\subsubsection{Overall Results for DOB Detection with the Triconex Controller}

As with the ABB controller, Scenario 3 was not handled well by the Triconex controller. If we ignore that scenario, we can set reliable detection thresholds for operation with either simulant at any level, under the assumption that CVF will be guaranteed by other means. Plotted in Figure 6.39 are true peak and false peak histograms for all Scenario 1 and 2 cases combined. The distributions for the true and false peaks are significantly separated, so a detection threshold can be set to give a high probability of detection and a low false alarm rate.

For the Triconex controller, the minimum separation between the distributions did not come from one limiting experimental condition (as was the case with the ABB controller). True peak confidence levels were lowest for Scenario 2 with water at the high and mid levels and for Scenario 1 with water at the mid 
level. False peak levels were highest for the clay simulant in Scenarios 1 and 2 at low level. The histograms for those cases were combined and are plotted below in Figure 6.40, overlaid with approximating normal distributions. From those normal distributions, it was estimated that approximately $99 \%$ of false peaks would fall under a confidence level of 18.8 (marked by the dashed line in the upper half of the figure), and approximately $99 \%$ of true peaks would be above a confidence level of 30.6 (marked by the dashed line in the lower half). A reliable detection threshold for Triconex operation under most conditions (excluding failure to completely fill a PJM) could be anywhere between 18.8 and 30.6.

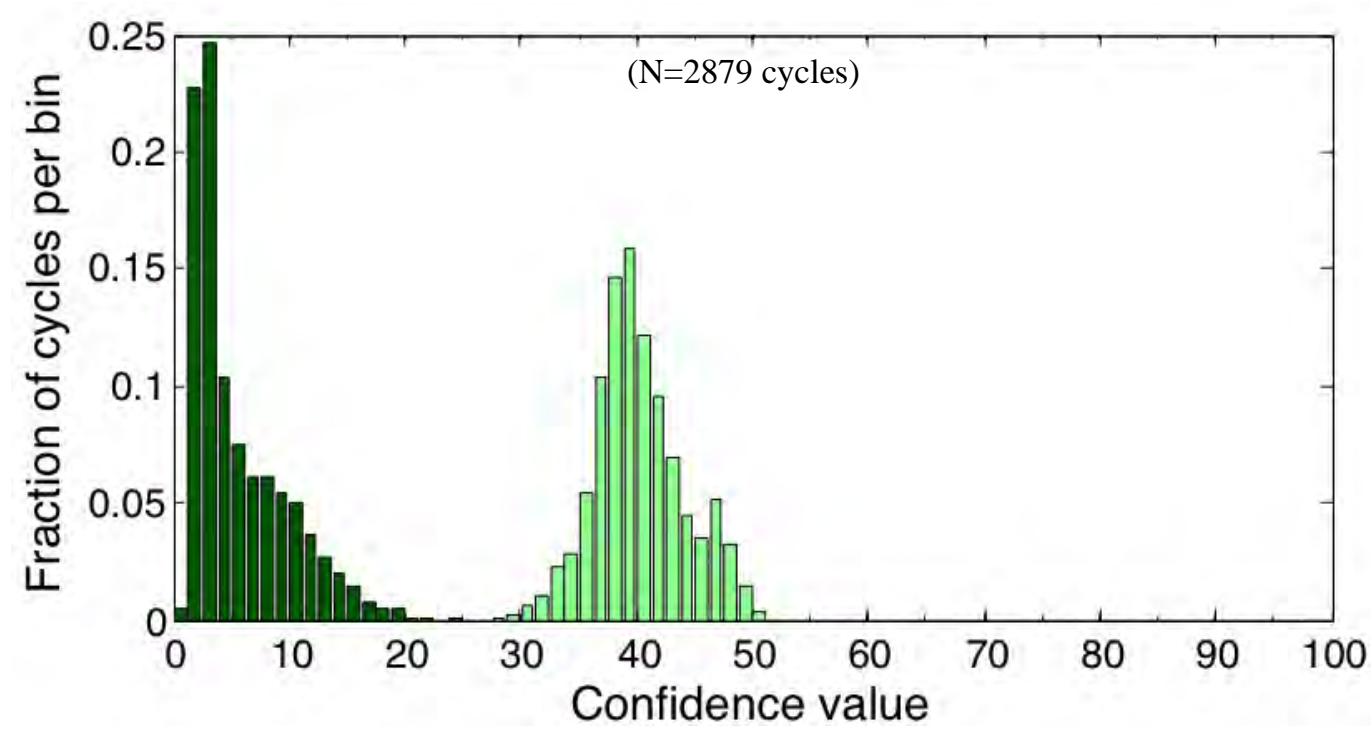

Figure 6.39. Combined Histograms for the True and False Overblow Peaks Over All Scenario 1 (4-PJM Full) and Scenario 2 (1PJM-Full) Cases (Both Simulants, All Levels)

for DOB Detection with Triconex Controller (Light shaded - true peaks. Dark shaded - false peaks.) 


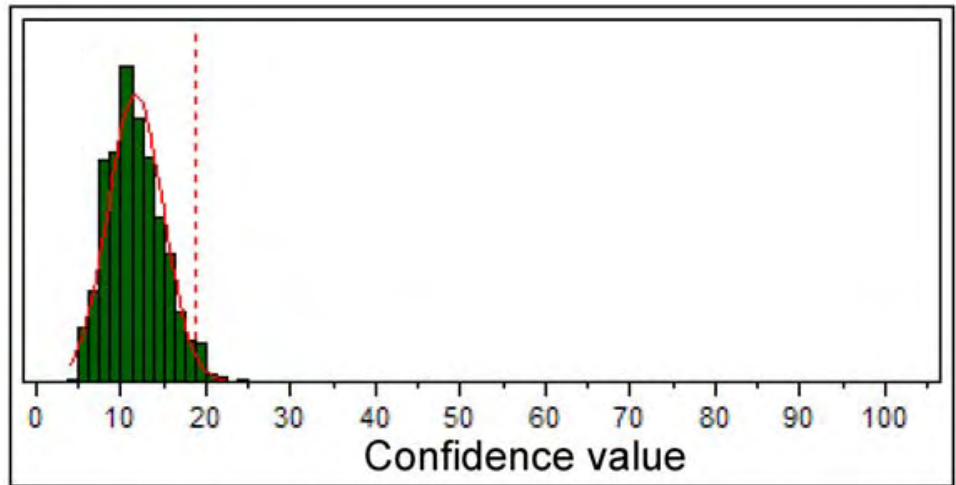

\section{Peak $=$ False}

Number of cycles: 610 Mean confidence level: 11.702252 Standard deviation: $\quad 3.2771729$

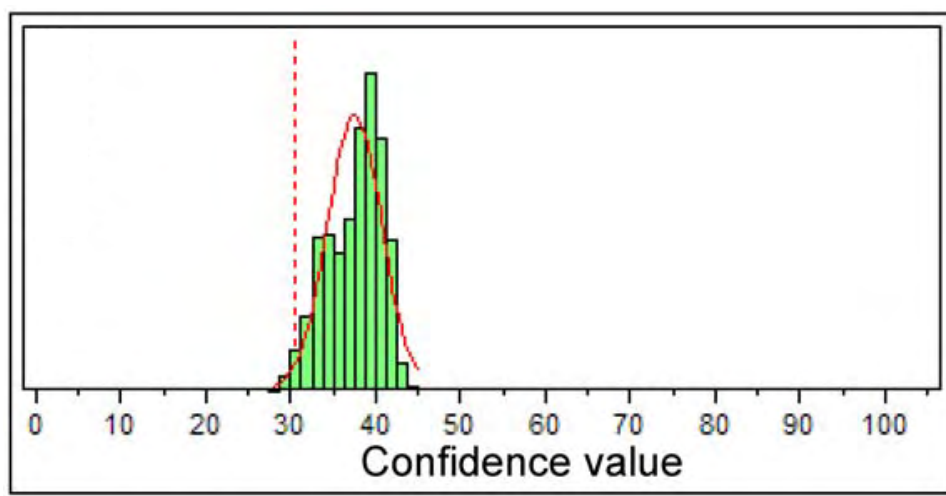

Peak=True

Number of cycles: 731 Mean confidence level: 37.516035 Standard deviation: 3.2022017

Figure 6.40. Limiting Histograms for True and False Overblow Peaks for DOB Detection with Triconex Controller and Approximating Normal Distributions

(Light shaded - true peaks. Dark shaded - false peaks.) 



\subsection{CVF Detection}

In this section, we discuss the ability of the BNI controllers to detect the charge vessel full condition. Unlike the tests of DOB detection, where different possible scenarios of DOB failure were investigated, the CVF tests were primarily focused on normal operation. In other words, scenarios that can affect CVF detection (for example, a blocked PJM nozzle) were not investigated.

The ability of ABB Controller and Triconex Controller control systems to detect CVF was evaluated at multiple vessel fill levels using clay and water simulants to bound the upper and lower rheological limits of the waste streams encountered in the WTP. The PJMs were cycled normally at each level and the resulting confidence levels observed. As mentioned above, no attempt was made to defeat the controller algorithms. Thresholds for CVF detection were estimated by comparing the peak confidence values in the neighborhood of the CVF to the noise values that appeared before the CVF. Noise values from early in the fill were removed from the analysis through the use of a mask. The mask was used in the analysis to simulate masking functions within the controllers. This section presents the results of the CVF detection experiments.

\subsection{Experimental Conditions}

During these experiments, all four PJMs were allowed to fill completely and drive normally. This set of experiments was done in conjunction with the Scenario 1 overblow experiments (see Section 6.1), so PJM\#A overblew on each cycle. The PJM\#A confidence level determined from the pressure transmitter on the drive and suction legs of the JPP were used in the analysis. The maximum, or true, value near the CVF point was measured for each cycle, as was the false peak that occurred late in the fill (after the mask period). In order to study the effect of mask period on the statistics for the false peak, two different mask times of 10 and 15 seconds (times from the start of the suction phase) were used in the analysis. The tests were performed with both clay and water simulants at three simulant fill levels corresponding to H/D ratios of $0.8,0.55$, and $0.3 .{ }^{1}$ During testing, the clay simulant rheology was tested frequently and adjusted, if necessary, to keep it within the target range of $30 \pm 5 \mathrm{~Pa}$.

\subsection{CVF Detection with the ABB Controller}

The results of CVF testing with the ABB controller are presented in the following sections. Identical distributions for the true and false peaks were obtained using the 10 second wide and 15 second wide masks. Thus the results below refer to both of these post-processing conditions.

\subsubsection{Clay Simulant}

Figure 7.1 shows the histograms for the true and false (pre-CVF) peaks of the PJM\#A confidence level for CVF detection with clay simulant. The upper, middle, and lower plots in this figure show the

\footnotetext{
${ }^{1}$ For the 336 test vessel with an internal diameter of 153 inches, these H/Ds correspond to fill levels of 122.4, 84, and 46 inches, respectively, as measured from the tank centerline. During testing, the fill level in the tank was maintained within \pm 2 inches of the target.
} 
data for the high, mid, and low fill level of the simulant. Each plot in this figure represents a minimum of 101 cycles for a total of 314 cycles for the three fill heights.
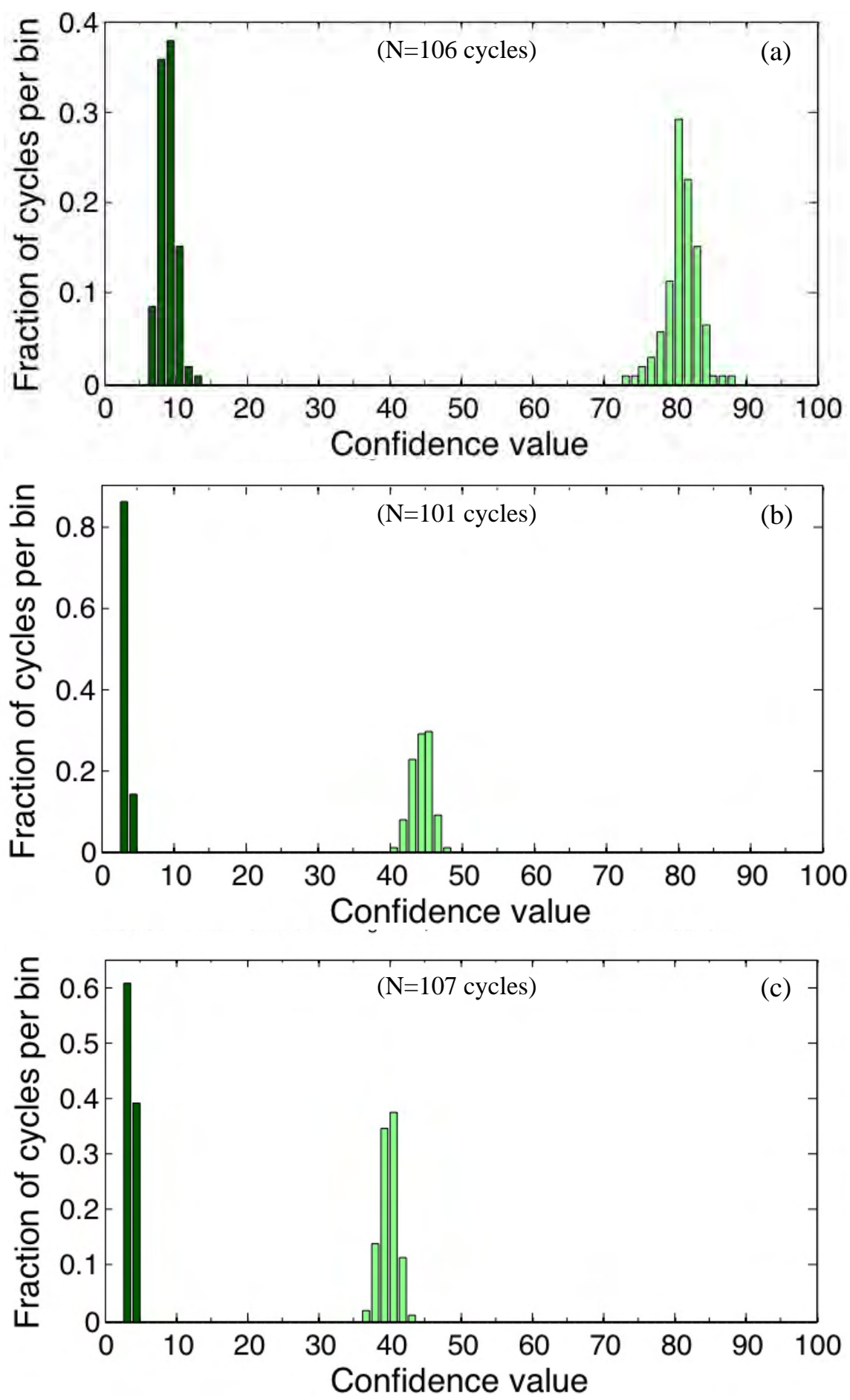

Figure 7.1. Histograms of the True and False Peaks for CVF Detection with ABB Controller in Clay Simulant at (a) High, (b) Mid, and (c) Low Fill Levels (Light shaded - true peaks. Dark shaded - false peaks.) 


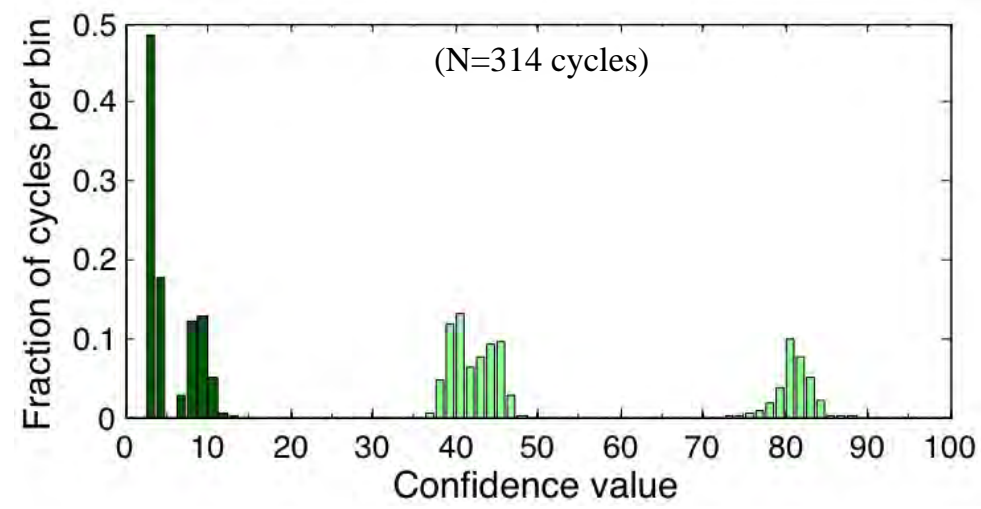

Figure 7.2. Histograms Over All Fill Levels of the True and False Peaks for CVF with ABB Controller in Clay Simulant

(Light shaded - true peaks. Dark shaded - false peaks.)
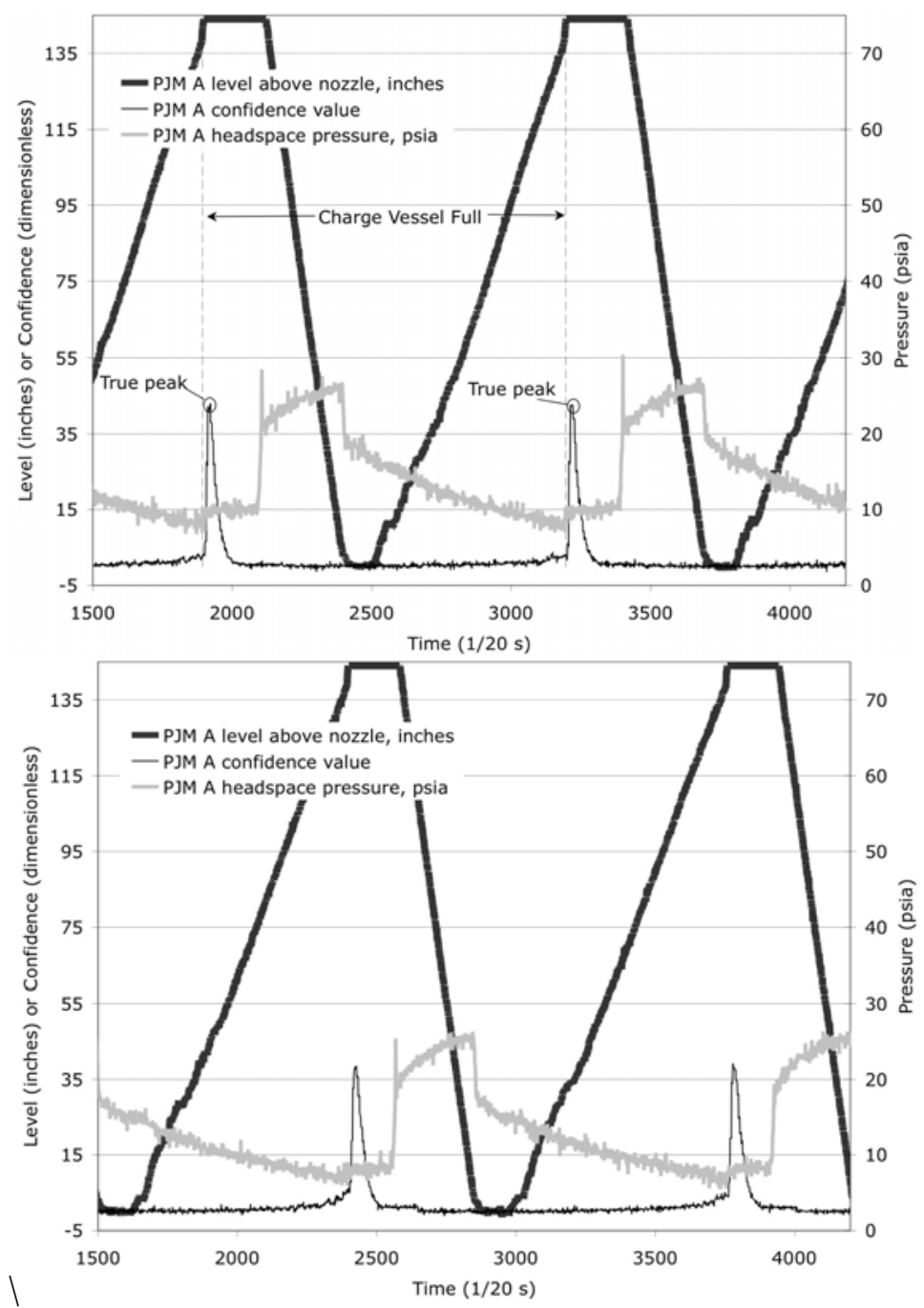

Figure 7.3. PJM\#A Confidence Values for CVF Detection with ABB Controller in Clay Simulant at the Mid (top) and Low (Bottom) Fill Levels 
It can be seen in Figure 7.1 that for the high, mid, and low fill level in clay simulant, the true overblow confidence peak range is 37 - 88 while the false peak range is 3 - 13. The fill level had an impact on the ranges of the true peaks; the confidence values tending to decrease with decreasing simulant level. However, the true and false peaks were always well separated over the range of fill levels as shown in Figure 7.2. This lack of overlap of the peaks indicates that a detection threshold value can be set for this simulant that will ensure a high probability that CVF will be detected at the correct time in a normal PJM cycle.

Modeling the true and false CVF peaks under the assumption of normal distributions allows thresholds for CVF detection to be estimated for the ABB controller with clay. False alarms can be limited to $1 \%$ or less with a threshold of 11.3 or greater. The probability of CVF detection will be $99 \%$ or greater with a threshold of 37.8 or less. A working threshold for clay can be chosen anywhere within the range of 11.3 to 37.8 .

Example time series of PJM\#A confidence levels for the ABB controller with clay simulant for each fill level are plotted in Figure 7.3. The confidence levels before CVF were essentially baseline noise without distinct false peaks. For the ABB controller the peak in confidence near CVF typically occurred roughly 1 second after the drop in JPP drive pressure discussed in Section 3.1.1.

\subsubsection{Water Simulant}

Figure 7.4 shows the histograms for the true and false peaks of the PJM\#A confidence level for CVF detection with water simulant. The upper, middle, and lower plots in this figure show the data for the high, mid, and low fill level of the simulant. Each plot in this figure represents a minimum of 104 cycles for a total of 513 cycles for the three fill heights.

It can be seen in Figure 7.4 that for the high, mid, and low fill level in water simulant, the true overblow confidence peak range is $39-71$ while the false peak range is $2-7$. Again, the fill level had an impact on the ranges of the true peaks, the confidence values tending to decrease with decreasing simulant level. The true and false peaks were always well separated over the range of fill levels however, as shown in Figure 7.5. This lack of overlap of the peaks once again indicates that a detection threshold value can be set for this simulant that will ensure a high probability that CVF will be detected at the correct time in a normal PJM cycle.

Modeling the true and false CVF peaks under the assumption of normal distributions allows thresholds for CVF detection to be estimated for the ABB controller with water. False alarms can be limited to $1 \%$ or less with a threshold of 6.3 or greater. The probability of CVF detection will be $99 \%$ or greater with a threshold of 40.0 or less. A working threshold for clay can be chosen anywhere within the range of 6.3 to 40.0 . 

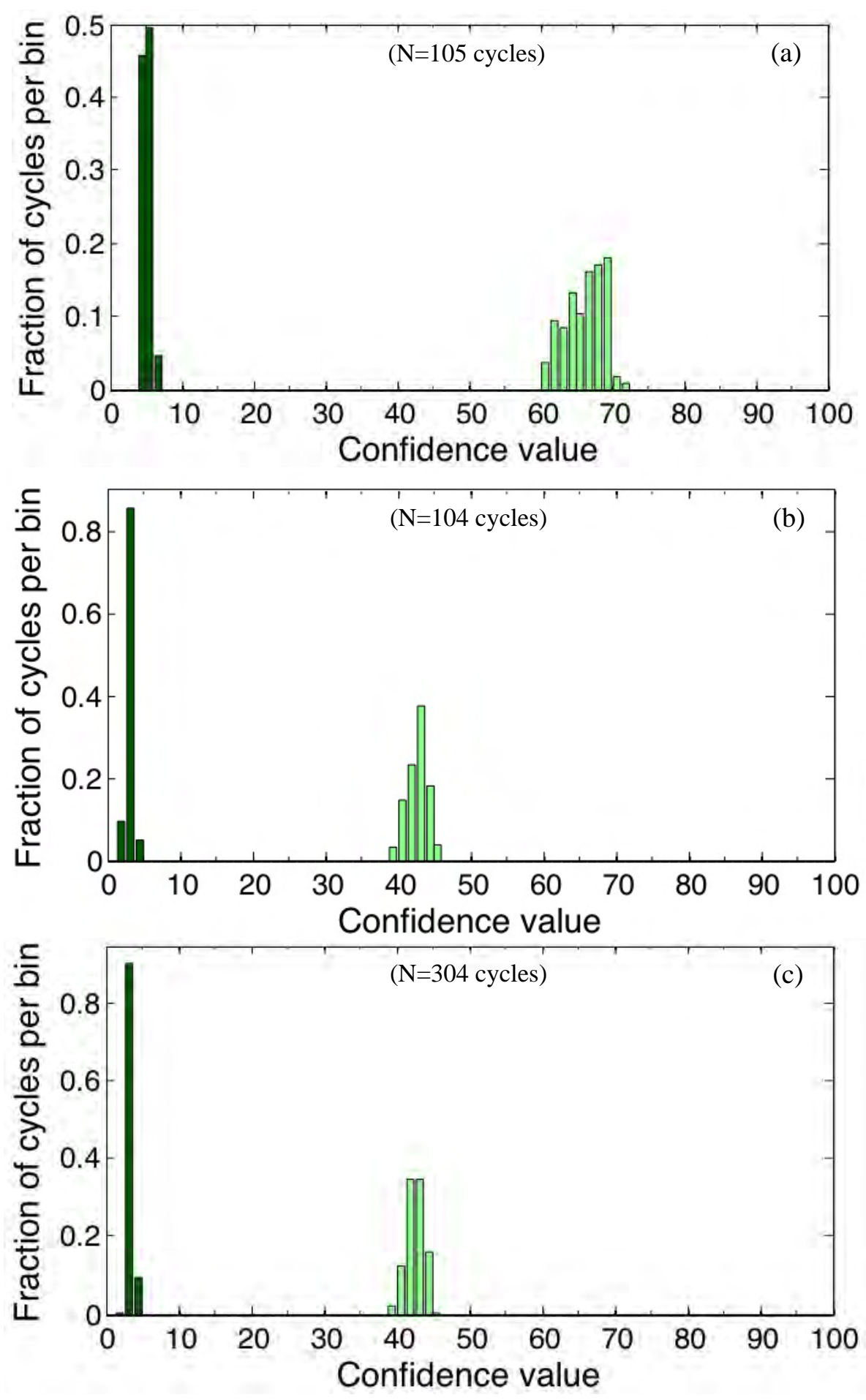

Figure 7.4. Histograms of the True and False Peaks for CVF Detection with ABB Controller in Water Simulant at (a) High, (b) Mid, and (c) Low Fill Levels

(Light shaded - true peaks. Dark shaded - false peaks.) 


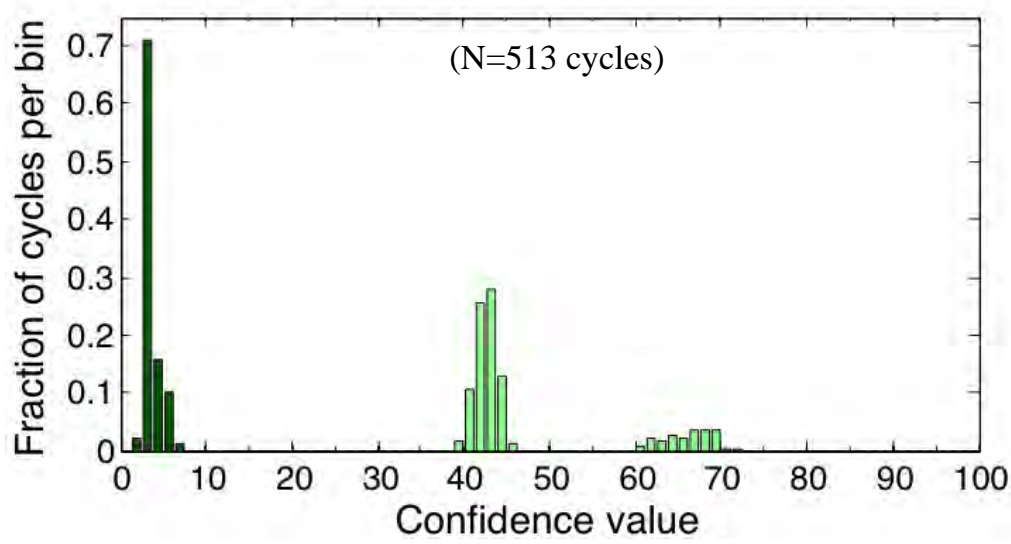

Figure 7.5. Histograms Over All Fill Levels of the True and False Peaks for CVF with ABB Controller in Water Simulant (Light shaded - true peaks. Dark shaded - false peaks.)

\subsubsection{Overall Results for CVF Detection with the ABB Controller}

Plotted in Figure 7.6 are true peak and false (pre-CVF) peak histograms for all cases (both simulants and all levels) combined. The distributions for the true and false peaks are significantly separated, so an overall detection threshold can be set to give a high probability of CVF detection at approximately the correct time in the PJM cycle.

For the ABB controller, the true peak confidence levels were lowest for clay simulant at the low liquid level. The false peak levels were highest for the clay simulant in at high level. The histograms for those cases were combined and are plotted below in Figure 7.7, overlaid with approximating normal distributions. From those normal distributions, it was estimated that approximately $99 \%$ of false peaks would fall under a confidence level of 11.3 (marked by the dashed line in the upper half of the figure), and approximately 99\% of true peaks would be above a confidence level of 37.8 (marked by the dashed line in the lower half). A reliable CVF detection threshold for ABB operation could be anywhere between 11.3 and 37.8 .

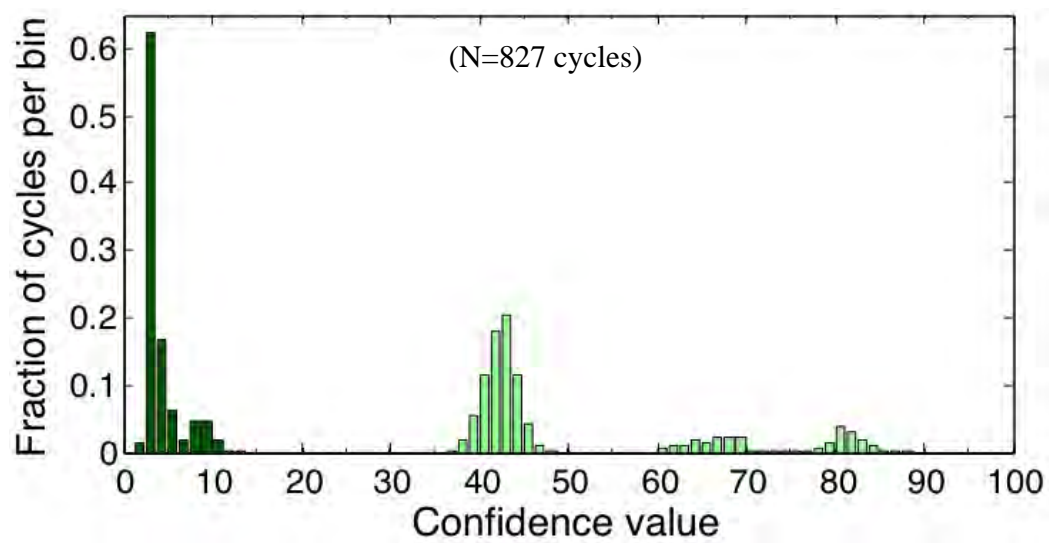

Figure 7.6. Combined Histograms for the True and False Peaks Over All Cases (both simulants, all levels) for CVF Detection with ABB Controller

(Light shaded - true peaks. Dark shaded - false peaks.) 


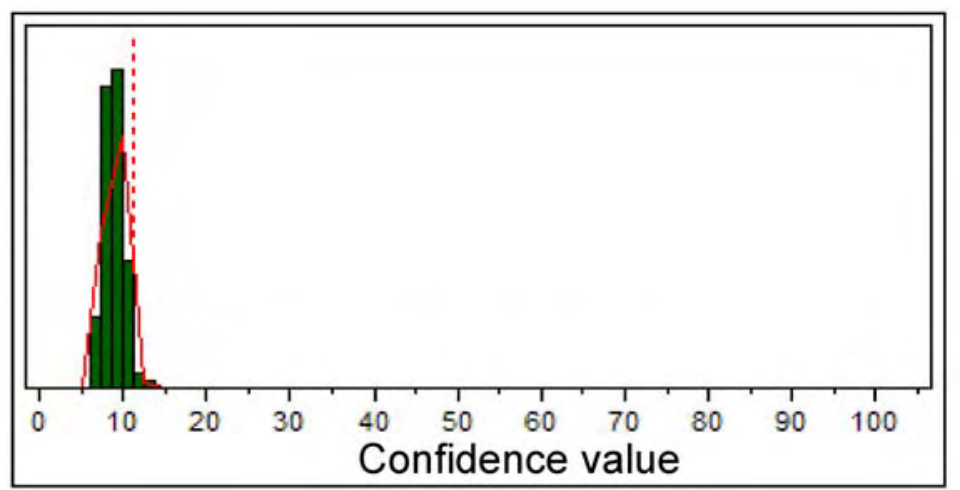

Peak $=$ False

Number of cycles: 106 Mean confidence level: 9.0136887 Standard deviation: 1.1739139

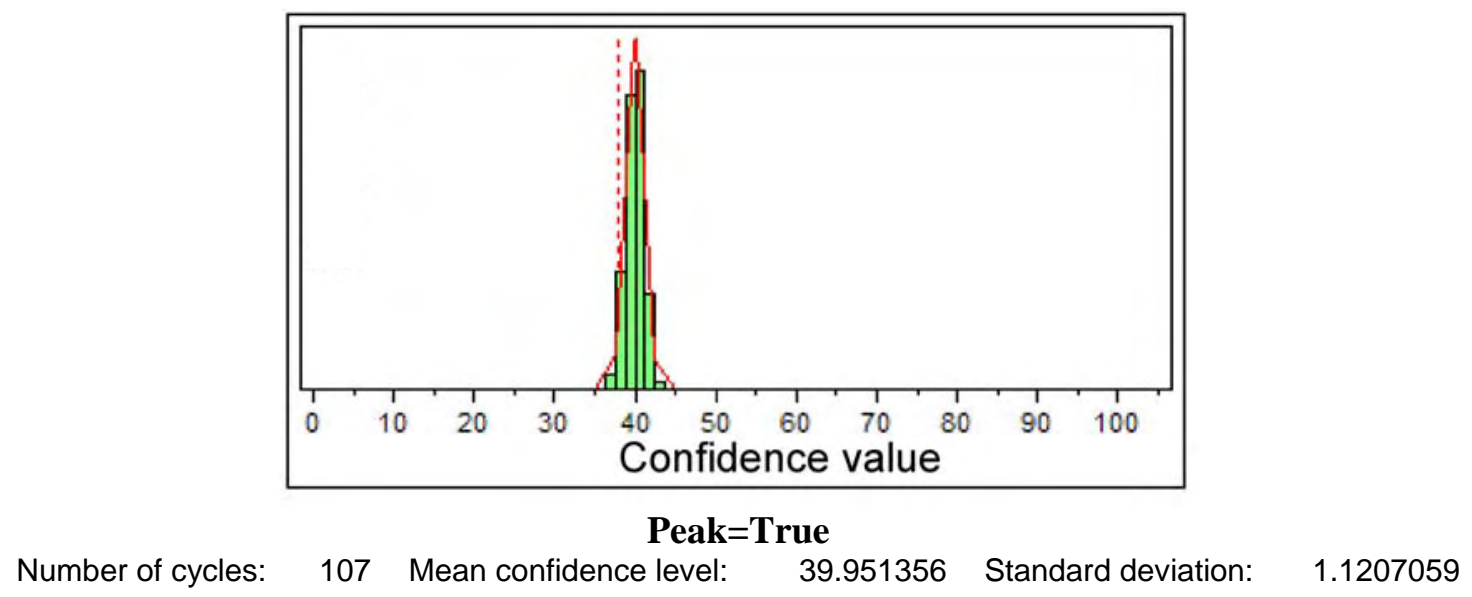

Figure 7.7. Limiting Histograms for True and False Peaks for CVF Detection with ABB Controller and Approximating Normal Distributions

(Light shaded - true peaks. Dark shaded - false peaks.)

\subsection{CVF Detection with the Triconex Controller}

The results of CVF testing with the Triconex controller are presented in the following sections. Identical distributions for the true and false peaks were obtained using the 10 second wide and 15 second wide masks at the high and low simulant levels. Thus the high and low level results below refer to both of these post-processing conditions.

\subsubsection{Clay Simulant}

Figure 7.8 shows the histograms for the true and false (pre-CVF) peaks of the PJM\#A confidence level for CVF detection with clay simulant. The upper, middle, and lower plots in this figure show the data for the high, mid, and low fill level of the simulant. Each plot in this figure represents a minimum of 105 cycles for a total of 517 cycles for the three fill heights. Two groups of histograms are presented for the mid level data — one set obtained with the 10 second wide mask and another set obtained with the 15 second wide mask. The wider mask reduced the width of the distribution of false peaks obtained at mid level, for reasons discussed below. 

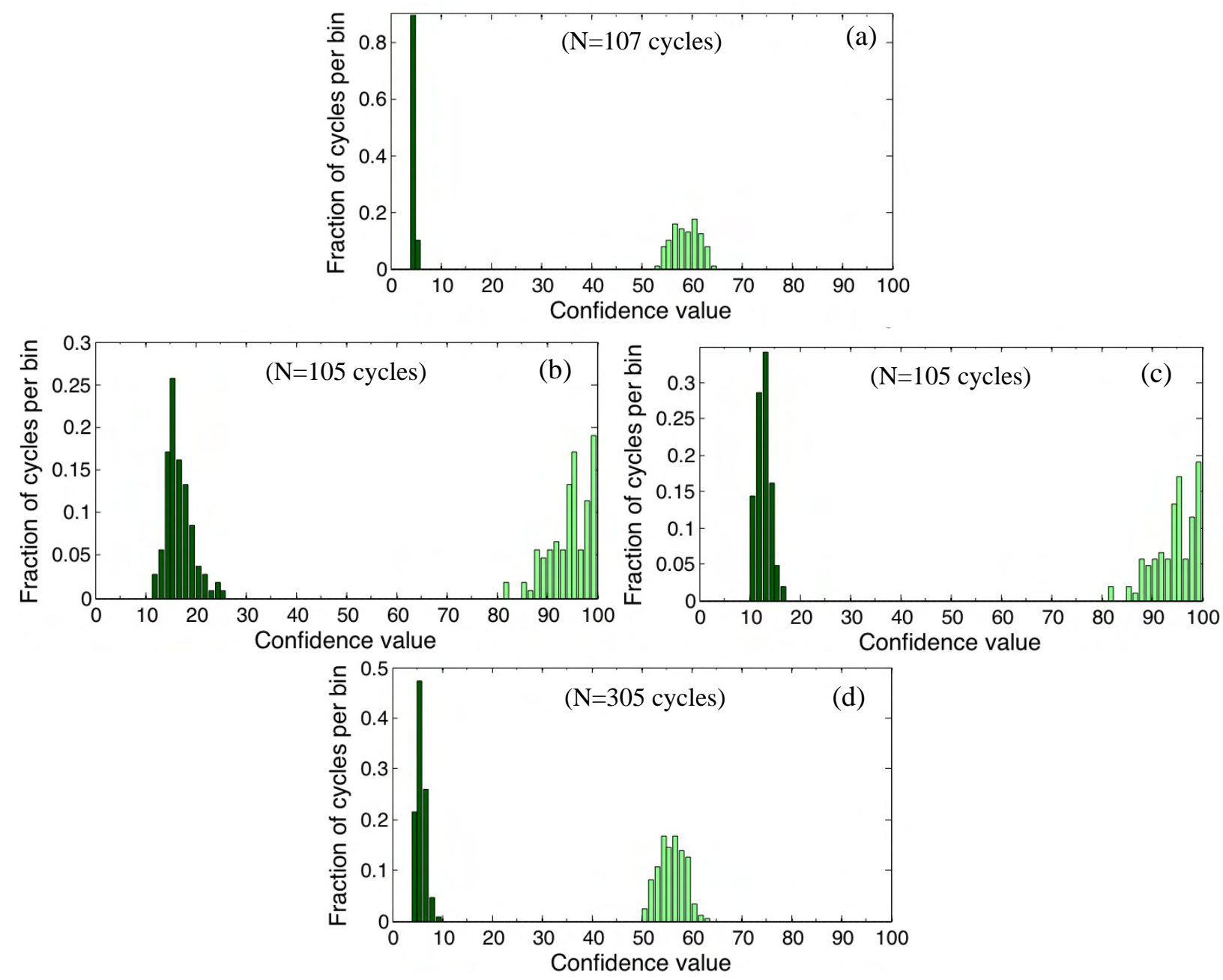

Figure 7.8. Histograms of the True and False Peaks for CVF Detection with Triconex Controller in Clay Simulant at (a) High, (b) Mid (10 second mask), (c) Mid (15 second mask) and (d) Low Fill Levels

(Light shaded - true peaks. Dark shaded - false peaks.)

It can be seen in Figure 7.8 that for the high, mid, and low fill level in clay simulant, the true overblow confidence peak range is 50 - 100 while the false peak range is 4 - 17 (with the 15 second wide mask; 25 with the 10 second mask). The mid-level confidence data had spurious peaks near the start of each fill; peaks that were mostly eliminated from the distributions of false peaks with the masks. However, the true and false peaks were always well separated over the range of fill levels as shown in Figure 7.9. This lack of overlap of the peaks indicates that a detection threshold value can be set for this simulant that will ensure a high probability that CVF will be detected at the correct time in a normal PJM cycle. 


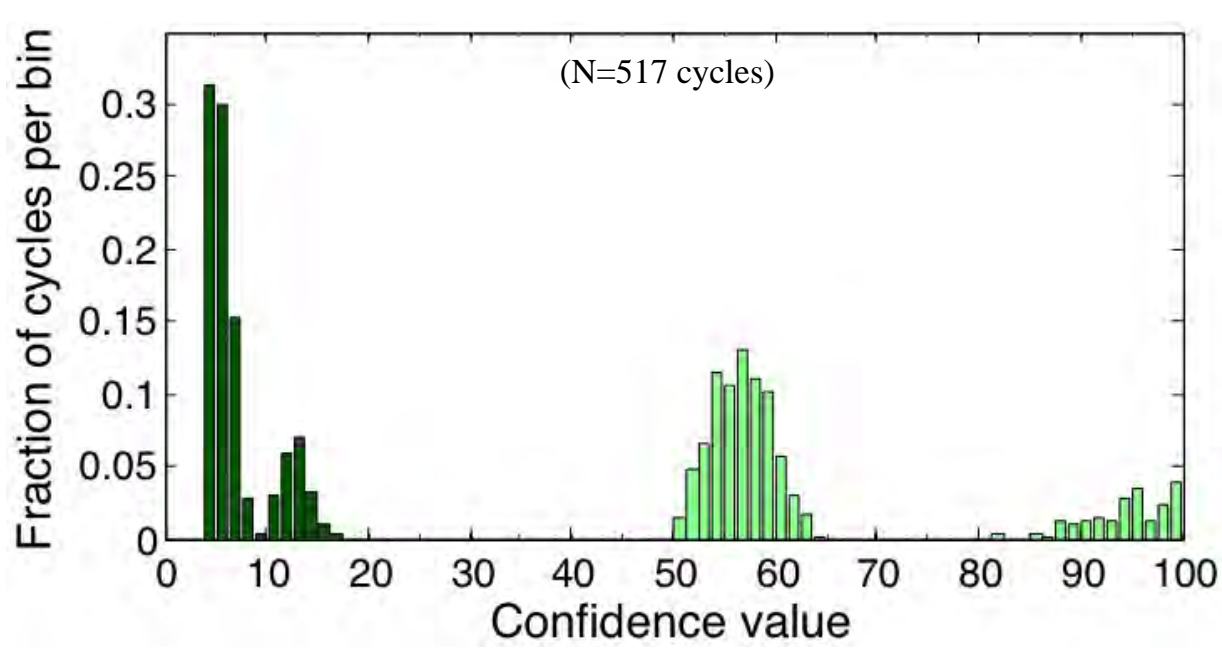

Figure 7.9. Histograms Over All Fill Levels of the True and False Peaks for CVF with Triconex Controller in Clay Simulant (obtained with the 15 second mask on the PJM\#A confidence data near the start of the fill) (Light shaded - true peaks. Dark shaded - false peaks.)

Modeling the true and false CVF peaks under the assumption of normal distributions allows thresholds for CVF detection to be estimated for the Triconex controller with clay. False alarms can be limited to $1 \%$ or less with a threshold of 15.4 (with the 15-second wide mask; 21.9 with the 10 -second mask) or greater. The probability of CVF detection will be $99 \%$ or greater with a threshold of 50.6 or less. A working threshold for clay can be chosen anywhere within the range of 15.4 to 50.6.

Example time series of PJM\#A confidence levels for the Triconex controller with clay simulant for each fill level are plotted in Figure 7.10. For the Triconex controller the peak in confidence near CVF typically occurred roughly 1 second after the drop in JPP drive pressure discussed in Section 3.1.1. The mid level data shows characteristic peaks early in the fill; peaks that seem to be roughly correlated with rising of the liquid level above the nozzle transition in the PJM. Their presence in the mid-level data, and not at the high or low levels, may be a function of the controller tuning for this case. The masks were intended to eliminate these peaks and most of their decay tails from the determination of the false peak values.

\subsubsection{Water Simulant}

Figure 7.11 shows the histograms for the true and false peaks of the PJM A confidence level for CVF detection with water simulant. The upper, middle, and lower plots in this figure show the data for the high, mid, and low fill level of the simulant. Each plot in this figure represents a minimum of 107 cycles for a total of 533 cycles for the three fill heights. Two groups of histograms are presented for the mid level data — one set obtained with the 10 second wide mask and another set obtained with the 15 second wide mask. 
It can be seen in Figure 7.11 that for the high, mid, and low fill level in water simulant, the true overblow confidence peak range is 49 - 100 while the false peak range is 3 - 16 (with the 15 second wide mask; 3 - 19 with the 10 second mask). The true and false peaks were again always well separated over the range of fill levels as shown in Figure 7.12. This lack of overlap of the peaks once again indicates that a detection threshold value can be set for this simulant that will ensure a high probability that CVF will be detected at the correct time in a normal PJM cycle. 

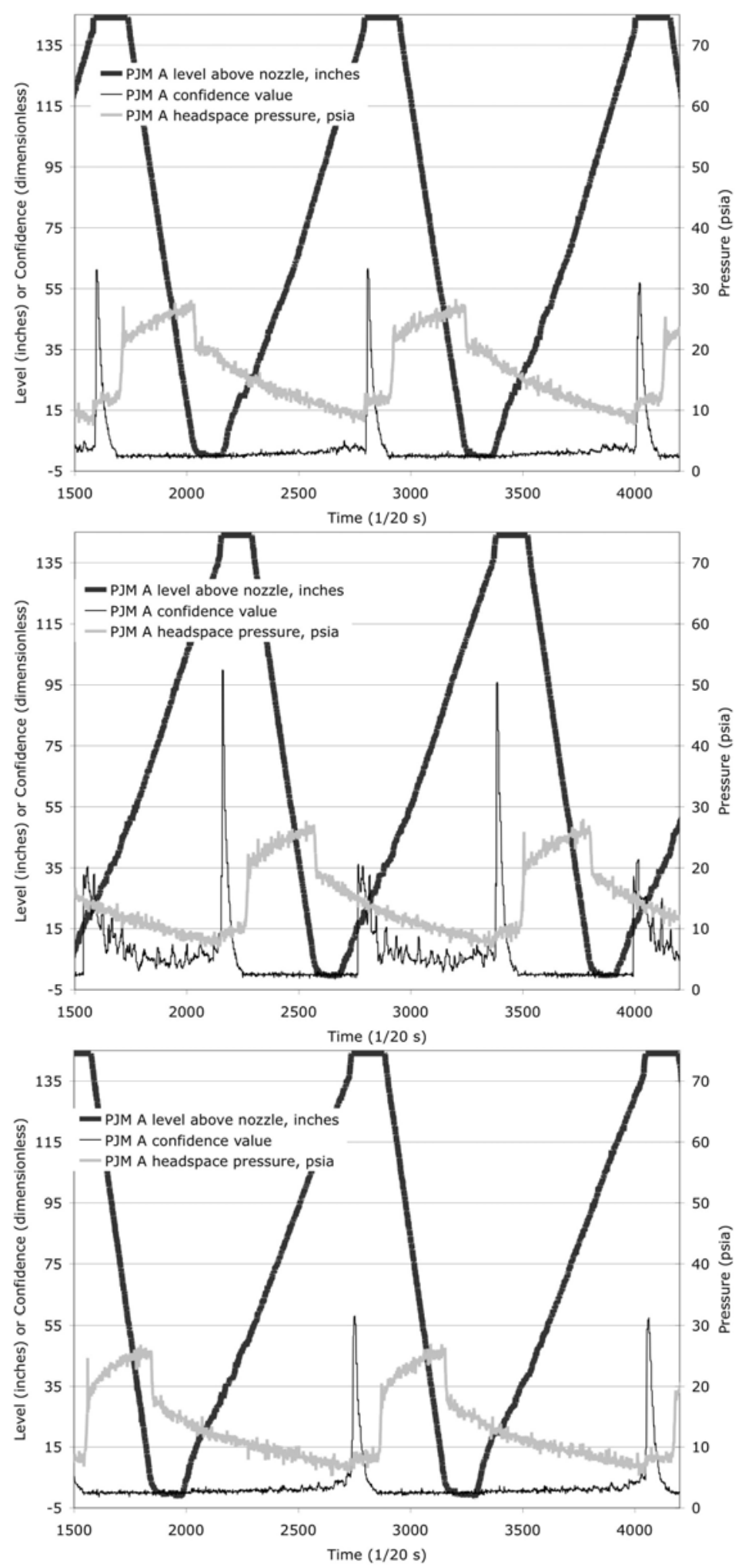

Figure 7.10. PJM\#A Confidence Values for CVF Detection with Triconex Controller in Clay Simulant at the High (top), Mid (middle) and Low (bottom) Fill Levels 
Modeling the true and false CVF peaks under the assumption of normal distributions allows thresholds for CVF detection to be estimated for the Triconex controller with water. False alarms can be limited to $1 \%$ or less with a threshold of 13.8 (with the 15 second wide mask, 15.3 with the 10 second mask) or greater. The probability of CVF detection will be $99 \%$ or greater with a threshold of 50.7 or less. A working threshold for clay can be chosen anywhere within the range of 13.8 to 50.7.
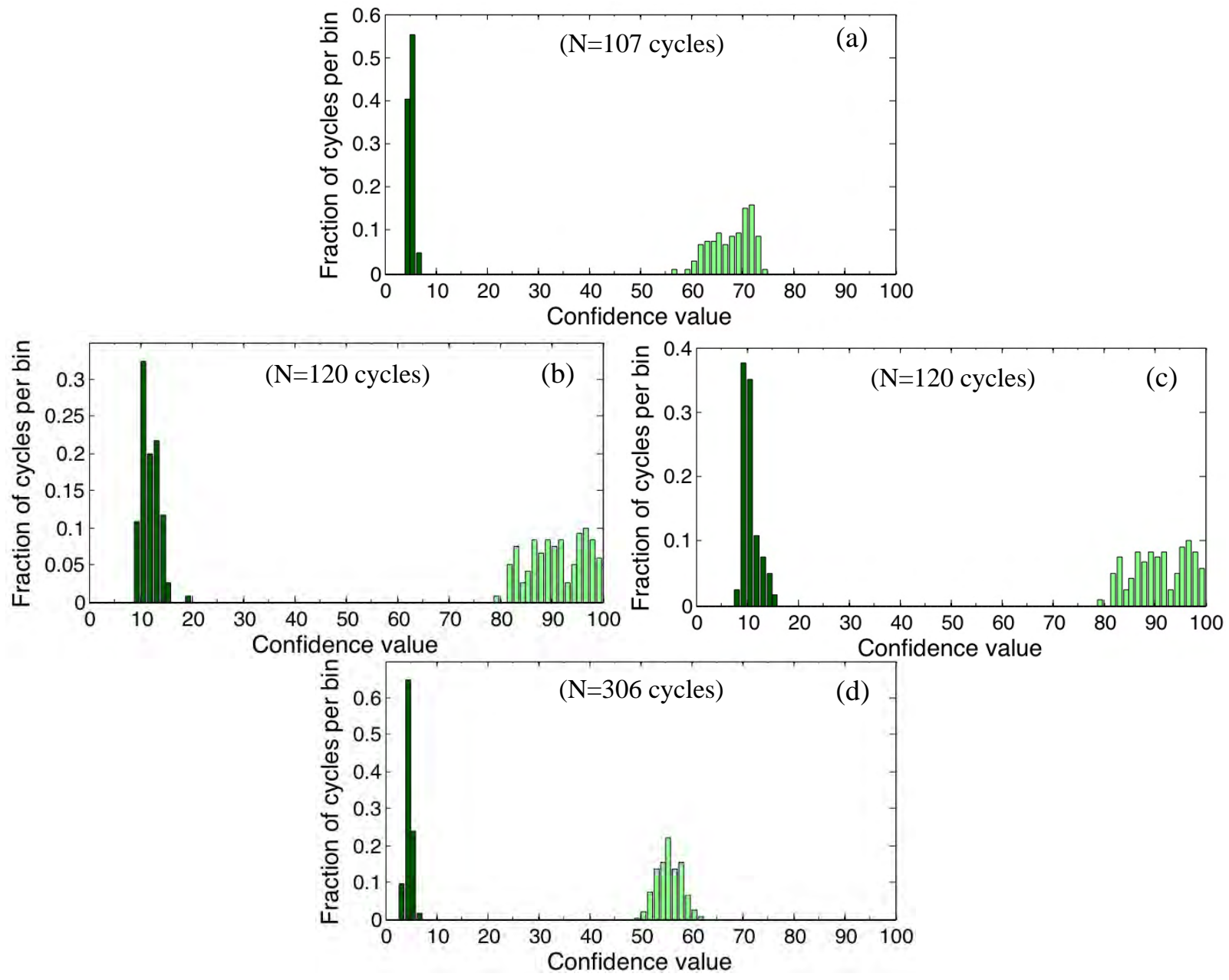

Figure 7.11. Histograms of the True and False Peaks for CVF Detection with Triconex Controller in Water Simulant at (a) High, (b) Mid (10 second mask), (c) Mid (15 second mask) and (d) Low Fill Levels

(Light shaded - true peaks. Dark shaded - false peaks.) 


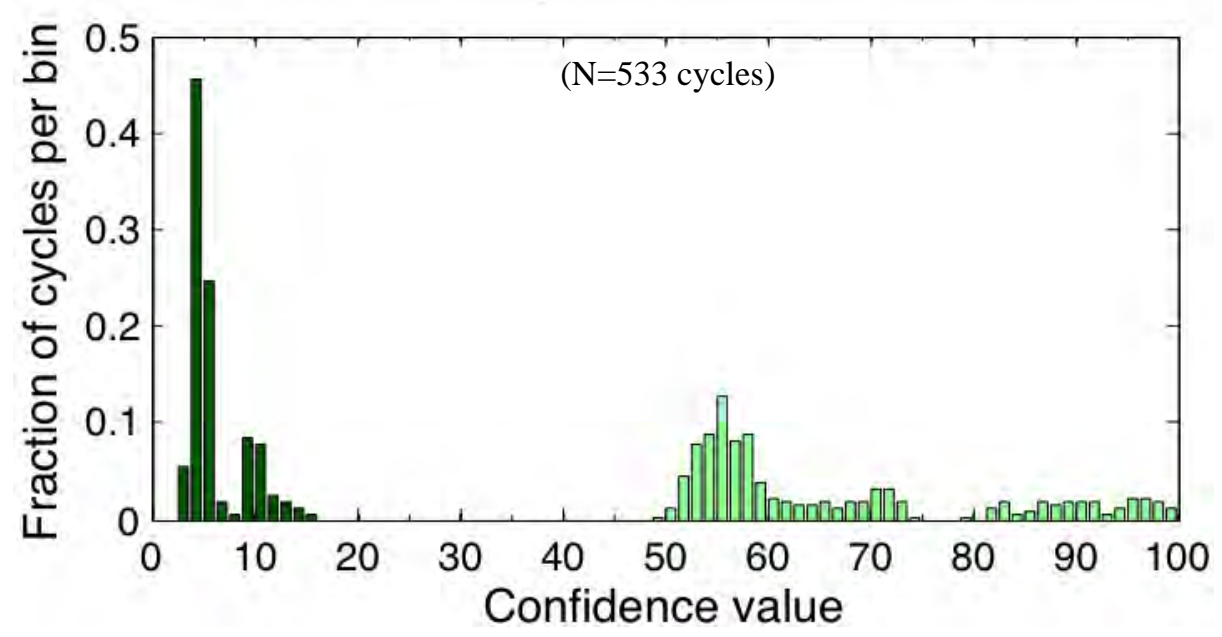

Figure 7.12. Histograms Over All Fill Levels of the True and False Peaks for CVF with Triconex Controller in Water Simulant (obtained with the 15 second mask on the PJM\#A confidence data near the start of the fill)

(Light shaded - true peaks. Dark shaded - false peaks.)

\subsubsection{Overall Results for CVF Detection with the Triconex Controller}

Plotted in Figure 7.13 are true peak and false (pre-CVF) peak histograms for all cases (both simulants and all levels) combined. The distributions for the true and false peaks are significantly separated, so an overall detection threshold can be set to give a high probability of CVF detection at approximately the correct time in the PJM cycle. 

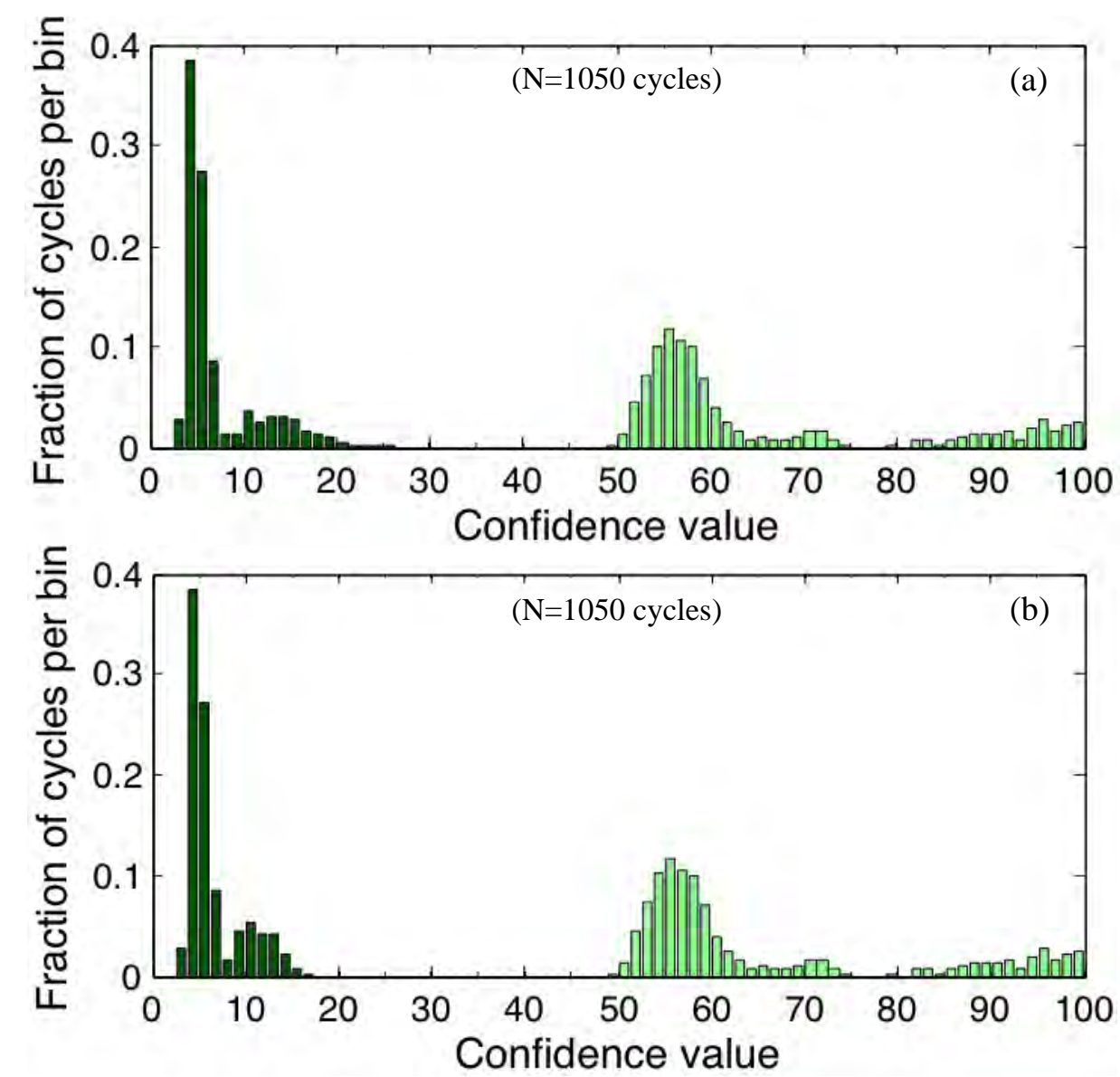

Figure 7.13. Combined Histograms for the True and False Peaks Over All Cases (both simulants, all levels) for CVF Detection with Triconex Controller with the 10 Second- (top) and 15 Second-wide (bottom) Masks (Light shaded - true peaks. Dark shaded - false peaks.)

For the Triconex controller, the true peak confidence levels were lowest for both clay and water simulants at the low liquid level. The false peak levels were highest for the clay simulant at the mid level. The histograms for those cases were combined and are plotted below in Figure 7.14, overlaid with approximating normal distributions. From those normal distributions, it was estimated that approximately $99 \%$ of false peaks would fall under a confidence level of 15.4 (with the 15 second wide mask, 21.9 with the 10 second mask) and approximately $99 \%$ of true peaks would be above a confidence level of 50.5 (with either mask width). A reliable CVF detection threshold for Triconex operation could be anywhere between 15.4 and 50.5 (these confidence levels are marked with dashed lines in the upper right and lower panels of Fig. 7.14). 


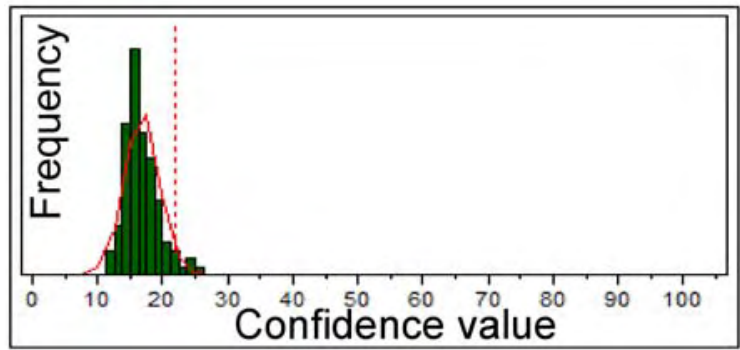

Peak=False, 10-second wide mask

Number of cycles: $\quad 105$ Mean confidence level: 16.778619 Standard deviation: 2.6568293

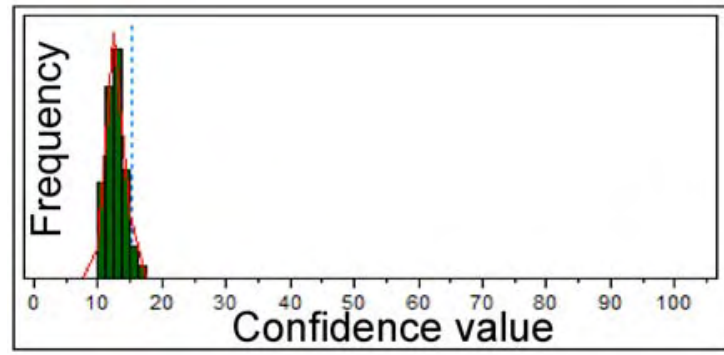

Peak=False, 15-second wide mask

Number of cycles: $\quad 105$ Mean confidence level: 12.775633 Standard deviation: 1.3435587

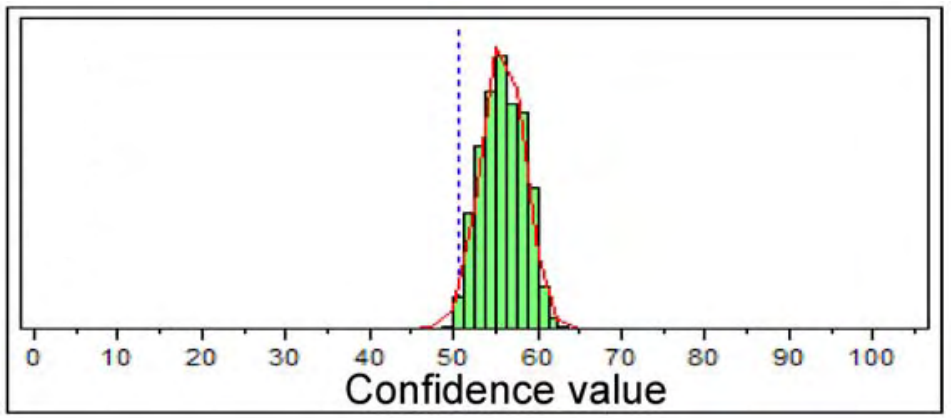

Peak=True (either mask)

Number of cycles: 611 Mean confidence level: 55.834629 Standard deviation: 2.4878938

Figure 7.14. Limiting Histograms for "True and False Peaks for CVF Detection with Triconex Controller and Approximating Normal Distributions

(Light shaded - true peaks. Dark shaded - false peaks.) 



\subsection{Predicting Time-to-Overblow}

Development of a correlation between time-to-overblow and drive pressure, fill height, and simulant density may allow the prediction of a maximum drive time (for the process conditions) to be incorporated into the PJM control strategy, minimizing the frequency of overblows. In the first part of this section we present the experimentally determined time-to-overblow for the two simulants and the three fill levels studied in the present testing. In Section 8.2 we present the results of correlating the data using the time-to-overblow model previously developed (see Section 12 of Bontha et al. 2007).

\subsection{Determination of Time-To-Overblow}

The time-to-overblow tests were performed with all four PJMs operating while varying the fill height and the simulant type. The experimental set-up and all other parameters, the nominal JPP drive and suction pressures in particular, were kept constant. During the tests, each drive was continued until there was an overblow to ensure that the total volume of the PJM was expelled. The time-to-overblow experiments were conducted in conjunction with the Scenario 1 overblow detection experiments discussed in Section 6. Refer to that section for more discussion of the operating conditions during the tests.

The time-to-overblow for a PJM cycle is defined as the difference between the starting time of the drive phase and the starting time of the overblow. The former was estimated from the time the JPP drive pressure began to rise after the end of the suction. The latter was estimated from the time the PJM\#A flush line pressure dropped precipitously just before the end of the drive. Plotted in Figure 8.1 are the flush line and drive pressures for a portion of a typical PJM cycle. The approximate starting points of the drive and the overblow are marked on the figure.

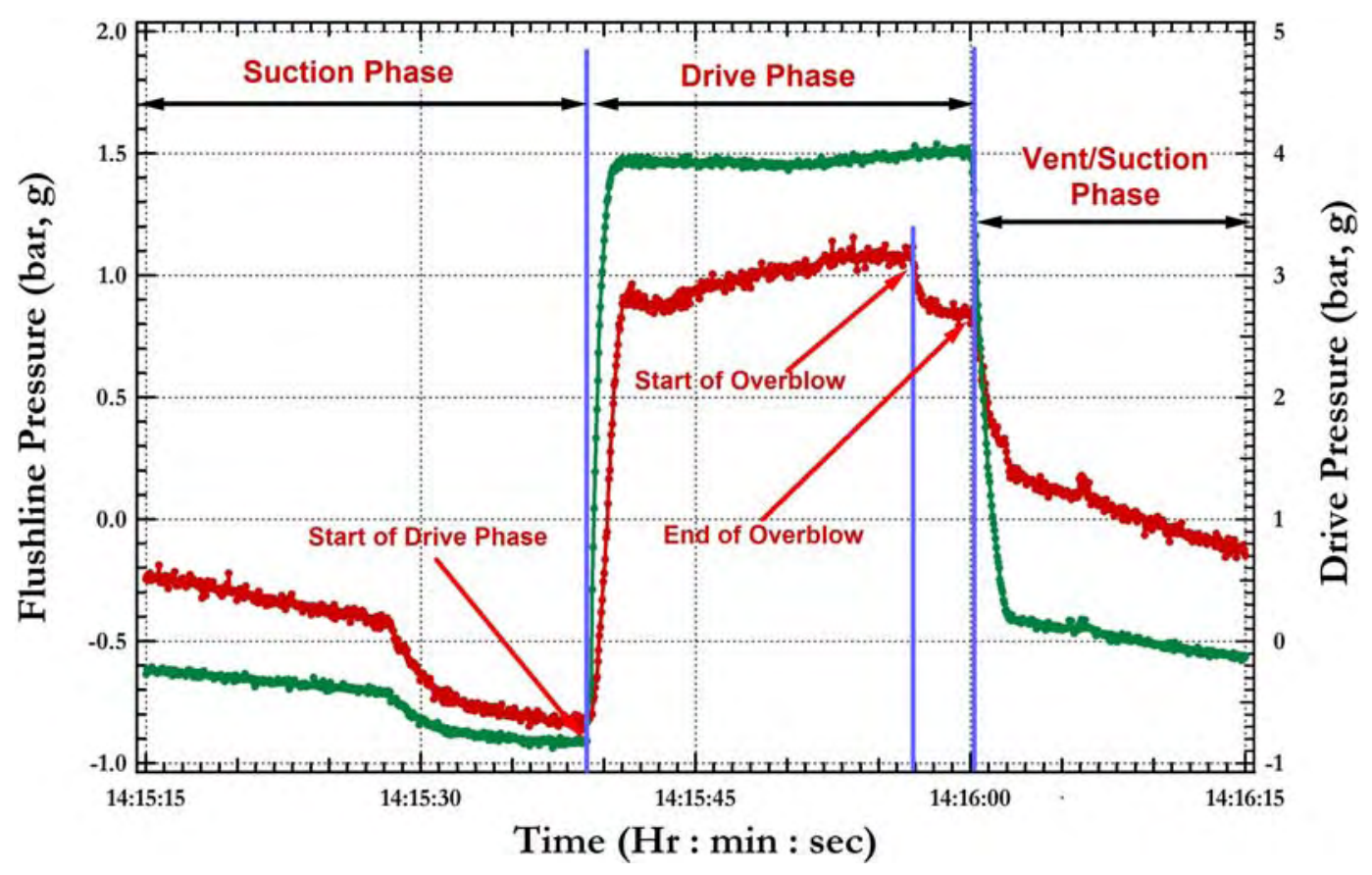

Figure 8.1. Illustration of the Drive Phase During a PJM Cycle 
Aggregate time-to-overblow data are listed in Table 8.1 for the water and clay simulants at the three fill heights. Each data point in the table represents an average of approximately 30 cycles of data. For a given simulant, the time-to-overblow increased with increasing fill height. For a given fill height, it increased with increasing density of the simulant (for example, when the simulant was changed from water to clay).

Table 8.1. Time-to-Overblow Data

\begin{tabular}{|c|c|c|c|c|c|c|c|}
\hline & \multicolumn{2}{|c|}{ Simulant } & \multirow[b]{2}{*}{$\begin{array}{l}\text { Number } \\
\text { of } \\
\text { cycles }\end{array}$} & \multirow[b]{2}{*}{$\begin{array}{l}\text { Avg. } \\
\text { headspace } \\
\text { pressure, } \\
\text { psia }^{(3)}\end{array}$} & \multicolumn{3}{|c|}{$t_{o b}$, seconds } \\
\hline Experiment $^{(1)}$ & Type & $\begin{array}{c}\text { Level, } \\
\text { inches }^{(2)}\end{array}$ & & & Min & Max & Average \\
\hline 080519_ABB_4PJM_CVF_20Hz & Clay & 55 & 31 & 26.8 & 17.7 & 17.9 & 17.8 \\
\hline 080521_ABB_4PJM_CVF_20Hz & Clay & 94 & 30 & 26.1 & 16.2 & 16.4 & 16.2 \\
\hline 080527_ABB_4PJM_CVF_20Hz & Clay & 132 & 30 & 25.4 & 15.5 & 15.8 & 15.6 \\
\hline 080603_ABB_4PJM_CVF_20Hz & Water & 55 & 30 & 26.4 & 16.5 & 16.7 & 16.6 \\
\hline 080609_ABB_4PJM_CVF_20Hz & Water & 94 & 30 & 25.7 & 15.7 & 15.9 & 15.8 \\
\hline 080613_ABB_4PJM_CVF_20Hz & Water & 132 & 30 & 25.4 & 15.0 & 15.1 & 15.0 \\
\hline $\begin{array}{l}\text { Notes: } \\
\text { (1) Represents the experimental da } \\
\text { (2) Liquid level below the rim of th } \\
\text { (3) } 162.5 \text { inches - (level below the } \\
\text { (3) Thesult shown is the average }\end{array}$ & nk - & rage o & $\begin{array}{l}\text { urement } \\
\text { pace pr }\end{array}$ & je and afte & un. & el a & e nozzle $=$ \\
\hline
\end{tabular}

\subsection{Modeling of the Time-to-Overblow}

Bontha et al. (2005) derived and verified a Bernoulli-based model that describes the dynamic height of a non-Newtonian fluid in a PJM vessel during operation. The approach allows $t_{o b}$ values to be correlated in terms of an excess headspace pressure $u$ (Bontha et al. 2007).

$$
t_{o b}=\left(C_{1} \frac{u}{\rho g}+C_{2}\right)^{1 / 2}-\left(C_{1} \frac{u}{\rho g}\right)^{1 / 2}
$$

where:

$$
\begin{aligned}
& \frac{u}{\rho g}=\frac{P_{1}-P_{2}}{\rho g}-z_{2}, \\
& P_{1}=\text { PJM headspace pressure (assumed constant), } \\
& P_{2}=1 \text { atm. = Pressure in the tank above the liquid, } \\
& z_{2_{0}}=\text { the liquid level in the tank above the nozzle at the instant of overblow, } \\
& C_{1}, C_{2} \text { are constants for a given PJM configuration. }
\end{aligned}
$$

The headspace pressure $\left(P_{1}\right)$ was approximated by the pressure inside the pulse tube just before overblow.

The above expression was derived assuming quasi-steady (neglecting fluid acceleration) PJM operation during the drive phase, constant headspace and tank pressures, and constant PJM diameter 
down to but not including the nozzle. Under such assumptions, constants $C_{1}$ and $C_{2}$ can be formally related to nozzle, PJM, and tank cross-sections and to the nozzle loss coefficient. In this report, we treat them as empirical parameters. In the PJM configuration used for these tests (see Section 3 of this report), the liquid level above the nozzle at overblow when all four PJMs are operating is approximately,

$$
\left.z_{2_{0}} \approx\left\lfloor 162.5 \text { inches }-\left(\begin{array}{l}
\text { Simulant level } \\
\text { from Table 9.1 }
\end{array}\right)\right\rfloor 1+4 \frac{A_{\mathrm{PJM}}}{A_{\text {tank }}}\right)
$$

with $\mathrm{A}_{\mathrm{PJM}}=433.3 \mathrm{in}^{2}$ and $\mathrm{A}_{\text {tank }}=16575.8 \mathrm{in}^{2}$.

There are two primary, independent variables, the drive head $\left(P_{1}-P_{2}\right) / \rho g$ and hydrostatic head $z_{2 o}$. These are combined in Equation 8.1 as the excess head $\mathrm{u} / \rho g$. These two factors are plotted against each other in Figure 8.2 for all the PJM cycles examined. There is one point plotted for each cycle in each experiment listed in Table 8.1. During these experiments, we systematically varied the hydrostatic head over a range of about 85 inches. The drive pressure $\left(P_{1}\right)$ was not deliberately changed. The changes in the drive head that occurred were due to either fluctuations in $P_{1}$ or were incidental to changes in the simulant density. Because the drive pressure was not changed, $u / \rho g$ varied only about 100 inches (between 160 inches and 260 inches).

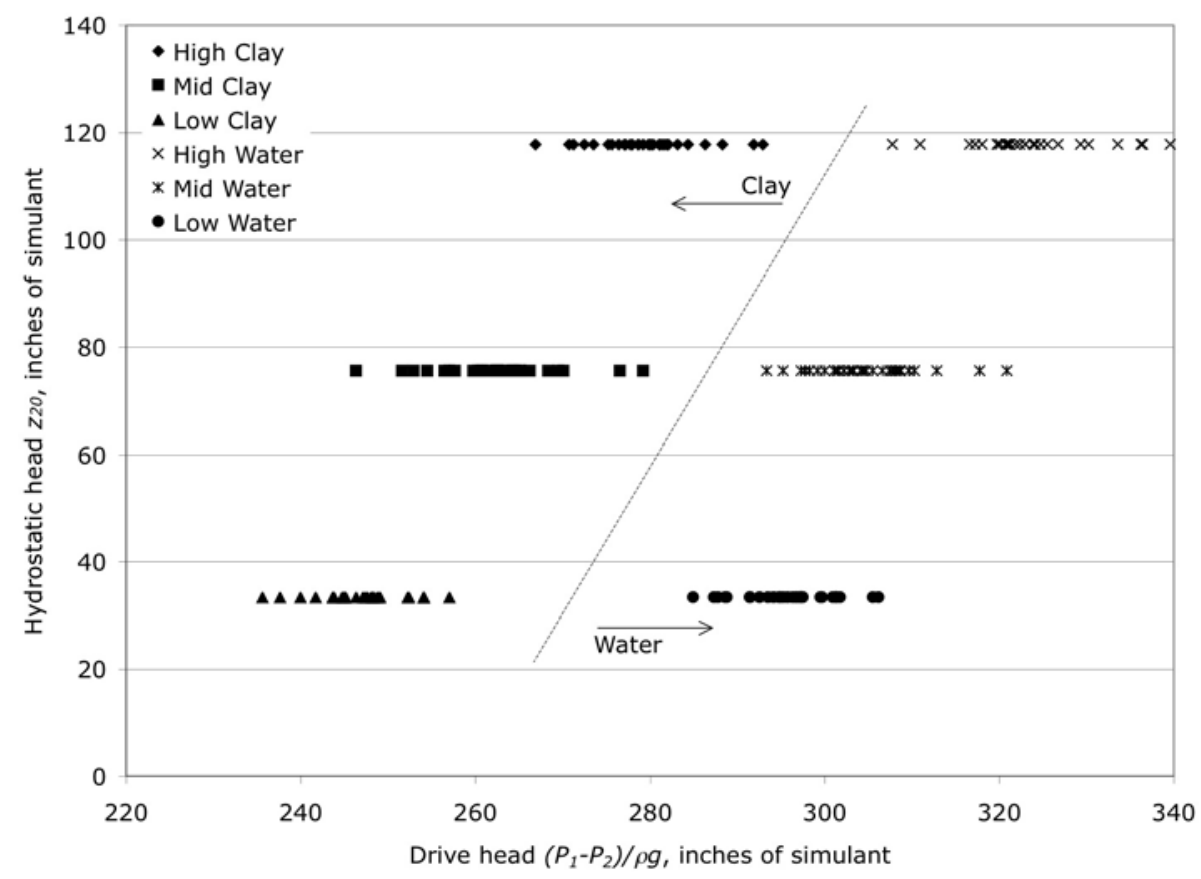

Figure 8.2. Factors that Influence the Time-to-Overblow

Equation 8.1 suggests that, for a given tank geometry and constant pressure inside the pulse tube during the drive phase, the time-to-overblow is a well-behaved function of the excess head $u / \rho g$, independent of the properties of the fluid, allowing all of the time-to-overblow data obtained from the same PJM configuration to be described by a single master curve. Plotted in Figure 8.3 are the time-tooverblow values versus $u / \rho g$ for all 181 PJM cycles of the experiments listed Table 8.1. A regression fit 
was used to estimate the parameters $C_{1}$ and $C_{2}$ (in Eq. 8.1) that provided the best fit to the overblow data, yielding:

$$
\begin{aligned}
& C_{1} \approx 4.01 \frac{\mathrm{sec}^{2}}{\mathrm{inch}} \pm 1.44 \\
& C_{2} \approx 1194 \mathrm{sec}^{2} \pm 167 .
\end{aligned}
$$

Here, the estimated uncertainties in the parameters are at the 95\% confidence level (the uncertainties are presented for information only). The resulting model is plotted with the data in Figure 8.3. Also plotted in the figure is the $95 \%$ confidence interval for predicting the observed overblow time for an arbitrary PJM cycle with the model. The model with the above parameters predicts the data to within $+/-0.72$ seconds (the uncertainty is for information only). The values of the constants, their uncertainties, and those of the time-to-overblow predictions are valid only for the equipment and range of $u / \rho g$ used in these tests.

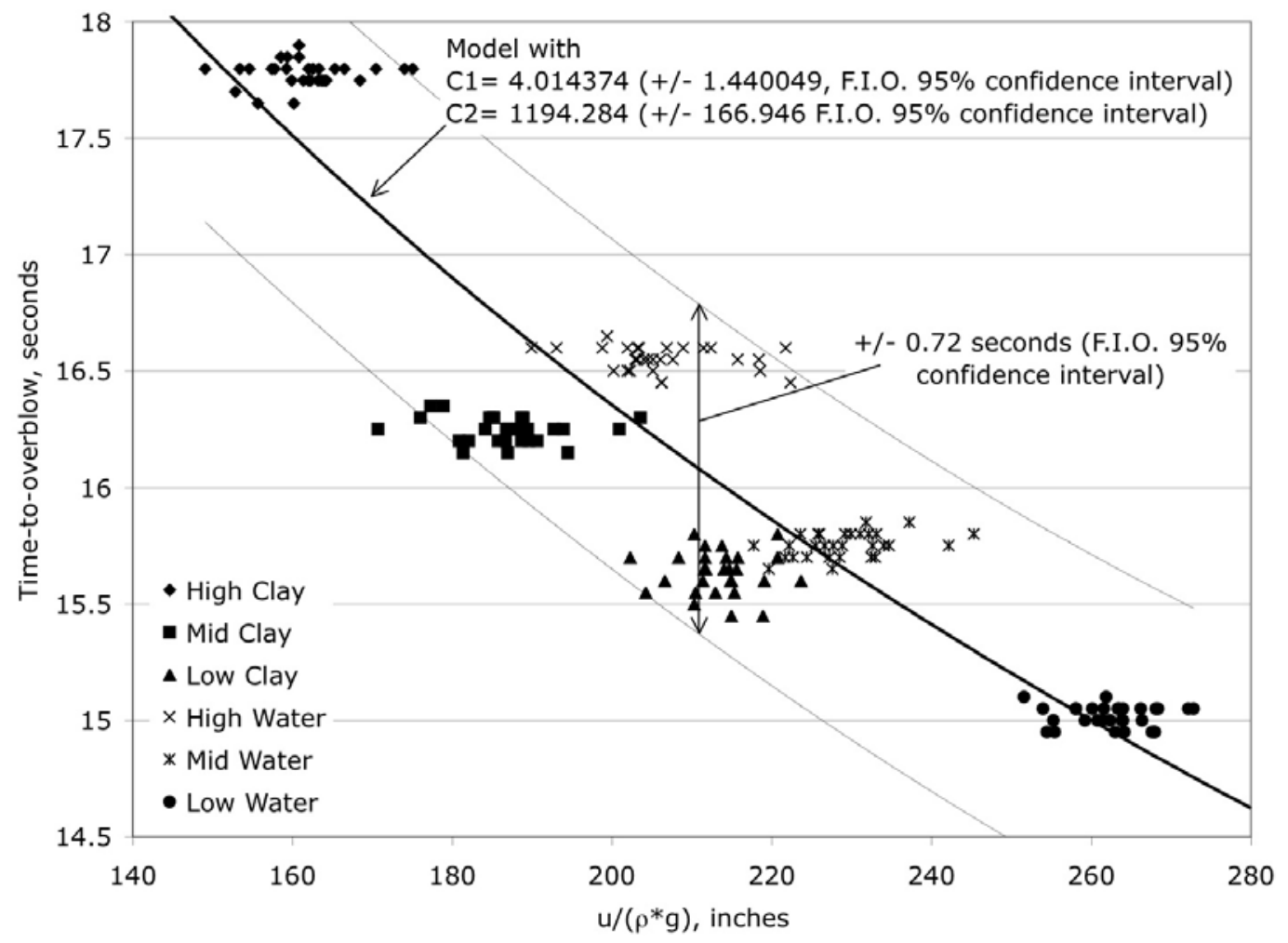

Figure 8.3. Time-to-Overblow Data in the 4PJM Configuration

The data in Figure 8.3 indicate that, provided the pressure inside the PJM is known, a single curve with independent variable $u / \rho g$ that depends only upon the tank and PJM geometry could be sufficient to correlate variations in the time-to-overblow with changes in simulant density and fill level in the vessel. The scatter in the experimental time-to-overblow versus the simple model prediction is attributed to the fact that in the real operation, the PJM pressure is not truly constant and acceleration effects do contribute to the time-to-overblow. 


\subsection{Time for Gravity Refill}

The time it takes a PJM to refill under gravity conditions is an important parameter, particularly during PJM operations at the elevated temperatures encountered in the ultra-filtration, feed preparation vessel where it is not possible to refill the PJMs using vacuum due to problems associated with flashing of the simulant at elevated temperatures and low pressures.

Gravity refill is compared to normal suction refill in Figure 9.1. In the figure the level in PJM\#A is plotted versus time (in units of 0.05 seconds) for the two refill methods, using clay at a level H/D of 0.8. At low levels the PJM fills at comparable rates in the two cases. However, with gravity refill the available liquid head in the tank limits the ultimate fill rate and level in the PJM. From the data in Figure 9.1 and the data in Table 9.1, it can be seen that it took about 20 seconds to fill the PJM to 88 inches under vacuum and it took $~ 45$ seconds to fill under gravity to the hydrostatic height of fluid in the PJM. It is also apparent in the figure that time at which the PJM is considered to be full in the gravity refill case is not sharply defined.

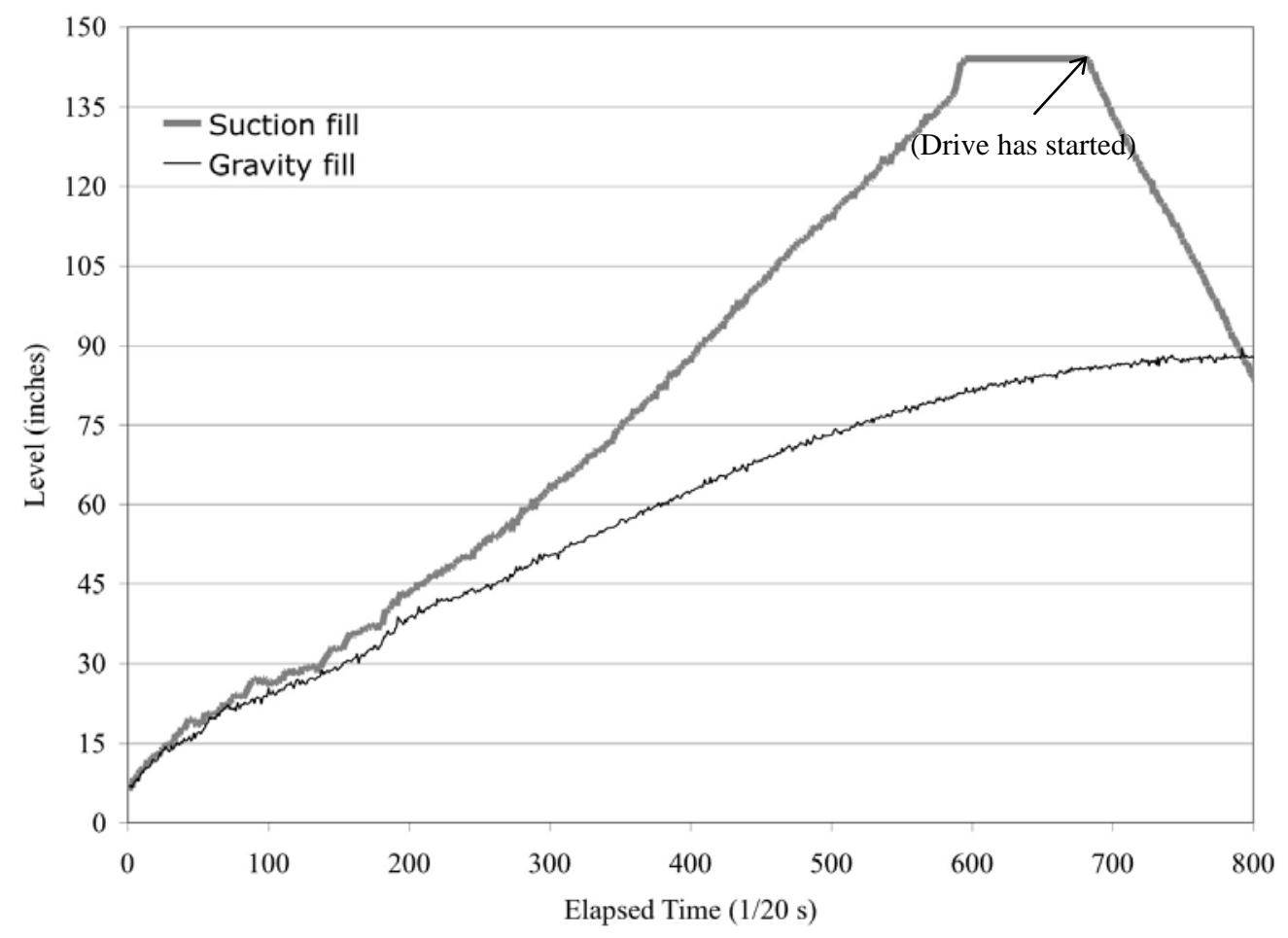

Figure 9.1. Typical PJM\#A Levels During Gravity Fill and Suction Fill Using Clay Simulant at the High Fill Level

The time it took the PJM to refill by gravity was determined as the time from the point when the drive phase ends to the point when the pulse tube is completely full. The time that the drive phase ends was determined from the pressure on the drive side of the JPP as shown in Figure 9.2. During the drive phase, the pressure on the drive side of the JPP remains constant until the drive valve is closed, after which the 
pressure rapidly decreases. Therefore, the end of the drive phase was determined from the time at which the drive pressure begins to rapidly decline, as indicated in the figure below.

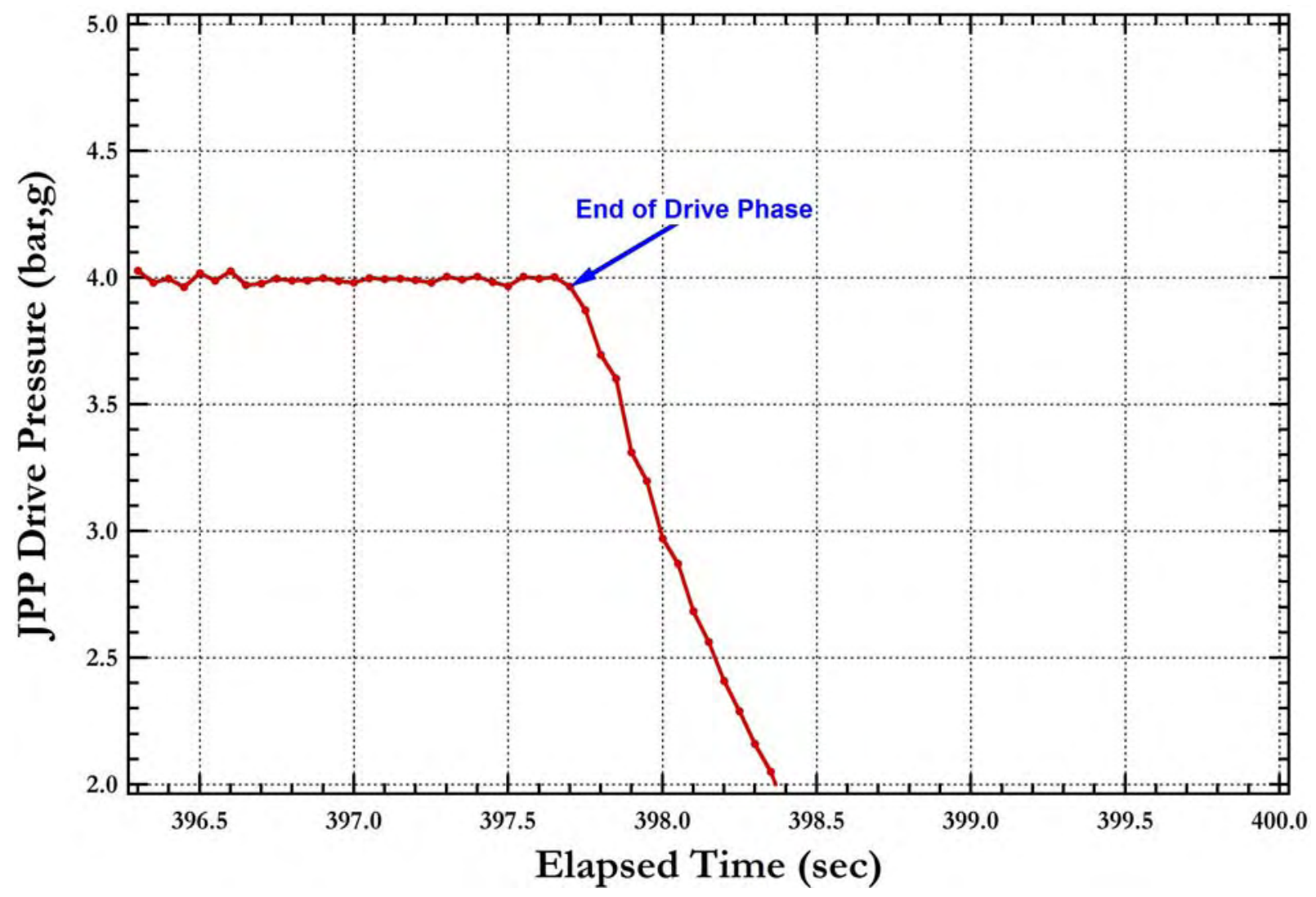

Figure 9.2. Typical PJM\#A Drive Pressure at the JPP Showing the End of the Drive Phase

During gravity refill, there is a significant length of time between when the drive valve is closed and when the PJM stops emptying and starts filling. During normal operation with suction fill, a vent phase occurs after the drive, typically lasting 2 to 4 seconds, after which the vacuum is applied. This tends to reduce the apparent duration of the fill phase down to the duration of applied vacuum. However, with gravity refill, the entire fill phase is conducted with the pulse tube venting. Under such conditions, it takes much longer for fluid in the pulse tube to stop descending and start rising.

The time the PJM was completely full was determined from the PJM level data. In the present analysis, the time the PJM was considered full was determined as the point when the PJM level was the same as the average level after the tube was full. Typical PJM level probe data during the gravity refill test is shown in Figure 9.3. It can be seen that unlike the JPP drive pressure data (see Figure 9.2) that showed a sharp transition once the drive valve was closed, the end of the refill phase was more difficult to determine from the PJM level data due to signal noise. The vertical lines in the figure show the typical uncertainty in determining the end time of the refill phase, which was roughly \pm two seconds (the uncertainty is presented For Information Only). 


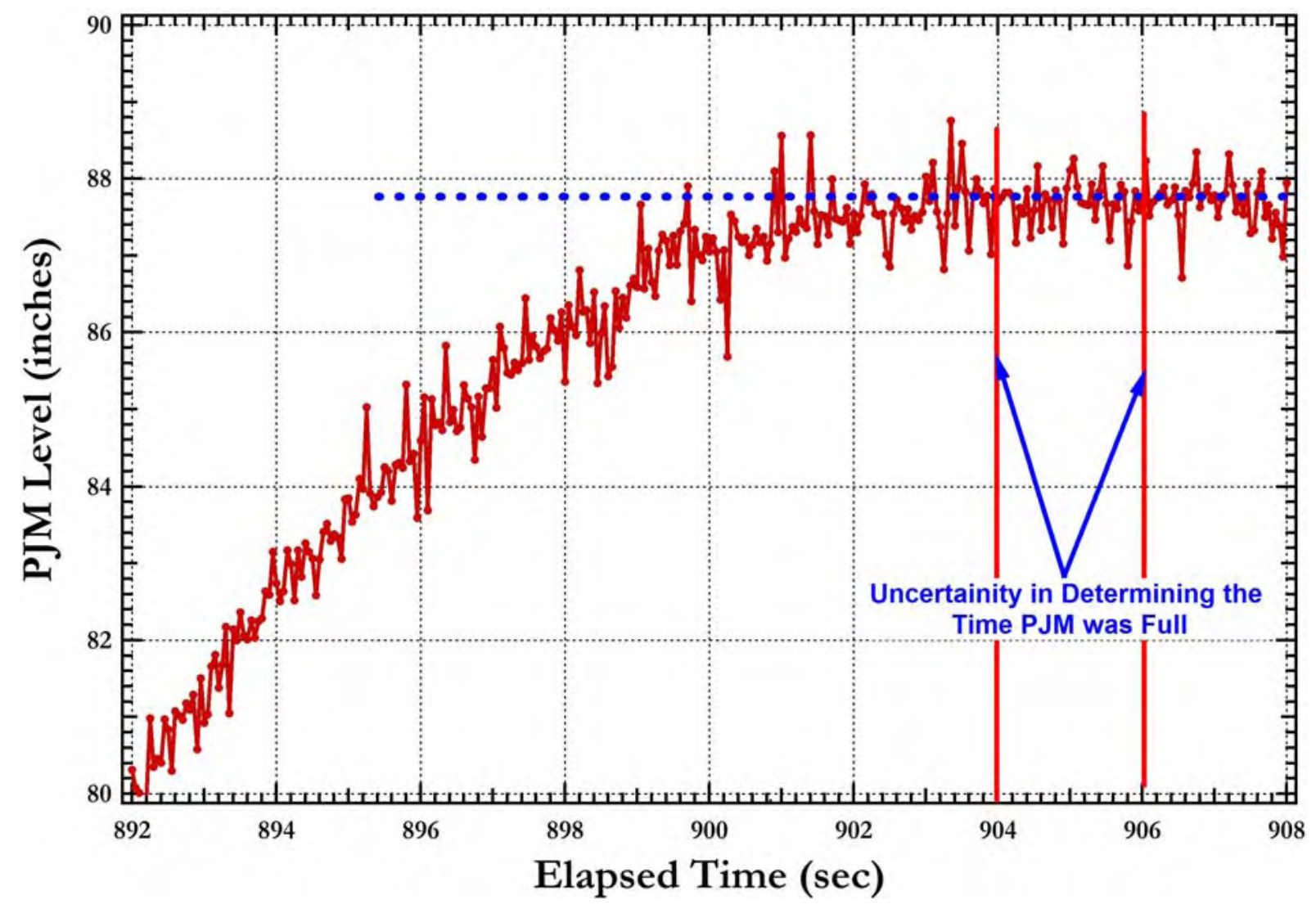

Figure 9.3. Typical PJM\#A Level Probe Data at the End of the Refill Phase

The time to refill the PJM was determined at the high fill level $(\mathrm{H} / \mathrm{D}=0.8)$ for both clay and water simulants. The gravity refill tests were performed using the ABB controller to operate PJM \#A (the other three PJMs were not operated). During these runs, the suction phase was turned off in the controller and PJM drive time of PJM \#A was adjusted such that the drive corresponded to approximately $85 \%$ of the PJM volume. The time to refill under gravity conditions for the clay and water simulants is shown in Table 9.1. Each data point in this table was an average of approximately 30 cycles of data. It can be seen that, contrary to expectation, the pulse tube fills faster with the clay simulant than with water. However, the difference in the refill times was not significant. This is probably because the major driving force for refill is the hydrostatic head outside the PJM, which is larger in the case of the clay simulant with a specific gravity of approximately 1.2 compared to water. Another possibility is the differences in the stroke lengths during the two tests. A comparison of the stroke lengths in clay and water simulants for a single cycle and multiple cycles is shown in Figure 9.4 and Figure 9.5. It can be seen that there is very little difference in the stroke lengths to contribute to the slight difference in the refill times.

Table 9.1. Gravity Refill Times for Clay and Water Simulants at an H/D = 0.8

\begin{tabular}{|l|c|c|}
\hline \multicolumn{1}{|c|}{ Simulant } & Time to Refill (sec) & Error (sec) \\
\hline Water & 49.1 & \pm 1.6 \\
\hline Clay & 46.1 & \pm 1.7 \\
\hline
\end{tabular}




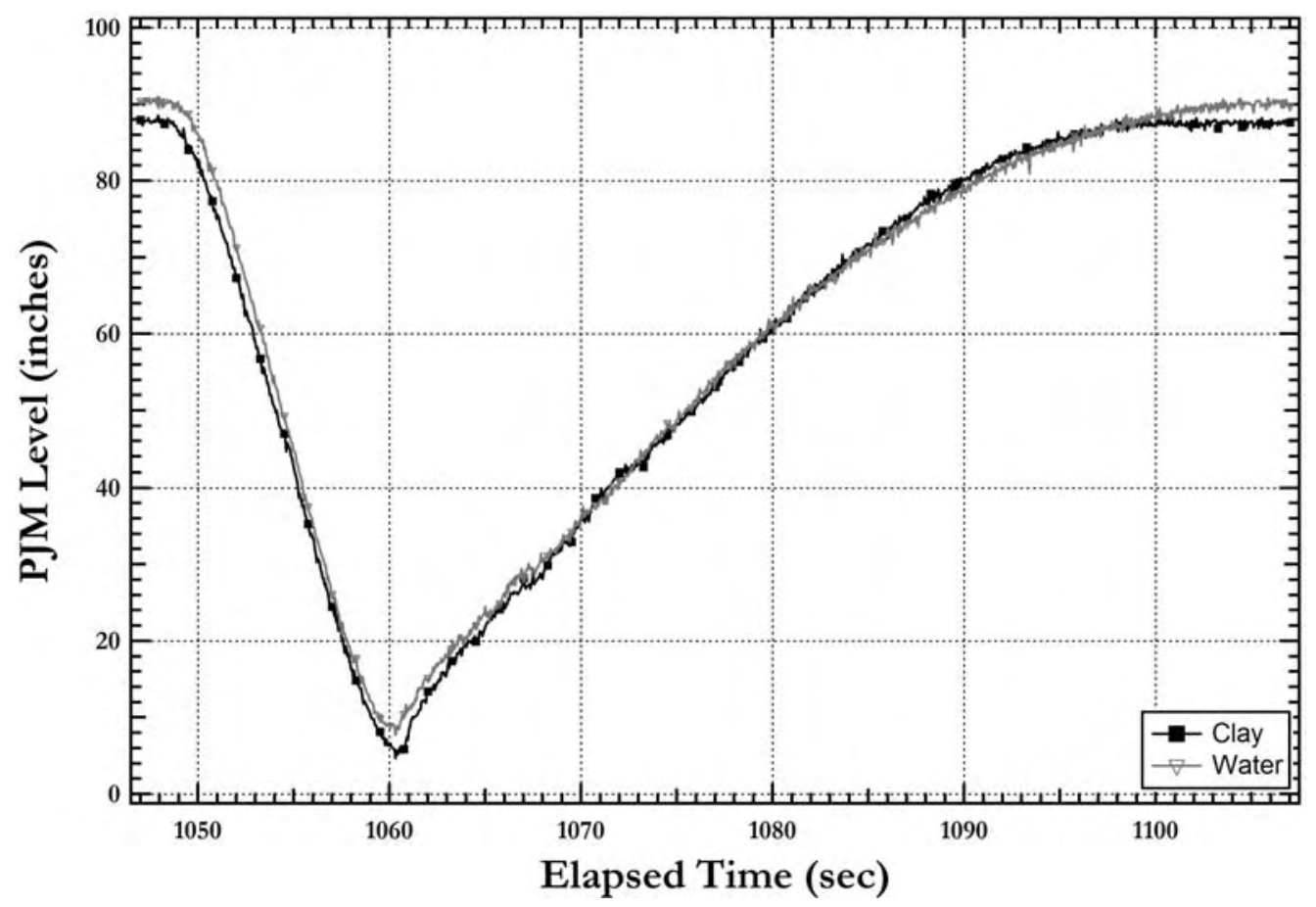

Figure 9.4. Comparison of a Single Cycle of PJM Level Data in the Gravity Refill Tests with Clay and Water Simulants

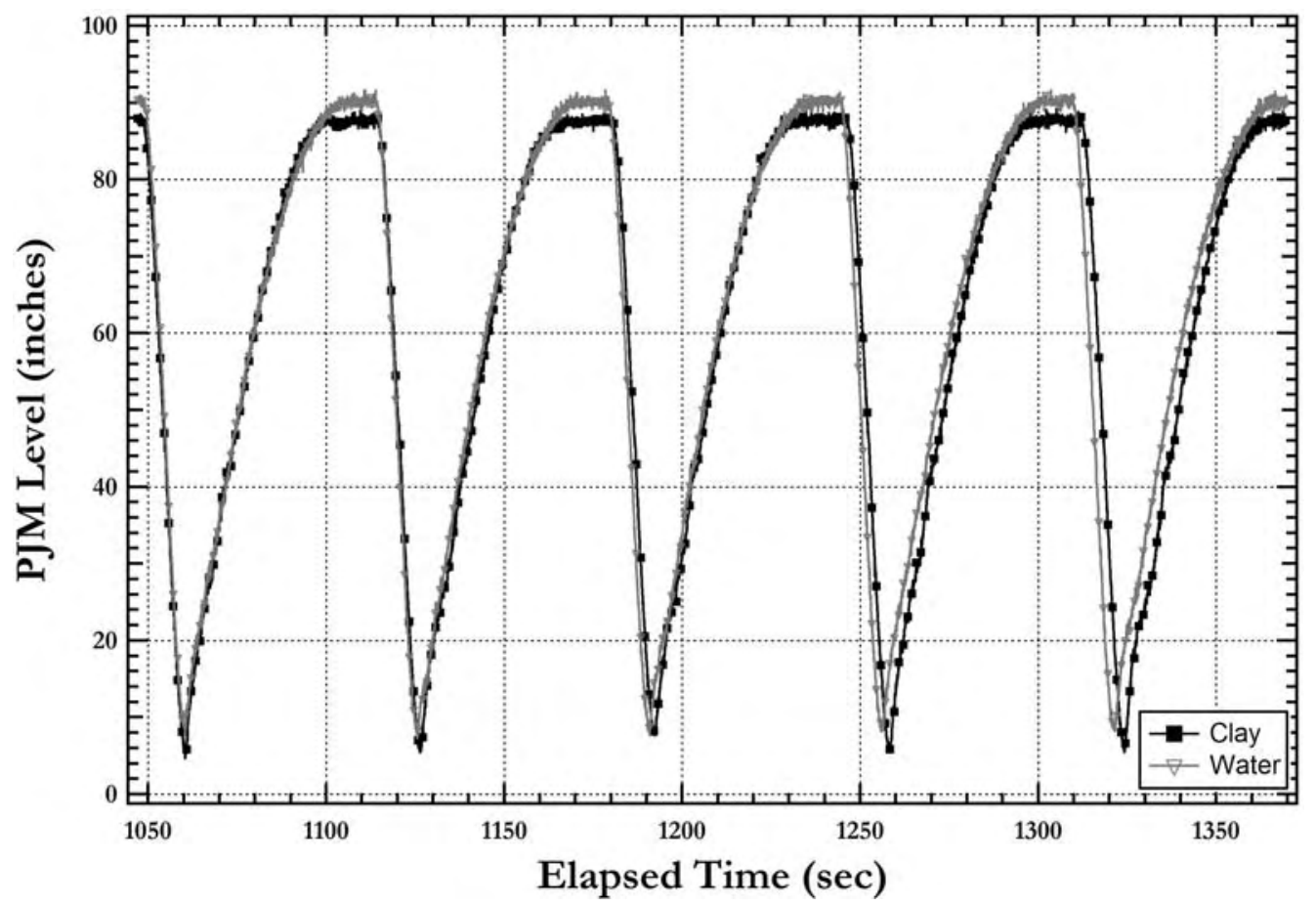

Figure 9.5. Comparison of a Single Cycle of PJM Level Data in the Gravity Refill Tests with Clay and Water Simulants 


\subsection{Effect of Scan Time}

The rate at which the PJM controller samples the signal from the pressure transmitter is an important parameter that controls the controller performance. Scanning at a slow speed reduces the processing requirements for the controller but could also result in the controller missing the true event of a DOB. On the other hand, increasing the scan rate could result in an increased likelihood of an event being observed but at a significant increase in the processing speeds/capacity of the controlling software.

\subsection{Experimental Conditions}

The effect of the scan rate on the ABB and Triconex controllers' ability to detect overblows was evaluated at four different scan times of 50, 100, 150, and $250 \mathrm{~ms}$. These scan times correspond to a scan rate of 20,10,6.7, and 4 samples per second (or Hz). All tests to determine the scan rate effect were performed with the water simulant at a high fill level $(\mathrm{h} / \mathrm{d}=0.8)$. In addition, during each scan rate run, the four PJMs were operated in such a manner that each cycle started with all four PJMs completely full and PJM\#A overblows at the end of the drive phase for a minimum of 3 seconds. Finally, for each scan rate run, a minimum of 20 cycles of data were collected.

\subsection{Results}

Figure 10.1 shows the effect of scan time on the performance of the ABB controller in terms of the true and noise peaks for DOB detection. Similarly, the effect of scan time on the Triconex controller is shown in Figure 10.2. In these figures, the shaded bars represent the true overblow confidence peak while the unfilled bars represent the maximum noise peak observed during the cycle prior to the overblow.

\subsection{Discussion}

It can be seen in Figure 10.1 and Figure 10.2 that, for both the ABB controller and the Triconex controller, as the scan time decreases from $250 \mathrm{~ms}$ to $50 \mathrm{~ms}$, the magnitude of the true overblow peak shows a far greater increase than the noise peak. In both figures, the open bars represent the maximum noise peak during the cycle prior to an overblow and the filled bars represent the confidence peak during a drive overblow. From the data in the figures, it is clear that the lower the scan time (or higher the scan rate), the better the controller's ability to detect overblows. Also, it appears from the data in the figures that the scan time has a slightly more pronounced effect on the ABB controller than the Triconex controller. This difference may be associated with the slight differences in the algorithm and to the differences in the types of hardware (signal conditioning boards, filters, etc.) used by the two controllers.

Despite the significant improvement in both the ABB and Triconex controller performance at faster scan rates, care should be taken to extrapolate from the data presented in this section because an insufficient number of cycles of data were taken. Since, during all of the controller testing performed during this period of testing, raw data from the pressure transmitters was recorded by the PNNL DAS at a sampling rate of $100 \mathrm{~Hz}$, it is recommended that these data be used to simulate the different sampling rates by the controller to obtain sufficient data to make a statistical determination of the effect scan time. 

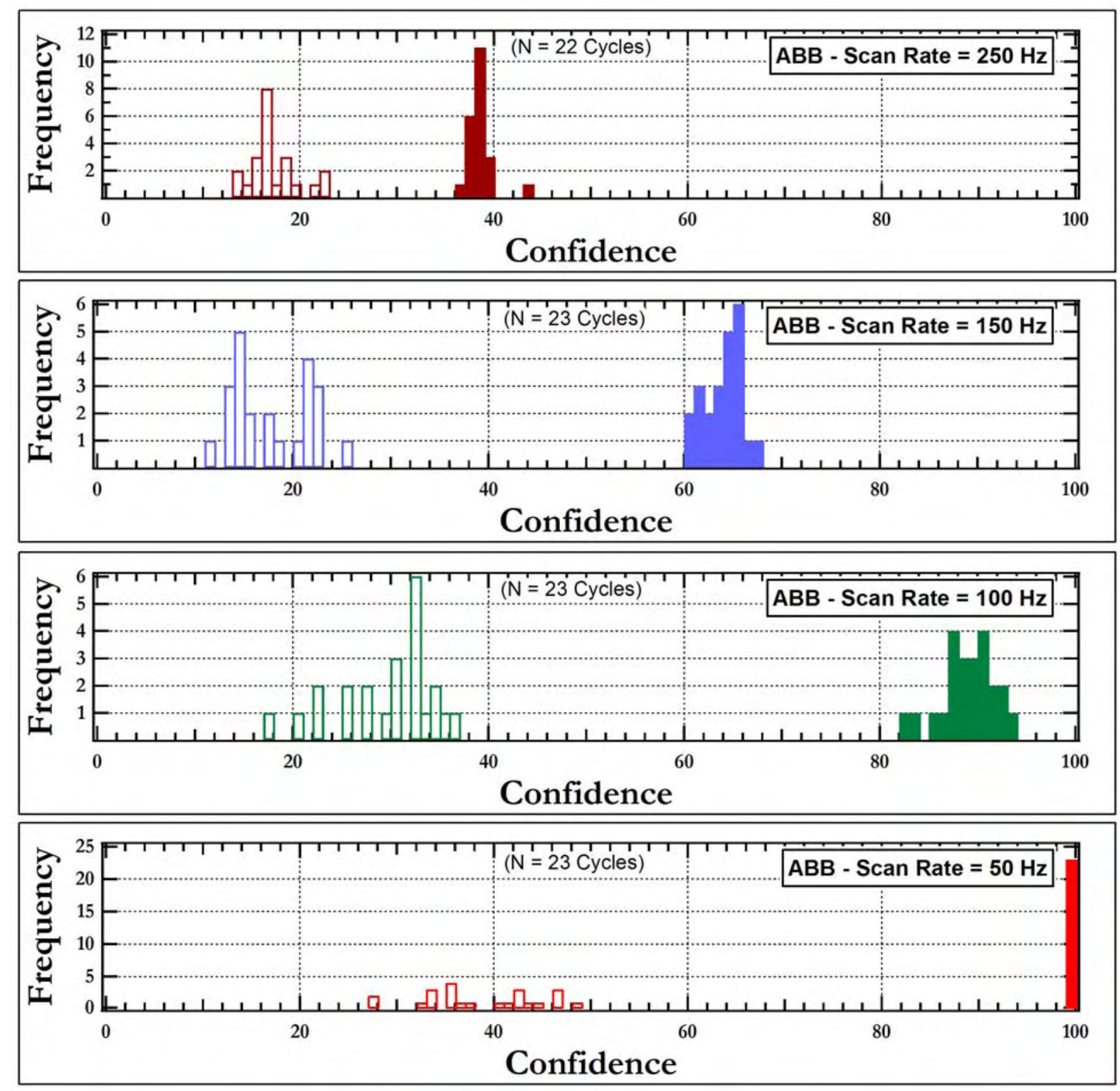

Figure 10.1. Effect of Scan Time on ABB Controller's Ability to Detect a Drive Overblow. The area under each distribution equals the total number of PJM cycles sampled, $\mathrm{N}$ 

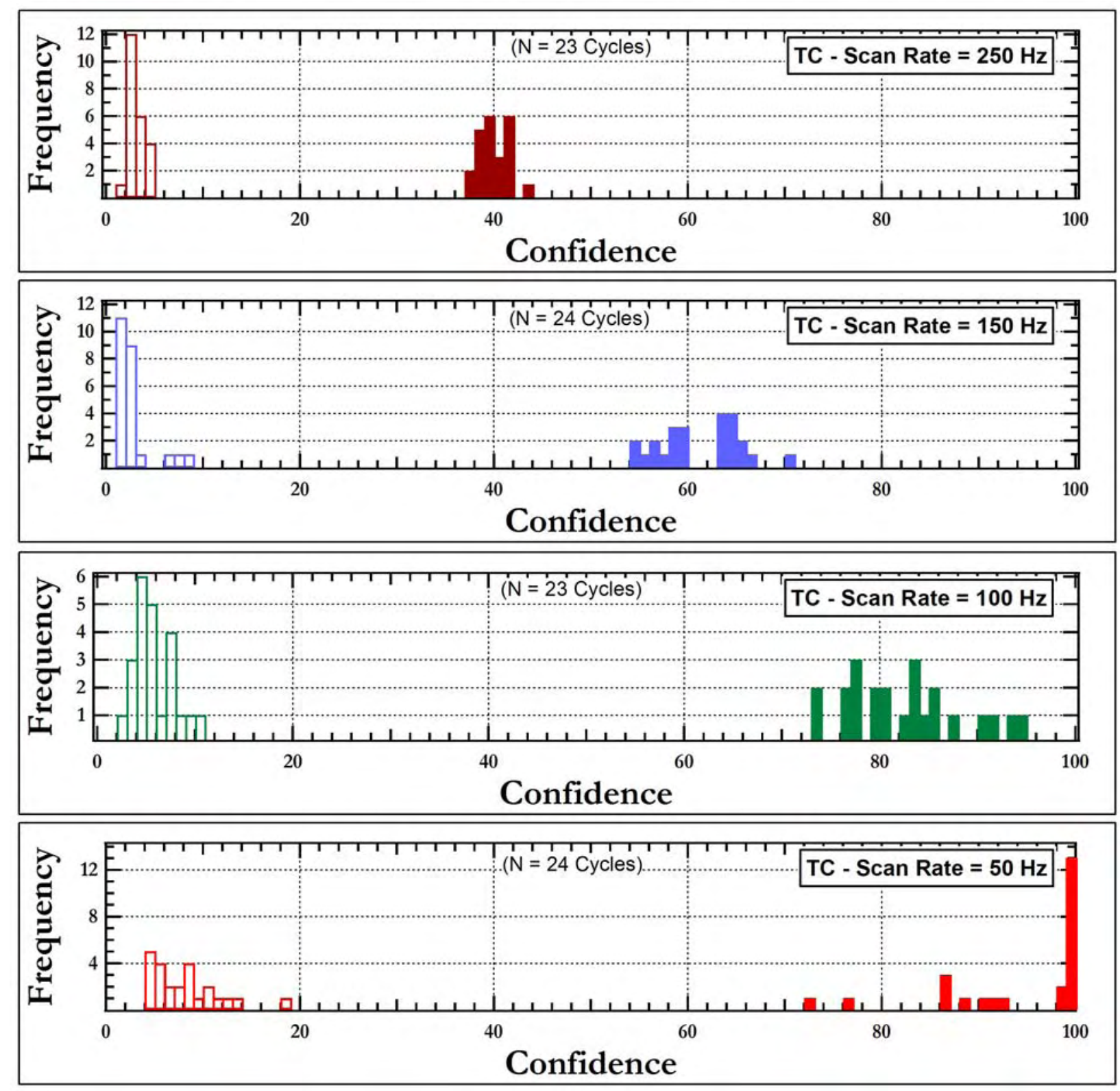

Figure 10.2. Effect of Scan Time on Triconex Controller's Ability to Detect a Drive Overblow. The area under each distribution equals the total number of PJM cycles sampled, $\mathrm{N}$ 



\subsection{Conclusions}

The results of the testing indicate drive overblow detection is possible with both the ABB and Triconex controllers that only under conditions when CVF can be detected at all times and under all circumstances. Under such conditions, the distributions of confidence levels during a drive overblow were well separated from the distribution of noise. Therefore it should be possible to set a detection threshold for overblows that gives a high probability of detection (>99\%) and a low probability of false alarms $(<1 \%)$.

Under conditions where absolute CVF detection cannot be guaranteed, both BNI controllers are not capable of detecting drive overblows. Both the ABB and Triconex controllers failed to reliably detect overblows under the scenario where a PJM overblow occurred because the pulse tube was not completely full before the start of the drive phase. Under such conditions the peak amplitudes of the flush line confidence levels were small and their distribution significantly overlapped the distribution of noise peaks. Thus the overblow signal was often indistinguishable from normal operating noise. Highly reliable detection of the charge vessel full condition is required in order to operate the PJMs with a very low probability of an overblow occurring.

Our overblow experiments were conducted at a single nominal drive pressure (which corresponds to a single nominal drive velocity). The repeatability and reliability of overblow detection at other drive pressures is unknown.

In these tests, both controllers reliably detected the CVF condition during normal PJM operation. It was demonstrated that a detection threshold for CVF could be set that would give a 99\% or higher probability of detection of CVF at approximately the correct point in time and a $1 \%$ percent or less probability of a false CVF detection signal before the PJM is truly full.

Although the results of the present study indicate reliable CVF detection under normal PJM operation, it should be noted that the CVF results obtained in the present study may be more positively biased than the signals that will be observed in the actual plant. This was an unavoidable consequence of including the level probe to measure the level of the slurry inside the PJM, which reduced the effective diameter of the airline at the top of the PJM by 0.75 inches. For a 23.5 inch pulse tube diameter with a Schedule 40 air-link pipe, this results in a 16\% increase in the area ratio of the PJM to the air-link line. The net result is that the observed controller confidence levels, particularly for CVF, being stronger in the present study that those which will be observed in the real plant.

In the experiments to test the CVF detection ability, the PJMs were always filled completely. We did not assess the probability of a false detection of CVF when in fact the PJM did not fill completely (as could have been caused by an obstruction to the PJM nozzle). We did not evaluate different scenarios (other than varying the simulant type and tank fill level) and did not attempt to defeat the CVF algorithm.

We demonstrated that variations in the time-to-overblow with tank level and simulant density could be described by a relationship developed from the Bernoulli equation. So, time-to-overblow exhibited the expected dependence on back pressure at the nozzles due to the liquid head in the tank. The expression worked well for the current configuration with 4 inch diameter nozzles, as it did in earlier work with 2 inch nozzles. 
The Bernoulli-based expression could conceivably be used to describe how time-to-overblow varies with PJM headspace or drive pressure. As all of the experiments were conducted at one nominal drive pressure, we did not test how well the expression described time-to-overblow for various drive pressures.

The time required to refill the PJMs by gravity was estimated with both clay and water simulants at the high liquid level. The average refill times were $46.1 \mathrm{sec}$ for clay and $48.1 \mathrm{sec}$ for water to within an uncertainty of about $+/-2$ seconds. The higher hydrostatic head in the tank for the clay simulant probably caused the shorter fill time for clay.

The effect of scan rate on the ability to detect overblows was tested with both controllers. In general, the amplitudes of the true overblow peaks, and the separations between the distributions of true and false peaks increased with increasing scan rate. Changing the scan rate had a greater effect on the ABB controller than on the Triconex. For both controllers, the separation between the true and false peak distributions at a 50ms scan time was only slightly better (wider) than the separation at a 100ms scan time.

Despite the significant improvement in both the ABB and Triconex controller performance at faster scan rates, care should be taken when extrapolating from the data presented because an insufficient number of cycles of data were taken. The study of the effect of scan rate on overblow detection relied on only 20 PJM cycles at each scan rate. We recommend that the pressure data we acquired at $100 \mathrm{~Hz}$ during all of the other experiments be used to simulate confidence levels at various scan rates. The optimal scan rate can be estimated more precisely from such simulated controller responses.

The performance of the ABB and Triconex controllers was evaluated at three different conditions of vessel fill and with two different simulant rheologies. In addition, for each test condition, a minimum of 100 and a maximum of over 300 PJM cycles of data were obtained to assess the controllers' ability to detect CVF and DOB conditions. These data were statistically analyzed to illustrate the repeatability of controller-calculated confidence levels over the length of time it took to run that many cycles. Despite the broad range of conditions used to assess the controllers' performance, these testing conditions are somewhat idealized in that they do not represent the long-term variability in the process and process measuring equipment. For example, the present study does not address changes in the instrument and equipment performance over time, nor does it address the effects of mixing inhomogenities within the vessel, the influence of slurry build up in the airlines to the PJMs, etc. The variability in the process and process measuring equipment or system in the long term were beyond the scope of the present work and cannot be addressed much beyond the test conditions and duration of this study. In addition, we cannot draw conclusions about reliability under unforeseen and unexamined contingencies. Therefore, any extrapolation of the data above and beyond the scope of the present work should be done with extreme caution. 


\subsection{References}

Bontha JR, DE Kurath, AP Poloski, WC Buchmiller, WH Combs, ED Johnson, HC Webber and KL Herman. 2007. Pulse Jet Mixer Controller and Instrumentation Testing. WTP-RPT-146 Rev. 0 (PNWD-3828), Battelle, Pacific Northwest Division, Richland, Washington.

Bontha JR, JM Bates, CW Enderlin, MG Dodson. 2003. Large Tank Experimental Data for Validation of the Fluent CFD Model of Pulsed Jet Mixers. WTP-RPT-081 Rev. 0 (PNWD-3303), Battelle, Pacific Northwest Division, Richland, Washington.

Bontha JR, LK Jagoda, CW Stewart, CD Johnson, DE Kurath, KS Koschik, PA Meyer, DL Lessor, ST Arm, F Nigl, CE Guzman-Leong, RL Russell, MS Fountain, GL Smith, M Friedrich, W Yantasee, SA Hartley, and ST Yokuda. 2005. Technical Basis for Predicting Mixing and Flammable Gas Behavior in the Ultrafiltration Feed Process and High-Level Waste Lag Storage Vessels with Non-Newtonian Slurries. WTP-RPT-132 Rev. 0 (PNWD-3676), Battelle, Pacific Northwest Division, Richland, Washington.

Dean A. 2004. PRESCON Control Algorithm Design Guide. 24590-QL-POA-MPEO-00002-14-01 Rev. 0.0, United Kingdom Atomic Energy Authority, Manor Court, Chilton, Didcot, United Kingdom.

Pfund DM, AW Baumann, JR Bontha, DE Kurath, TE Michener, M Hoza, F Nigl, WH Combs, ST Yokuda, JA Fort, RJ Leigh, OP Bredt, and EC Golovich. 2008. Pulse Jet Mixer Overblow Testing for Assessment of Loadings During Multiple Overblows. WTP-RPT-150 Rev. 0 (PNNL-17231), Pacific Northwest National Laboratory, Richland Washington.

Poloski AP, PA Meyer, LK Jagoda, and PR Hrma. 2004. Non-Newtonian Slurry Simulant Development and Selection for Pulse Jet Mixer Testing. WTP-RPT-111 Rev. 0 (PNWD-3495), Battelle, Pacific Northwest Division, Richland, Washington.

Poloski AP, ST Arm, OP Bredt, TB Calloway, Y Onishi, RA Peterson, GL Smith, and HD Smith. 2006. Final Report: Technical Basis for HLW Vitrification Stream Physical and Rheological Property Bounding Conditions. WTP-RPT-112 Rev. 0 (PNWD-3675), Battelle, Pacific Northwest Division, Richland, Washington. 

Appendix A

\section{Testing Log Run}





\section{Appendix A: Testing Log Run}

\begin{tabular}{|c|c|c|c|c|c|c|c|c|c|}
\hline Run Designation & DAS-1 Files & Start Time & End Time & Type & $\begin{array}{r}\text { Sin } \\
\text { Ht. fron } \\
\text { Rim }\end{array}$ & H/D & $\mathrm{T}_{\mathrm{ys}}(\mathrm{Pa})$ & $\begin{array}{c}\text { LRB } \\
59943 \\
\text { Pages }\end{array}$ & $\begin{array}{c}\text { Test } \\
\text { Instruction }\end{array}$ \\
\hline \multicolumn{10}{|c|}{ CLAY TESTING } \\
\hline \multicolumn{10}{|c|}{ ABB High Level } \\
\hline ABB HI: DOB - 4 PJM (300 Cycles) & 080516_ABB_4PJM_DOB & May 16, 2008 10:05 AM & May 16, 2008 02:02 PM & Clay & 55.8 & 0.80 & 32.82 & $90-91$ & TI-RPP-WTP-632 \\
\hline ABB HI: DOB - PJM A (300 Cycles) & 080516_ABB_PJMA_DOB & May 16, 2008 03:05 PM & May 16, 2008 07:57 PM & Clay & 55.8 & 0.80 & 32.82 & 92 & TI-RPP-WTP-632 \\
\hline ABB HI: CVF (100 Cycles) & 080519_ABB_4PJM_CVF & May 19, 2008 02:15 PM & May 19, 2008 04:12 PM & Clay & 55 & 0.81 & 30.9 & 95 & TI-RPP-WTP-632 \\
\hline ABB HI: Gravity Refill & 080521_Gravity_Refill & May 21, 2008 09:46 AM & May 21, 2008 10:36 AM & Clay & 55.5 & 0.80 & 30.9 & 105 & TI-RPP-WTP-635 \\
\hline \multicolumn{10}{|c|}{ Triconex High Level } \\
\hline TRI HI: DOB - 4 PJM (300 Cycles) & 080520_TC_4PJM_DOB & May 20, 2008 10:03 AM & May 20, 2008 02:34 PM & Clay & 55.3 & 0.80 & 30.9 & $99-101$ & TI-RPP-WTP-632 \\
\hline TRI HI: DOB - PJM A (300 Cycles) & 080520_TC_PJMA_DOB & May 20, 2008 03:13 PM & Not Available & Clay & 55.3 & 0.80 & 30.9 & 104 & TI-RPP-WTP-634 \\
\hline TRI HI: CVF (100 Cycles) & 080519_TC_4PJM_CVF & May 19, 2008 06:21 PM & May 19, 2008 08:09 PM & Clay & 55 & 0.81 & 30.9 & $96-98$ & TI-RPP-WTP-632 \\
\hline \multicolumn{10}{|c|}{ Drop Tank Level } \\
\hline \multicolumn{10}{|c|}{ ABB Mid-Level } \\
\hline ABB MID: DOB - 4 PJM (300 Cycles) & 080521_ABB_4PJM_DOB & May 21, 2008 12:18 PM & May 21, 2008 04:26 PM & Clay & 94 & 0.55 & 30.9 & $106-107$ & TI-RPP-WTP-634 \\
\hline ABB MID: DOB - PJM A (300 Cycles) & 080522_ABB_PJMA_DOB & May 22, 2008 08:50 AM & May 22, 2008 01:43 PM & Clay & 94.4 & 0.55 & 30.42 & 108 & TI-RPP-WTP-634 \\
\hline ABB MID: CVF (100 Cycles) & 080521_ABB_4PJM_CVF & May 21, 2008 05:00 PM & May 21, 2008 06:49 PM & Clay & 94 & 0.55 & 30.9 & 107 & TI-RPP-WTP-634 \\
\hline \multicolumn{10}{|c|}{ Triconex Mid-Level } \\
\hline TRI MID: DOB - 4 PJM (300 Cycles) & 080522_TC_4PJM_DOB & May 22, 2008 03:13 PM & May 22, 2008 07:25 PM & Clay & 94.4 & 0.55 & 30.42 & 109 & TI-RPP-WTP-634 \\
\hline TRI MID: DOB - PJM A (300 Cycles) & 080523_TC_1PJM_DOB & May 23, 2008 08:28 AM & May 23, 2008 01:11 PM & Clay & 94.8 & 0.55 & 30.42 & 110 & TI-RPP-WTP-634 \\
\hline TRI MID: CVF (100 Cycles) & 080523_TC_4PJM_CVF & May 23, 2008 01:42 PM & May 23, 2008 03:30 PM & Clay & 94.8 & 0.55 & 30.42 & 110 & TI-RPP-WTP-634 \\
\hline \multicolumn{9}{|c|}{ ABB Low Level } & \\
\hline ABB LOW: DOB - PJM A (300 Cycles) & 080527_ABB_PJMA_DOB & May 27, 2008 09:59 AM & May 27, 2008 03:04 PM & Clay & 132 & 0.30 & 29.87 & 113 & TI-RPP-WTP-634 \\
\hline ABB LOW: CVF (100 Cycles) & 080527_ABB_CVF & May 27, 2008 03:49 PM & May 27, 2008 08:21 PM & Clay & 132 & 0.30 & 29.87 & $113-114$ & TI-RPP-WTP-634 \\
\hline \multicolumn{10}{|c|}{ Triconex Low Level } \\
\hline TRI LOW: DOB - PJM A (300 Cycles) & 080528_TC_PJMA_DOB & May 28, 2008 08:50 AM & May 28, 2008 01:42 PM & Clay & 131.6 & 0.30 & 29.87 & 115 & TI-RPP-WTP-634 \\
\hline TRI LOW: CVF (300 Cycles) & 080528_TC_4PJM_CVF & May 28, 2008 03:22 PM & May 28, 2008 09:51 PM & Clay & 131.6 & 0.30 & 29.87 & 116 & TI-RPP-WTP-634 \\
\hline
\end{tabular}




\section{Appendix A: Testing Log Run}

\begin{tabular}{|c|c|c|c|c|c|c|c|c|c|}
\hline Run Designation & DAS-1 Files & Start Time & End Time & Type & $\begin{array}{c}\text { Sir } \\
\text { Ht. } \\
\text { from } \\
\text { Rim }\end{array}$ & $H / D$ & $\mathrm{~T}_{\mathrm{ys}}(\mathrm{Pa})$ & $\begin{array}{c}\text { LRB } \\
59943 \\
\text { Pages }\end{array}$ & $\begin{array}{c}\text { Test } \\
\text { Instruction }\end{array}$ \\
\hline \multicolumn{10}{|c|}{ WATER TESTING } \\
\hline \multicolumn{10}{|c|}{ ABB High Level } \\
\hline ABB HI: DOB - 4 PJM (300 Cycles) & 080603_ABB_4PJM_DOB & June 03, 2008 08:45 AM & June 03, 2008 12:34 PM & Water & 55 & 0.81 & N/A & 126 & TI-RPP-WTP-638 \\
\hline ABB HI: DOB - PJM A (300 Cycles) & 080604_ABB_PJMA_DOB & June 04, 2008 08:52 AM & June 04, 2008 01:26 PM & Water & 55.1 & 0.80 & N/A & 128 & TI-RPP-WTP-638 \\
\hline ABB HI: CVF (100 Cycles) & 080603_ABB_4PJM_CVF & June 03, 2008 01:13 PM & June 03, 2008 03:01 PM & Water & 55 & 0.81 & N/A & 127 & TI-RPP-WTP-638 \\
\hline ABB HI: Gravity Refill & 080606_Gravity_Refill & June 06, 2008 02:42 PM & June 06, 2008 03:24 PM & Water & 55.2 & 0.80 & N/A & 138 & TI-RPP-WTP-635 \\
\hline ABB HI: Scan Rate $250 \mathrm{~ms}$ & 080605_ABB_250_SR & June 05, 2008 04:41 PM & June 05, 2008 05:05 PM & Water & 55.1 & 0.80 & N/A & $134-135$ & TI-RPP-WTP-639 \\
\hline ABB HI: Scan Rate 150ms & 080605_ABB_150_SR & June 05, 2008 05:10 PM & June 05, 2008 05:33 PM & Water & 55.1 & 0.80 & N/A & $134-135$ & TI-RPP-WTP-639 \\
\hline ABB HI: Scan Rate $100 \mathrm{~ms}$ & 080605_ABB_100_SR & June 05, 2008 05:37 PM & June 05, 2008 06:00 PM & Water & 55.1 & 0.80 & N/A & $134-135$ & TI-RPP-WTP-639 \\
\hline ABB HI: Scan Rate $50 \mathrm{~ms}$ & 080605_ABB_050_SR & June 05, 2008 06:03 PM & June 05, 2008 06:26 PM & Water & 55.1 & 0.80 & $\mathrm{~N} / \mathrm{A}$ & $134-135$ & TI-RPP-WTP-639 \\
\hline \multicolumn{10}{|c|}{ Triconex High Level } \\
\hline TRI HI: DOB - 4 PJM (300 Cycles) & 080606_TK_4PJM_DOB & June 06,2008 08:33 AM & June 06, 2008 12:35 PM & Water & 55.2 & 0.80 & N/A & 136 & TI-RPP-WTP-638 \\
\hline TRI HI: DOB - PJM A (300 Cycles) & 080605_TC_PJMA_DOB & June 05, 2008 08:44 AM & June 05, 2008 01:18 PM & Water & 55.1 & 0.80 & N/A & $130-131$ & TI-RPP-WTP-638 \\
\hline TRI HI: CVF (100 Cycles) & 080604_TC_4PJM_CVF & June 04, 2008 02:31 PM & June 04, 2008 04:13 PM & Water & 55.1 & 0.80 & N/A & 129 & TI-RPP-WTP-638 \\
\hline TRI HI: Scan Rate $250 \mathrm{~ms}$ & 080605_TC_250_SR & June 05, 2008 01:46 PM & June 05, 2008 02:09 PM & Water & 55.1 & 0.80 & N/A & $131-132$ & TI-RPP-WTP-639 \\
\hline TRI HI: Scan Rate $150 \mathrm{~ms}$ & 080605_TC_150_SR & June 05, 2008 02:13 PM & June 05, 2008 02:37 PM & Water & 55.1 & 0.80 & N/A & $131-132$ & TI-RPP-WTP-639 \\
\hline TRI HI: Scan Rate $100 \mathrm{~ms}$ & 080605_TC_100_SR & June 05, 2008 02:40 PM & June 05, 2008 03:03 PM & Water & 55.1 & 0.80 & $\mathrm{~N} / \mathrm{A}$ & $131-132$ & TI-RPP-WTP-639 \\
\hline TRI HI: Scan Rate $50 \mathrm{~ms}$ & 080605_TC_050_SR & June 05, 2008 03:05 PM & June 05, 2008 03:27 PM & Water & 55.1 & 0.80 & $\mathrm{~N} / \mathrm{A}$ & $131-132$ & TI-RPP-WTP-639 \\
\hline \multicolumn{10}{|c|}{ Drop Tank Level } \\
\hline \multicolumn{10}{|c|}{ ABB Mid-Level } \\
\hline ABB MID: DOB - 4 PJM (300 Cycles) & 080609_ABB_4PJM_DOB & June 09, 2008 08:41 AM & June 09, 2008 12:40 PM & Water & 94 & 0.55 & $\mathrm{~N} / \mathrm{A}$ & 139 & TI-RPP-WTP-638 \\
\hline ABB MID: DOB - PJM A (300 Cycles) & 080610_ABB_PJMA_DOB & June 10, 2008 08:25 AM & June 10, 2008 01:10 PM & Water & 94 & 0.55 & N/A & $141-142$ & TI-RPP-WTP-638 \\
\hline ABB MID: CVF (100 Cycles) & 080609_ABB_4PJM_CVF & June 09, 2008 01:21 PM & June 09, $200803: 10$ PM & Water & 94 & 0.55 & $\mathrm{~N} / \mathrm{A}$ & 140 & TI-RPP-WTP-638 \\
\hline \multicolumn{10}{|c|}{ ABB Mid-Level } \\
\hline TRI MID: DOB - 4 PJM (300 Cycles) & 080610_TK_4PJM_DOB & June 10, 2008 02:01 PM & June 10, 2008 06:10 PM & Water & 94 & 0.55 & N/A & 143 & TI-RPP-WTP-638 \\
\hline TRI MID: DOB - PJM A (300 Cycles) & 080611_TC_PJMA_DOB & June 11, 2008 08:37 AM & June 11, 2008 01:11 PM & Water & 94.2 & 0.55 & N/A & 144 & TI-RPP-WTP-638 \\
\hline TRI MID: CVF (100 Cycles) & 080611_TC_4PJM_CVF & June 11, 2008 02:22 PM & June 11, 2008 04:22 PM & Water & 94.2 & 0.55 & N/A & 145 & TI-RPP-WTP-638 \\
\hline
\end{tabular}




\begin{tabular}{|c|c|c|c|c|c|c|c|c|c|}
\hline Run Designation & DAS-1 Files & Start Time & End Time & Type & $\begin{array}{l}\text { Sim } \\
\text { Ht. } \\
\text { from } \\
\text { Rim }\end{array}$ & lant & $T_{y s}(P a)$ & $\begin{array}{c}\text { LRB } \\
59943 \\
\text { Pages }\end{array}$ & $\begin{array}{c}\text { Test } \\
\text { Instruction }\end{array}$ \\
\hline \multicolumn{10}{|c|}{ ABB Low Level } \\
\hline ABB LOW: DOB - PJM A (300 Cycles) & 080612_ABB_PJMA_DOB & June 12, 2008 09:19 AM & June 12, 2008 02:12 PM & Water & 131.8 & 0.30 & $\mathrm{~N} / \mathrm{A}$ & 147 & TI-RPP-WTP-638 \\
\hline ABB LOW: CVF (300 Cycles) & 080613_ABB_4PJM_CVF & June 13, 2008 10:05 AM & June 13, 2008 03:33 PM & Water & 131.8 & 0.30 & $\mathrm{~N} / \mathrm{A}$ & 149 & TI-RPP-WTP-638 \\
\hline \multicolumn{10}{|c|}{ Triconex Low Level } \\
\hline TRI LOW: DOB - PJM A (300 Cycles) & 080616_TC_PJMA_DOB & June 16, 2008 11:10 AM & June 16, 2008 03:55 PM & Water & 131.8 & 0.30 & N/A & $150-151$ & TI-RPP-WTP-638 \\
\hline TRI LOW: CVF (300 Cycles) & 080617_TC_4PJM_CVF & June 17, 2008 09:00 AM & June 17, 2008 02:23 PM & Water & 131.8 & 0.30 & $\mathrm{~N} / \mathrm{A}$ & 152 & TI-RPP-WTP-638 \\
\hline
\end{tabular}



PNNL-18267

WTP-RPT-179, Rev 0

\section{Distribution}

No. of

Copies

OFFSITE
No. of

Copies

ONSITE

7 Pacific Northwest National Laboratory
A. W. Baumann
K7-28
J. R. Bontha
P7-25
D. E. Kurath
K3-52
R. J. Leigh
K7-50
D. M. Pfund
K7-15
D. R. Weier
K6-08
W. A. Wilcox
K3-75
Project File (1)
K3-52
Information Release (pdf)
4 Bechtel National, Inc.
E. D. Johnson
H4-02
Y. Wang
H4-02
WTP R\&T Docs (2)
H4-02 


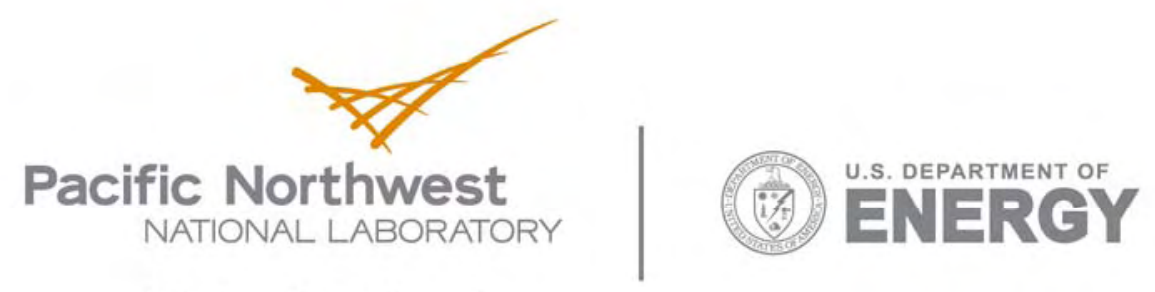

902 Battelle Boulevard

P.O. Box 999

Richland, WA 99352

1-888-375-PNNL (7665)

www.pnl.gov 